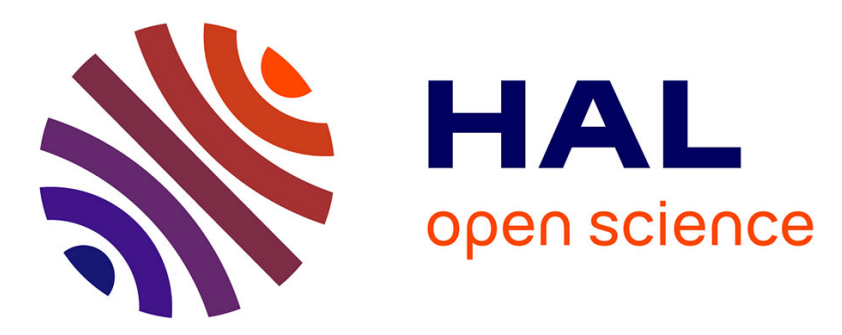

\title{
L'évolution des vaisselles médiévales à Arles : l'exemple du dépotoir des prêcheurs
}

\author{
Marie Leenhardt, Jean Piton, Lucy Vallauri, Danièle Foy
}

\section{To cite this version:}

Marie Leenhardt, Jean Piton, Lucy Vallauri, Danièle Foy. L'évolution des vaisselles médiévales à Arles: l'exemple du dépotoir des prêcheurs. Archéologie du Midi Médiéval, 1996, volume 14, p. 97-139. hal-00880059

\section{HAL Id: hal-00880059 https://hal.science/hal-00880059}

Submitted on 8 Nov 2013

HAL is a multi-disciplinary open access archive for the deposit and dissemination of scientific research documents, whether they are published or not. The documents may come from teaching and research institutions in France or abroad, or from public or private research centers.
L'archive ouverte pluridisciplinaire HAL, est destinée au dépôt et à la diffusion de documents scientifiques de niveau recherche, publiés ou non, émanant des établissements d'enseignement et de recherche français ou étrangers, des laboratoires publics ou privés. 


\section{Marie Leenhardt \\ Jean Piton \\ Lucy Vallauri \\ Danièle Foy}

\section{L'évolution des vaisselles médiévales à Arles : l'exemple du dépotoir des prêcheurs}

In: Archéologie du Midi médiéval. Tome 14, 1996. pp. 97-139.

\section{Résumé}

La diversité des céramiques, associées à des verres et des restes de faune, rejetées dans un gros dépotoir de l'église des Prêcheurs témoigne de la vie quotidienne dans un quartier arlésien au Moyen Age. Les différentes catégories de vaisselles communes régionales et de faïences locales ou importées montrent une évolution dans les techniques, dans les formes et dans l'approvisionnement de la seconde moitié du XIIle au milieu du XVe s. L'étude de ce vaisselier permet en particulier de quantifier la part relative des différentes officines rhodaniennes ou languedociennes qui ont alimenté la ville pendant cette séquence chronologique.

\section{Abstract}

The diversity of the ceramics (pieces of pottery), together with glasses and remains of animal life, thrown into a huge dump of the "Prêcheurs" Church witnesses some aspects of the everyday life in a district of Arles in the Middle Ages. The different kinds of common local or imported crockery, show an evolution of the techniques, of the shapes and in the supply sources from the middle of the XIIIth to the beginning of the XVth century. The study of this crockery permits particularly to quantify the part relative to the different shops of the Rhone valley or the Languedoc region that supplied the town during this chronological sequence.

Citer ce document / Cite this document :

Leenhardt Marie, Piton Jean, Vallauri Lucy, Foy Danièle. L'évolution des vaisselles médiévales à Arles : l'exemple du dépotoir des prêcheurs. In: Archéologie du Midi médiéval. Tome 14, 1996. pp. 97-139.

doi : 10.3406/amime.1996.1298

http://www.persee.fr/web/revues/home/prescript/article/amime_0758-7708_1996_num_14_1_1298 


\title{
L'ÉVOLUTION \\ DES VAISSELLES MÉDIÉVALES À ARLES : L'EXEMPLE DU DÉPOTOIR DES PRÊCHEURS
}

\author{
M. Leenhardt*, J. Piton**, L. Vallauri*, D. Foy*
}

La diversité des céramiques, associées à des verres et des restes de faune, rejetées dans un gros dépotoir de l'église des Prêcheurs témoigne de la vie quotidienne dans un quartier arlésien au Moyen Age. Les différentes catégories de vaisselles communes régionales et de faïences locales ou importées montrent une évolution dans les techniques, dans les formes et dans l'approvisionnement de la seconde moitié du XIIIe au milieu du XVe s. L'étude de ce vaisselier permet en particulier de quantifier la part relative des différentes officines rhodaniennes ou languedociennes qui ont alimenté la ville pendant cette séquence chronologique.

The diversity of the ceramics (pieces of pottery), together with glasses and remains of animal life, thrown into a huge dump of the "Prêcheurs" Church witnesses some aspects of the everyday life in a district of Arles in the Middle Ages. The different kinds of common local or imported crockery, show an evolution of the techniques, of the shapes and in the supply sources from the middle of the XIIIth to the beginning of the XVth century. The study of this crockery permits particularly to quantify the part relative to the different shops of the Rhone valley or the Languedoc region that supplied the town during this chronological sequence.

Si les vaisselles utilisées à Arles pendant l'époque antique et l'Antiquité tardive sont désormais bien répertoriées, celles du Moyen Age demeurent encore mal connues. Le vide documentaire tend peu à peu à se combler grâce aux travaux récents effectués dans la ville. Le faciès céramologique du haut Moyen Age et de l'an mil, difficile à cerner en Provence comme en Languedoc, vient d'être précisé par plusieurs lots de matériel issus de la Commanderie Sainte Luce, de la Place Suarez et de l'annexe de l'Hôtel Arlaten (C.A.T.H.M.A. 1991, 1992, 1993, Piton 1993). Pour la période suivante, le dossier n'était jusque là pas très abondant. La découverte en 1988 d'un gros dépotoir dans l'église des Prêcheurs donnait pour la première fois l'occasion de dresser un panorama des vaisselles en usage au Moyen Age dans ce port rhodanien (1). L'enquête conduite dans le cadre de ce travail a cependant permis de recenser dans la ville d'autres ensembles de céramiques médiévales et d'enrichir ces premiers résultats.

Les plus anciennes découvertes à la Tour des Mourgues (2) ont mis en évidence un petit groupe de vaisselles décorées des XIIIe-XVe siècles, originaires du Maghreb, de Ligurie, Pise, Catalogne et Valence. Ces importations méditerranéennes étaient associées à des faïences régionales vertes et brunes de la vallée du Rhône et à des vaisselles glaçurées de l'Uzège. Des sondages effectués dans la chapelle des chaises à l'église Saint-Trophime, ont livré deux objets insolites en pâte rouge glaçurée d'origine régionale ou languedocienne attribuables au XIIIe siècle (?) (3). Le premier est formé de trois vases à bec ponté accolés et reliés dans la partie centrale par un couvercle tronconique dont le bouton sert de préhension. Le second plus fragmenté et percé de découpes pouvait servir de brasero, encensoir ou pot odorifère. Un autre ensemble provenant de remblais du XIIIe et XIVe siècles dans les Thermes de Constantin (4) a révélé de nombreuses céramiques communes à pâte grise ou brune ainsi que de belles séries de vaisselles en pâte kaolinitique de l'Uzège dont l'étude stratigraphique détaillée serait très instructive. Ce lot confirme la présence d'importations espagnoles et italiques à côté des faïences régionales. La fouille d'une fosse à l'Hôpital Van Gogh (5) précise les vaisselles kaolinitiques en usage au tournant du XIVe siècle et celles en pâte calcaire sans revêtement recouverte de façon exceptionnelle de vernis plombifère. L'existence d'un bol émaillé et décoré de palmettes bleues confirme les importations valenciennes à la fin du XIVe siècle (Du nouveau sur l'Arles Antique $1987: n^{\circ}$ 89). Enfin, le récent déblaie-

* Laboratoire d Archéologie Médiévale Méditerranéenne. UMR 6572. CNRS. Aix-en-Provence.

* Laboratoire d Archéologie Municipale. Arles.

(1) Fouille effectuée par l'Equipe du Laboratoire d'Archéologie Municipale (responsable J.-M. Rouquetle). Ce dépotoir a fait l'objet d'une courte notice à l'ócasion de la présentation de l'exposition Poteries d'Oe (Piton et al 1995). Des verres ont aussi été présentés dans l'exposition A travers le verre en 1989.

(2) Fouilles F. Benoît 1943. Musée de l'Arles Antique et Muséon Arlaten.

(3) Fouilles J.-M. Rouquette 1971. Musće de l'Arles Antique.

(4) Fouille J.-M. Rouquette 1971-1973. Musée de l'Arles Antique.

(5) Fouille effectuée en 1985 par l'Equipe du Laboratoire d'Archéologie Municipale (responsable C. Sintès). Musée de l'Arles Antique. 
ment de la Tour Sud de la Porte d'Auguste (6), comblée par un remblai du XVIe siècle, fournit bon nombre d'importations florentines, ligures et valenciennes qui se partagent à l'époque moderne le marché.

L'ensemble étudié ici présente de nombreux avantages. Il est d'une part abondant et bien conservé. D'autre part, il associe de nombreuses céramiques régionales et importées qui s'échelonnent sur près de deux siècles. En outre, il permet de dresser l'évolution de l'approvisionnement d'une ville particulièrement bien située sur l'axe rhodanien, ouvert sur la Méditerranée mais aussi placée au carrefour de grandes régions productrices de céramique au Moyen Age. La ville même d'Arles, de par la qualité des argiles locales, ne semble pas avoir eu de tradition potière (Amouric et al 1995a). Nous ne connaissons à ce jour qu'un seul four à Trinquetaille dégagé au lieu-dit la Verrerie. Malheureusement cette découverte ancienne, attribuée alors au Moyen Age, n'a pu être vérifiée par l'étude du matériel entreposé autrefois au Muséon Arlaten (Benoît 1944).

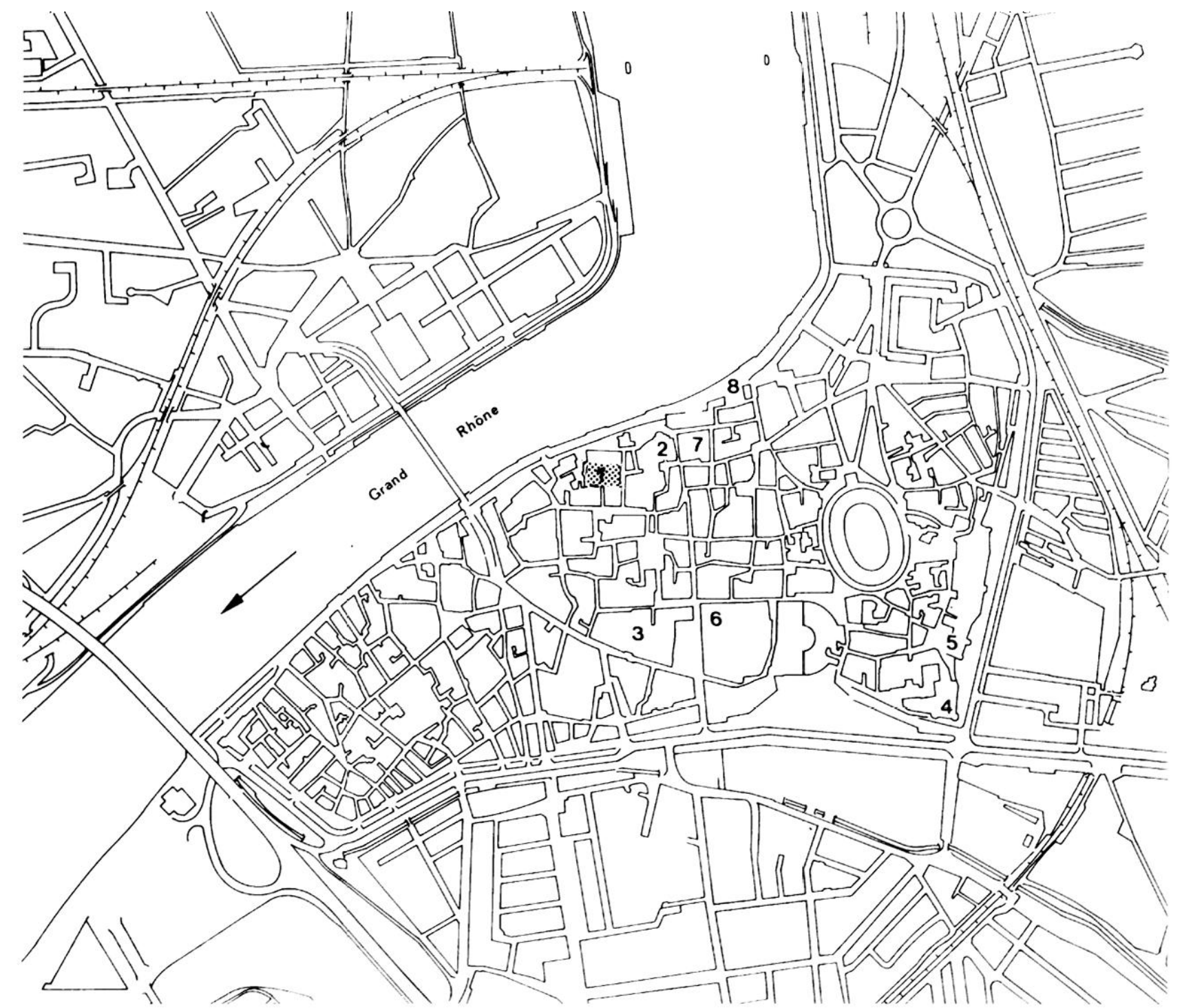

Fig. 1 : Localisation de la découverte et des principaux sites arlésiens ayant livré des poteries médiévales. 1. Les Prêcheurs, 2. Les Thermes de Constantin. 3. Hôpital Van Gogh, 4. Tour des Mourgues, 5. Tour de la porte d'Auguste, 6. Eglise Saint-Trophime, 7. Commanderie Sainte-Luce. 8. Place Suarez, 9. Annexe de l’Hôtel Arlaten. J. Brémond.

\section{Conditions de découvertes et données stratigra- phiques}

C'est à l'occasion de la restauration de l'église des Frères-Prêcheurs que plusieurs sondages ont été réalisés entre 1984 et 1988, dans le vaste édifice gothique à nef unique et chapelles latérales, construit en 1448 sur les bords du Rhône (fig. 1). Ce bâtiment établi à l'est du couvent de la première église, suite au transfert autorisé par le pape Innocent VI en 1361 pour cause d'insécurité, se situe à proximité du quartier de la juiverie.

La fosse étroite et profonde, qui a servi de dépotoir à l'époque médiévale, a été découverte dans la chapelle II (fig. 2). Elle s'inscrit dans un réseau complexe de murs perpendiculaires antiques dont un grand mur à bossages de la fin du Ier siècle avant J.C. (murs 16, 47, 52 et 76 ). Le mur roman (79), qui s'intercale entre les murs antiques, forme la limite nord tandis que les restes du mur 51 bordent cet espace rectangulaire à l'est. Le mur 79 est le té- 

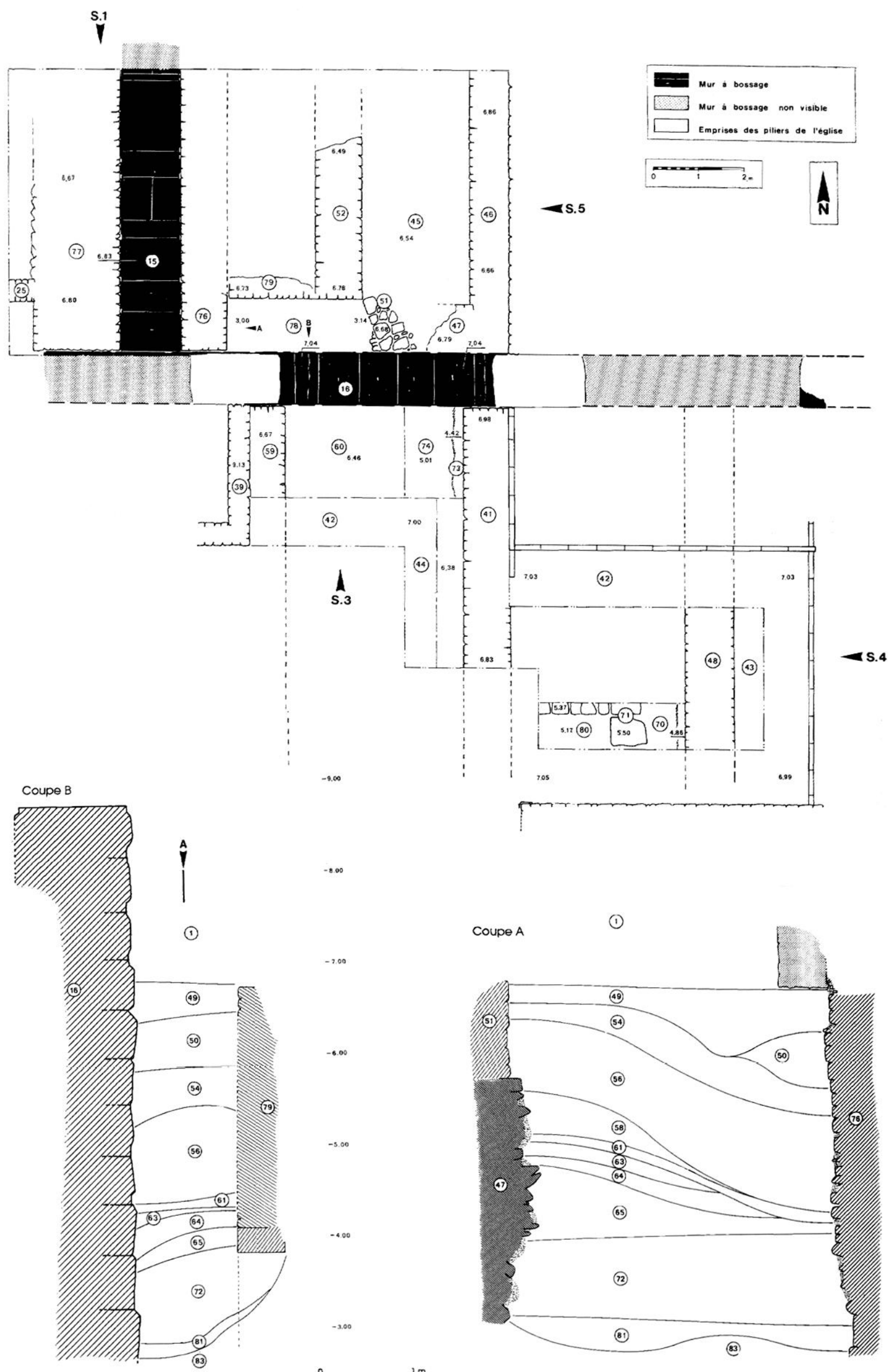

Fig. 2 : Plan et coupes du sondage. J. Brémond. 
moin d'une belle construction médiévale soutenue par un arc de décharge dégagé à 4 mètres de profondeur à la base de la fosse. Ces structures sont difficiles à interpréter, compte tenu de l'exiguïté du sondage, des arasements postérieurs et de la remontée des eaux. Elles témoignent cependant d'un habitat antérieur au XIIIe siècle qui se trouvait sur les terrains acquis par les Prêcheurs pour l'édification de leur église. Ce petit espace vide mais profond qui s'est comblé progressivement depuis le XIIIe siècle jusqu'au milieu du XVe siècle, date de la construction de la nef, n'a cependant pas été conservé sur toute sa hauteur. Mais le matériel recueilli dans le dépotoir confirme globalement les données fournies par l'histoire du site.

L'ensemble des céramiques recueillies totalise 3784 tessons (fig. 3 et 4). Malgré le taux élevé de fragmentation, 238 objets ont été individualisés; certains étaient pratiquement complets après recollage, d'autres bien reconnaissables par la forme ou par le décor spécifiques. L'étude en laboratoire conduite dans un premier temps par contexte, conforte les distinctions de couches notées au moment de la fouille comme en témoignent les différentes associations de céramiques importées et régionales. Cependant le fort pendage des remblais explique en partie des recollages observés au contact des niveaux. La stratification des dépôts s'étage sur sept niveaux d'inégale valeur.

La couche 81 , la plus profonde semble bien autonome et homogène. Elle réunit 369 tessons soit $9,8 \%$ de l'ensemble. Elle regroupe une majorité de céramiques grises et brunes sans revêtement $(68,5 \%)$, de rares céramiques oxydantes rouges avec ou sans glaçure et des céramiques en pâte claire glaçurée kaolinitique dans les mêmes proportions. Les seules faïences régionales sont en pâte calcaire à couverte monochrome verte. Quatre importations sont des protomajoliques originaires du Maghreb ou d'Italie du
Sud. L'ensemble cohérent indique une datation dans le XIIIe siècle. Celle-ci est corroborée par la présence d'un denier en billon de l'évêché de Clermont en usage à la fin du XIIe-XIIIe siècle (7) (fig. 5).

Dans le contexte suivant 72 , le faciès céramologique change totalement. Cette couche très conséquente réunit 2005 tessons et constitue comme la couche 65 avec laquelle elle recolle en partie, le véritable dépotoir mêlé à des éléments de faune. La céramique grise devenue exceptionnelle est supplantée par la céramique en pâte claire kaolinitique de l'Uzège, le plus souvent glaçurée. De nouvelles catégories apparaissent : les productions calcaires sans revêtement, les faïences décorées en vert et brun de la vallée du Rhône et de l'Uzège qui remplacent les monochromes. La transformation se traduit aussi dans les origines des céramiques importées qui regroupent cette fois principalement des sgraffitos archaïques ligures, mais aussi des céramiques glaçurées catalanes et de la faïence verte et brune pisane.

Dans la couche 65 qui totalise 1159 tessons, on retrouve les mêmes associations mais dans des proportions différentes. La céramique commune glaçurée en pâte kaolinitique reste majoritaire mais en quantité plus faible. Apparaissent des céramiques en pâte beige grossière ainsi que des faïences valenciennes à décor bleu et des faïences catalanes à décor vert et brun. On note une réduction notable des sgraffitos archaïques ligures. Cet ensemble 72-65 difficile à séparer par l'importance des recollages, s'étage cependant d'une façon chronologique indéniable avec des différences perceptibles surtout à partir des céramiques importées. La datation proposée est assez large et couvre la fin du XIIIe siècle et la première moitié du XIVe siècle.

Signalons dans le contexte 65 , la présence d'un joli objet figuré en os (fig. 6) (8). Ce manche foré, de petit couteau ou de poignard, long de $9 \mathrm{~cm}$, est bien caractéristique des

\begin{tabular}{|c|c|c|c|c|c|c|c|c|c|c|c|c|c|c|c|c|c|c|c|c|}
\hline \multirow{2}{*}{\begin{tabular}{|l|} 
contexte \\
\end{tabular}} & \multicolumn{11}{|c|}{ Productions régionales } & \multicolumn{9}{|c|}{ importations } \\
\hline & grise & \begin{tabular}{|l|} 
brune \\
micacese
\end{tabular} & $\begin{array}{l}\text { rouge } \\
\text { glaçurée }\end{array}$ & \begin{tabular}{|l|} 
autres \\
rouges
\end{tabular} & \begin{tabular}{|l|} 
beige \\
grossière
\end{tabular} & $\begin{array}{l}\begin{array}{l}\text { glaçurée } \\
\text { kaol }\end{array} \\
\end{array}$ & $\begin{array}{l}\begin{array}{l}\text { vo } \\
\text { kaol. }\end{array} \\
\end{array}$ & \begin{tabular}{|l|} 
calcaire \\
sans revét
\end{tabular} & $\begin{array}{l}\text { calcaire } \\
\text { monoch }\end{array}$ & $\begin{array}{l}\text { calcaire } \\
\text { vo }\end{array}$ & \begin{tabular}{|l|} 
total \\
régional
\end{tabular} & Maghreb & \begin{tabular}{|l|} 
Italie \\
du Sud \\
\end{tabular} & Tigurie & Pise & Catalogne & Vaience & $\begin{array}{l}\text { indéter- } \\
\text { mines }\end{array}$ & $\begin{array}{l}\text { total } \\
\text { import. }\end{array}$ & total \\
\hline 81 & 250 & 16 & 25 & 28 & & 28 & & & 18 & & 365 & 2 & 1 & & & & & 1 & 4 & 368 \\
\hline 72 & 20 & 1 & 1 & 21 & & 1819 & 3 & 70 & 3 & 12 & 1950 & & & 37 & 8 & 9 & & 1 & 55 & 5 \\
\hline 65 & 21 & 2 & & 2 & 4 & 1062 & 7 & 24 & 8 & 12 & 1142 & & & 7 & & 6 & 4 & & 17 & 1158 \\
\hline 63 & & & & & & 15 & & & & & 15 & & & & & & & & & 15 \\
\hline 61 & & & & & & 132 & & & 5 & 2 & 139 & & & & & & 6 & & 6 & 145 \\
\hline 56 & & & & & 2 & 33 & & & 5 & 5 & 48 & & & & & & 1 & & 1 & 49 \\
\hline 54 & 3 & & & & 1 & 30 & & & 3 & 2 & 36 & & & 1 & & & 5 & & 6 & 42 \\
\hline total & 294 & 19 & 26 & 51 & 7 & 3119 & 10 & 9. & 42 & 33 & 3695 & 2 & 1 & 45 & 8 & 15 & 16 & 2 & 89 & 3784 \\
\hline$\%$ & 7,76 & 0,5 & 0,68 & 1,34 & 0,18 & 82,43 & 0,26 & 2,48 & 1,1 & 0,87 & 976 & 0,05 & 0,02 & 1,2 & 0,2 & 0,4 & 0,48 & 0,05 & 2,4 & 100 \\
\hline
\end{tabular}
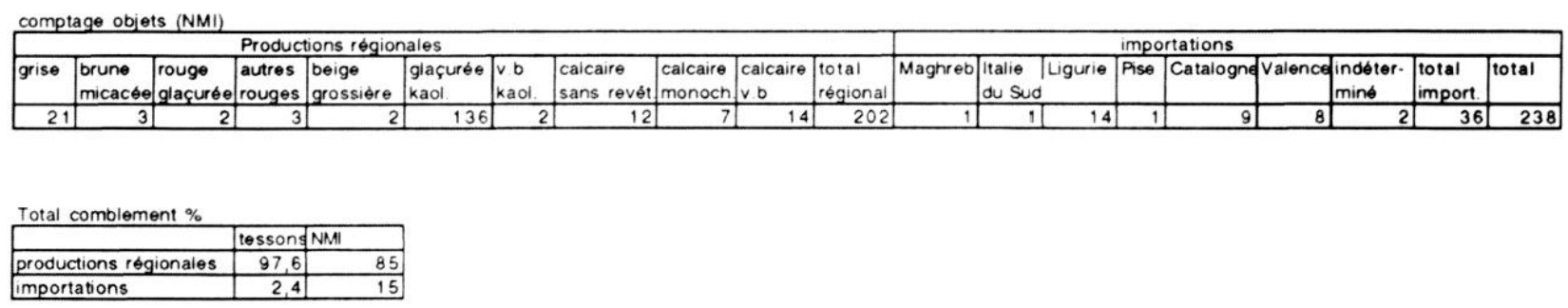

Fig. 3 : Répartition chronologique des céramiques par tessons et NMI.

(7) Identification J.L. Charlet et J.P. Pelletier. Avers : VRBS. ARVERNA. Croix à bras arrondis. cantonnée de quatre trèfles attachés dans les angles par de longs pédoncules. Revers : SCA. MARIA. Tête couronnée de face. très basse et engagée dans le grénetis intérieur. Type très proche de Pocy d Avant $1961: \mathbf{n}^{\circ} 22.52-2253$.

(8) Nous remercions tout particulièrement N. Rodrigues-Meyer, A. Prache et J.R. Gaborit, M. Fixot pour l'identification de cet objet el pour la documentation qu ils ont mis a notre disposition. 


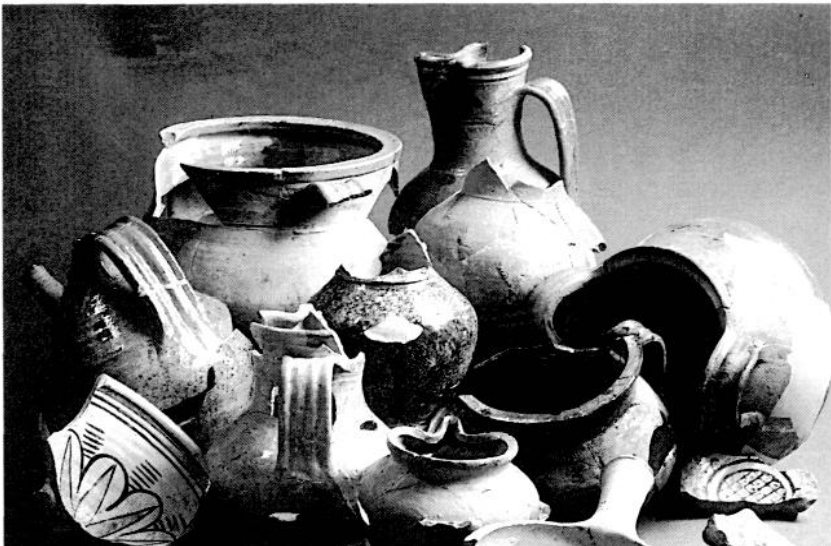

Fig. 4 : Ensemble des vaisselles communes et émaillées. Cl. CCJ, C. Durand.
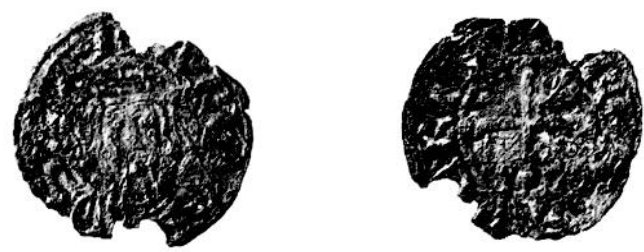

Fig. 5 : Denier de l'Evêché de Clermont. Cl. Y. Rigoir.

pièces françaises ou italiennes dites “à imagerie”, très à la mode au XIVe siècle (Koechlin 1968 : 416-423, TI, 405-410, TII ; Gay 1887 : 794). De nombreux personnages empruntés à la vie courtoise ou religieuse sculptés sur des manches de couteaux, peignes et gravoirs sont conservés dans les collections et musées de Paris, Londres, Lille, Genève, Turin. etc. On en identifie actuellement sur des chantiers ruraux et urbains, à Mauroux dans le Lot, à Saint-Denis par exemple ou dans le dépotoir du Petit-Palais d'Avignon daté avant 1365 (Archéologie et vie quotidienne 1990 : 359 ; Thiriot 1989 : 89, fig. 67). La statuette d'Arles qui s'intègre bien dans cet esprit décoratif est néanmoins originale. De facture fruste, ce petit personnage à l'air naï et pittoresque, représente l'image du prêtre tel qu'il est défini dans le Lévitique, chapitre 8, pour Aaron et ses fils. Il est drapé dans une longue tunique, la tête couverte d'une tiare à rubans pendants dans le dos, l'éphod ou écharpe jetée sur les épaules et tient sur son bras droit un petit bélier pour le sacrifice.

Les dernières couches $63,61,56$ et 54 , plus pauvres en matériel, ne réunissent que $6,6 \%$ de l'ensemble. Ce dernier lot très fragmenté, réunit surtout de la céramique commune glaçurée kaolinitique ainsi que des faïences vertes et brunes de la région avignonnaise de la seconde moitié du XIVe et du début du XVe siècle. Les seules importations qui subsistent sont des faïences valenciennes à décor bleu et lustre, très abondantes à la fin du XIVe et dans le courant du XVe siècle dans les contextes provençaux et pontificaux (Carru 1995c). Elles fournissent le terminus de ce remplissage de fosse comblée au moment de la construction de l'édifice gothique vers 1448. A la base des couches 56-54, un lot de verreries était rassemblé (cf. infra), témoin tout comme le manche en os, d'une certaine qualité de la vie quotidienne dans ce quartier arlésien.

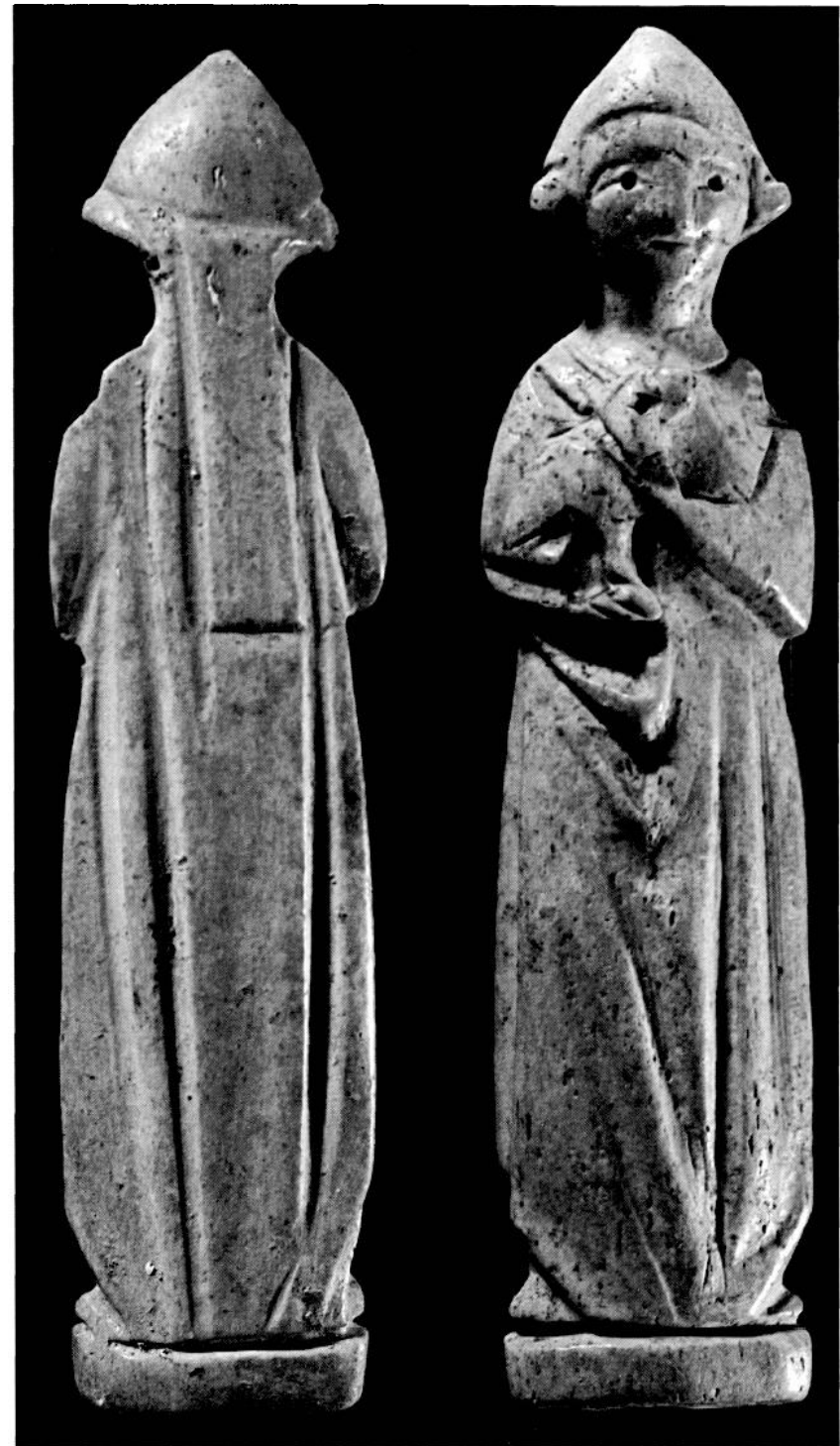

Fig. 6 : Manche de couteau en os. Cl. Y. Rigoir.

\section{Les céramiques}

Toutes périodes confondues, les images fournies par le comptage des tessons comme par celui en nombre minimum d'individus sont sensiblement les mêmes (fig. 3). Dans les deux cas, les productions régionales sont largement dominantes et ne représentent pas moins de $85 \%$ en comptage par objets. Dans ce pourcentage les céramiques importées sont en fait un peu surévaluées car plus faciles à individualiser que les céramiques communes régionales. Elles constituent cependant de bons traceurs chronologiques. Cette situation encore plus contrastée en comptage par tessons, entre les céramiques régionales $(97,6 \%)$ et importées $(2,4 \%)$, est cependant très comparable à celle rencontrée dans tous les contextes avignonnais contemporains (Alonso, Thiriot 1996 ; Carru à paraître : fig. $\mathrm{n}^{\circ} 7$ ). La ville pontificale est alimentée prioritairement par les ateliers de l'Uzège et ceux de la vallée du Rhône, contrairement à la côte provençale et Marseille en particulier qui bénéficient d'une plus grande commercialisation de céramiques méditerranéennes. Celles-ci très diversifiées et abondantes peuvent composer plus de la moitié des vaisseliers (Démians d'Archimbaud, Vallauri à paraître). 

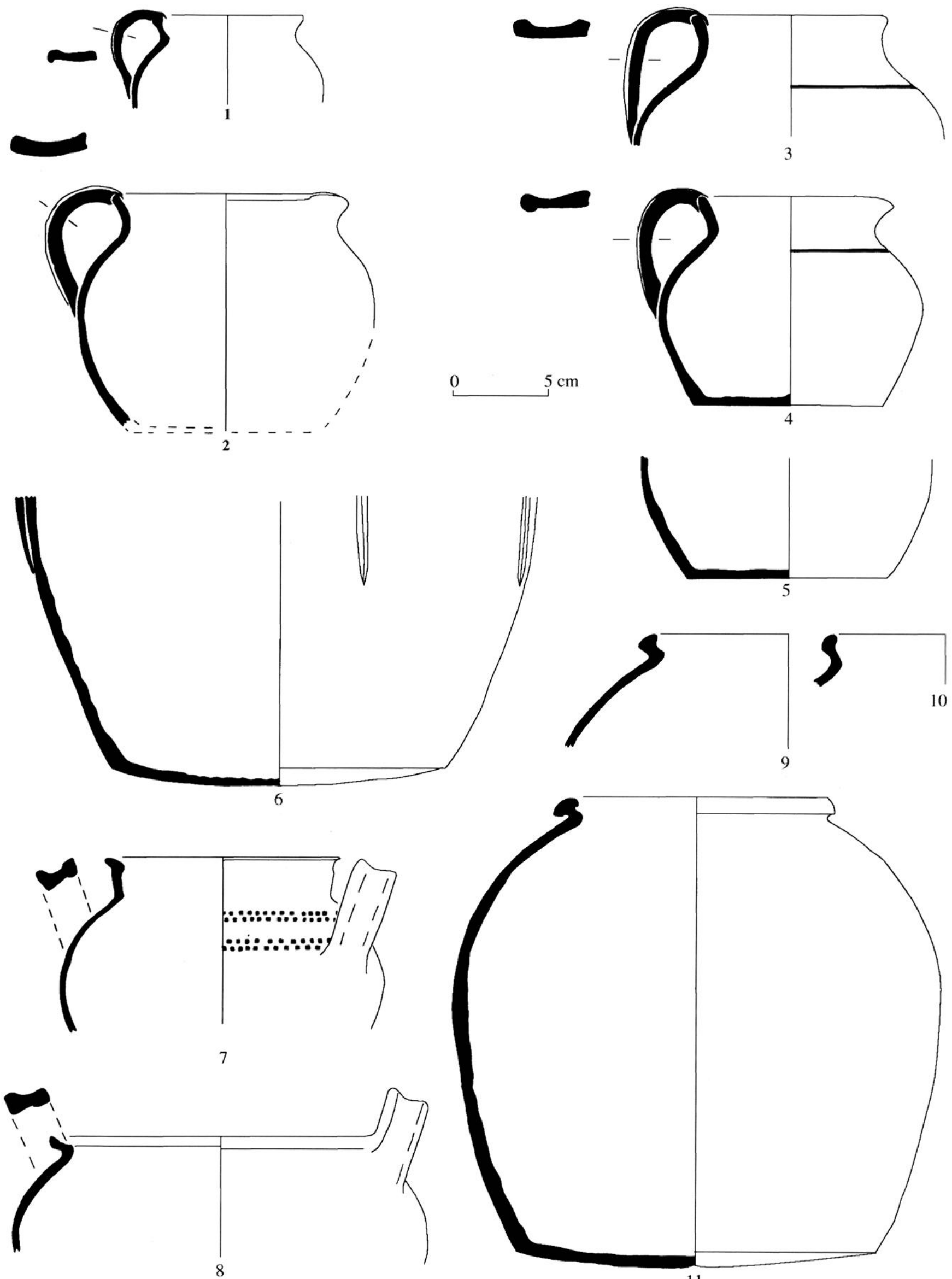

Fig. 7 : Céramiques grises issues de la couche 81. M. Leenhardt. 
L'étude qui suit, détaillée par production et chronologie, retrace l'évolution de l'approvisionnement et l'originalité des vaisselles révélées dans le port rhodanien.

\section{1. Les productions régionales}

\section{Les céramiques grises}

Ces poteries grises à cuisson réductrice sont majoritaires dans la couche la plus ancienne (couche 81 ) où elles représentent près de $70 \%$ des vaisselles communes. Elles se répartissent entre plusieurs productions révélant un approvisionnement diversifié pour la ville d'Arles : pâte siliceuse à nombreuses inclusions, dure et bien cuite, de couleur gris moyen (fig. $7 n^{\circ} 2-4$ ); pâte réfractaire blanche à surface noire (fig. $7 \mathrm{n}^{\circ} 1$ ); pâte réfractaire, grossière et très noire (fig. $7 \mathrm{n}^{\circ} 7-8$ ) ; pâte gris foncé ou gris brun de texture hétérogène truffée de multiples et fines inclusions (fig. 8 $\mathrm{n}^{\circ} 2-3$ ) ; enfin pâte de couleur gris moyen, à grain fin et inclusions siliceuses éparses ou rares, à surface légèrement bosselée ou bien lisse (fig. $7 n^{\circ} 6-11$ et fig. $8 n^{\circ} 1$ et 5-9). Dès la période suivante (couche 72) ces groupes sont devenus résiduels, attestés par quelques tessons informes dont la proportion par rapport à l'ensemble des céramiques communes devient négligeable ; en revanche une production grise à pâte calcaire apparaît alors, très exceptionnelle puisque attestée par un seul objet (fig. $8 \mathrm{n}^{\circ} 4$ ). Dans les couches supérieures du comblement, les poteries grises ont disparu.

Du point de vue des formes, ces 21 objets renvoient à des vaisselles en usage, selon les cas, au début du XIIIe s. ou dans le seconde partie de ce siècle et jusqu'au tournant du XIVe s. Le grand pot en pâte fine à bord rectangulaire, bec tubulaire, cordon rapporté et digité (fig. $8 \mathrm{n}^{\circ} 1$ ) présente beaucoup d'affinités avec les pots de l'atelier de Mimet dans l'arrière-pays marseillais (Pelletier, Vallauri 1992 : 235, fig. 6), malheureusement son état fragmentaire interdit de préciser quel type d'anse il possédait. En revanche le grand pot à bord en bourrelet (fig. $7 \mathrm{n}^{\circ} 11$ ) et les fonds de pots à base large, fabriqués dans une pâte fine à inclusions éparses, dont la panse est parfois renforcée de bandes appliquées de section semi-circulaire (fig. $7 \mathrm{n}^{\circ} 6$ ) rappellent plutôt, par leur technique de fabrication autant que par l'aspect de la pâte, ceux de l'atelier de SaintGilles-du-Gard à la fin du même siècle. Les pégaus, quant à eux, avec un bord simple, une anse rubanée incluant le bord, un bec pincé et une pâte bien cuite et dégraissant abondant (fig. $7 n^{\circ} 2-5$ ), correspondent à ceux de SaintGilles-du-Gard (Leenhardt, Thiriot 1989 : fig. 5 et 6). Un seul évoque par son bord à gorge, de forme nerveuse et sa pâte blanche à surface noire les ateliers à pâte réfractaire de la basse vallée du Rhône (fig. $7 \mathrm{n}^{\circ} 1$ ). Les marmites demeurent rares et deux types coexistent : le premier, à anses horizontales implantées sur le bord et sans col (fig. $7 \mathrm{n}^{\circ} 8$ ) rappelle celui fabriqué à Saint-Gilles-du-Gard (Leenhardt, Thiriot 1989 : fig. $10 n^{\circ} 1-6$ ). Il renvoie aussi à une marmite possédant cette fois un col court et recensée dans les niveaux de consommation du bourg des potiers de Marseille Sainte-Barbe (Pelletier 1997 : fig. $46 \mathrm{n}^{\circ}$ 32) ou encore à des objets représentés dans la seconde moitié du XIIIe s. au château de Beaucaire et contemporains de types semblables en pâte claire glaçurée de l'Uzège (Schneider 1995 ; Leenhardt 1995c : fig. 58). Des exemples en pâte grise, avec les mêmes anses horizontales sur le bord, sont aussi attestés au château d'Allègre (Gard) et dans le village de Boulbon (Bouches-du-Rhône). L'autre marmite est caractérisée par un décor à la molette et deux anses horizontales implantées cette fois sur l'épaulement (fig. $7 \mathrm{n}^{\circ}$ 7) : ce second type existe fréquemment dans les productions à pâte grise des ateliers varois (Démians d'Archimbaud 1981 : fig. 245-256) ou du Vaucluse (Bonhoure, Marchesi 1993 : fig. $5 \mathrm{n}^{\circ}$ 7-8), mais il est plus rare en Languedoc (Leenhardt, Thiriot 1989 : fig. $9 \mathrm{n}^{\circ}$ 2-3). Concernant les vases à liquide, il faut signaler un fragment de bec verseur ponté en pâte fine. Mieux conservé, le seul exemple de cruche à col haut (fig. $8 \mathrm{n}^{\circ}$ 6) est la réplique exacte, par sa forme autant que sa pâte, des cruches fabriquées à SaintGilles-du-Gard (Leenhardt, Thiriot 1989 : fig. $16 \mathrm{n}^{\circ} 1-4$ ) ; rares au XIIIe s. dans l'atelier de Bonnieux (Bonhoure, Marchesi 1993 : fig. $8 n^{\circ} 5-6$ ), ces vases à liquide gris perdurent dans la première moitié du XIVe $s$. sur les sites consommateurs languedociens (Poteries d'Oc 1995 : fig. 102). Par ailleurs pour la cruche grise en pâte grossière, à panse fermée, bec tréflé et anse de panier (fig. $8 \mathrm{n}^{\circ} 2$ ), le parallèle avec les ateliers de Saint-Gilles encore mais aussi avec ceux de Bollène, en fonctionnement au XIIIe s., s'impose (Leenhardt, Thiriot 1989 : fig. $15 \mathrm{n}^{\circ} 14$; Thiriot 1987 : fig. $10 \mathrm{n}^{\circ} 4$ ). La seule forme ouverte à bord à carène recueillie dans cette fosse (fig. $8 n^{\circ} 3$ ) est identique à celle qui figure parmi les céramiques collectées aux Thermes d'Arles dans la couche II attribuée au XIIIe s. en raison de la prédominance des céramiques grises. Elle rappelle aussi unc autrc formc présente à Marseille, SainteBarbe, dans les contextes de consommation du XIIIe s. ainsi qu'à quelques objets produits à Saint-Gilles (Leenhardt, Thiriot 1989 : fig. $14 n^{\circ} 9-10$ ). Le petit pot à anse de panier (fig. $8 n^{\circ} 8$ ) en pâte grise fine n'a pas d'équivalent dans les productions grises provençales ou languedociennes. En revanche par sa taille et sa forme il présente une bonne analogie avec ceux en pâte calcaire claire et sans revêtement produits dans l'atelier de Marseille au XIIle s. (Vallauri, Leenhardt 1997 : fig. 247 n 1-6), ou avec un pot recueilli dans la nécropole de Viviers (Leenhardt, Vallauri 1988 : fig. $68 \mathrm{n}^{\circ} 13$ ); la ressemblance est plus lointaine avec le pot à anse de panier en pâte calcaire émaillée découvert à Lunel-Viel dans un contexte du début du XIVe s. (Leenhardt, Raynaud 1995 : fig. 50). Enfin la tirelire globulaire à fente horizontale et à pâte fine (fig. $8 \mathrm{n}^{\circ}$ 5), dont un parallèle en pâte grossière est issu, à Arles encore, des fouilles des Thermes (couche II) trouve de bonnes répliques au XIIIe s. et jusqu'au tournant du siècle suivant dans diverses productions languedociennes ou provençales, tant en pâte grise, que rouge siliceuse ou calcaire (Leenhardt, Thiriot 1989 : fig. $18 \mathrm{n}^{\circ}$ 16-17 ; Leenhardt 1995 b ; Vallauri, Leenhardt 1997 : fig. $250 \mathrm{n}^{\circ}$ 1-10).

Les comparaisons régionales indiquent donc pour les récipients culinaires, vases à liquide ou à fonction spécifique de cette couche 81 une datation dans le XIIIe siècle. Si de rares objets peuvent se référer aux productions du début du siècle, d'autres semblent originaires des ateliers de 

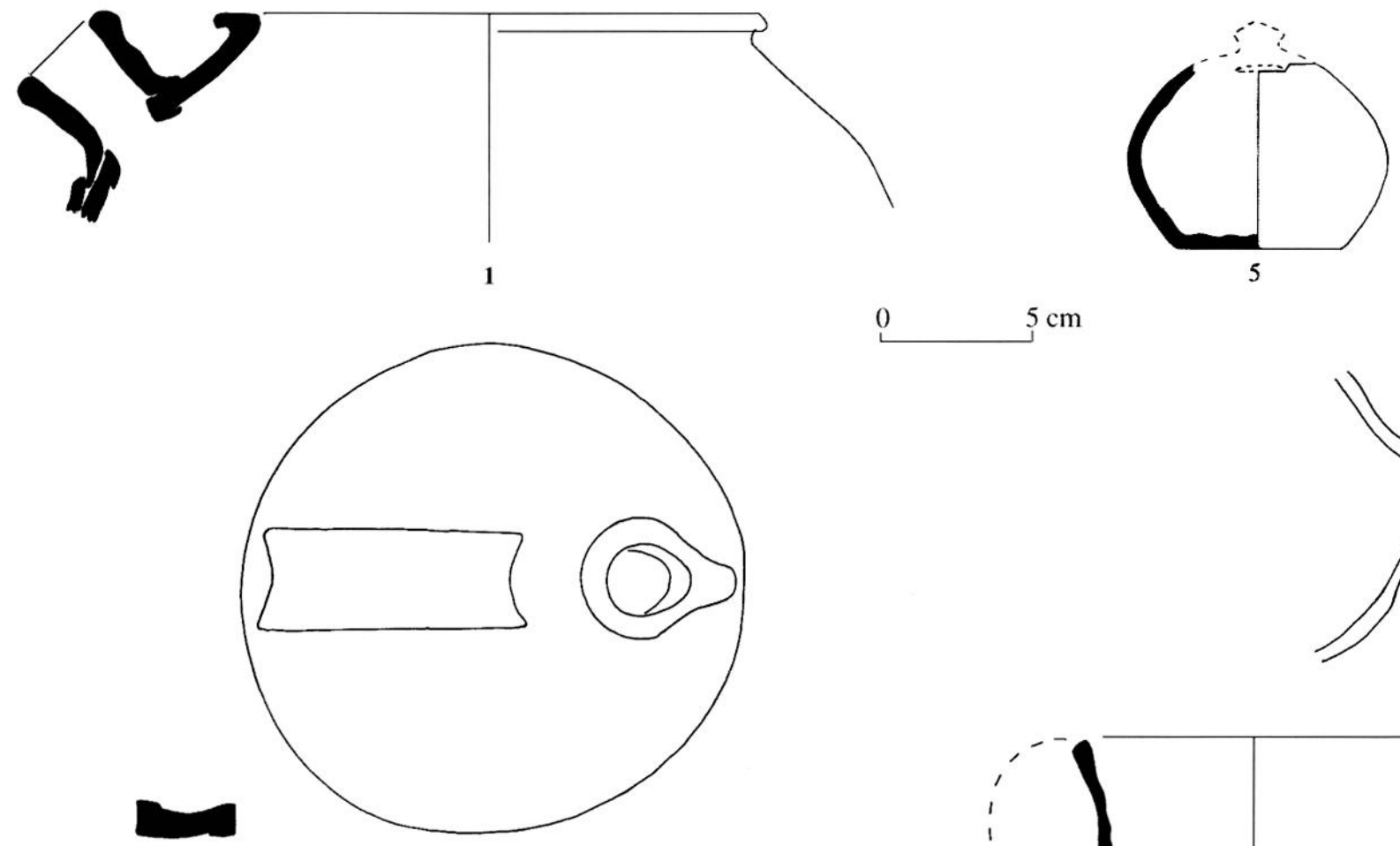

0

$5 \mathrm{~cm}$
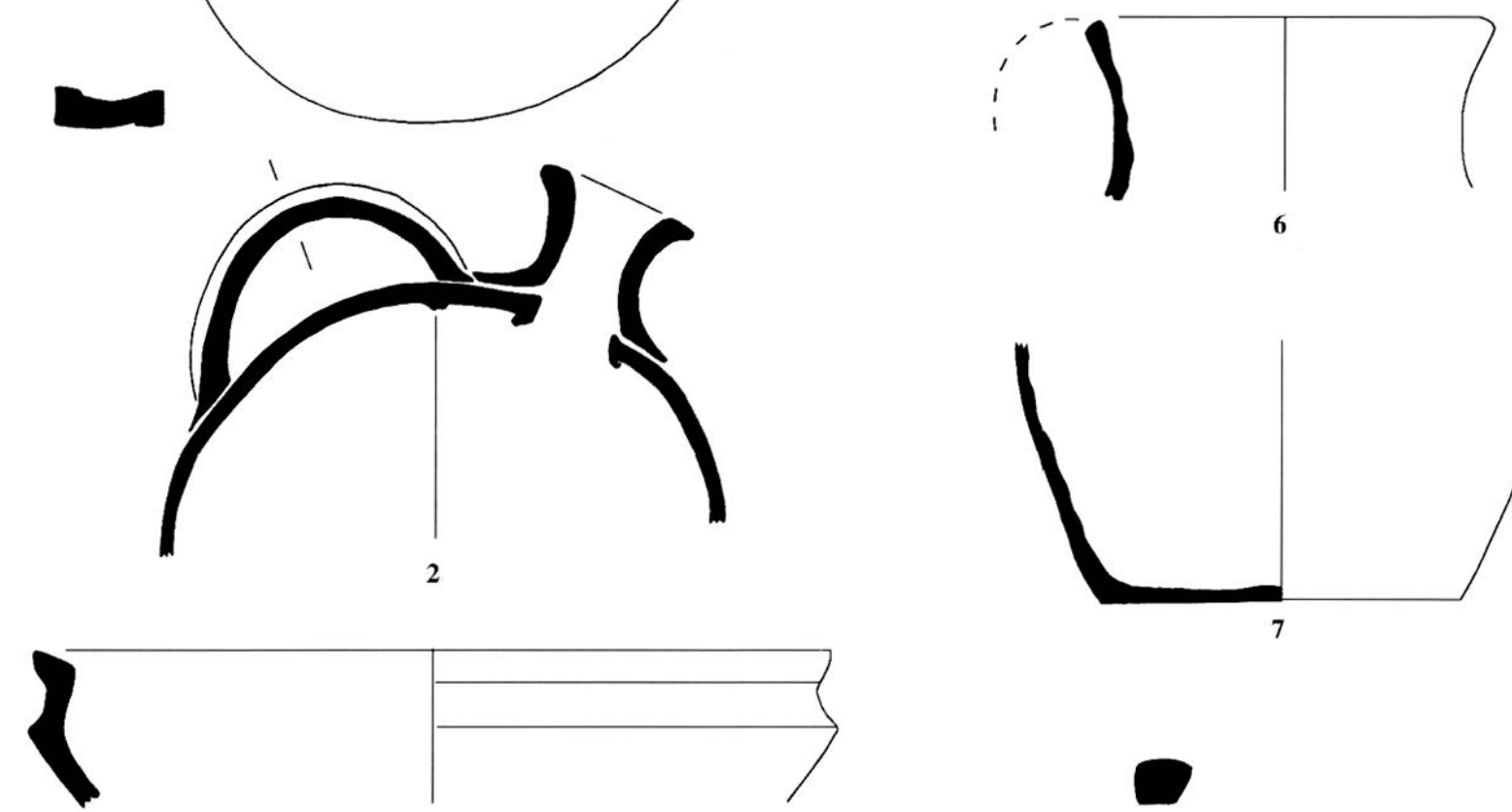

3
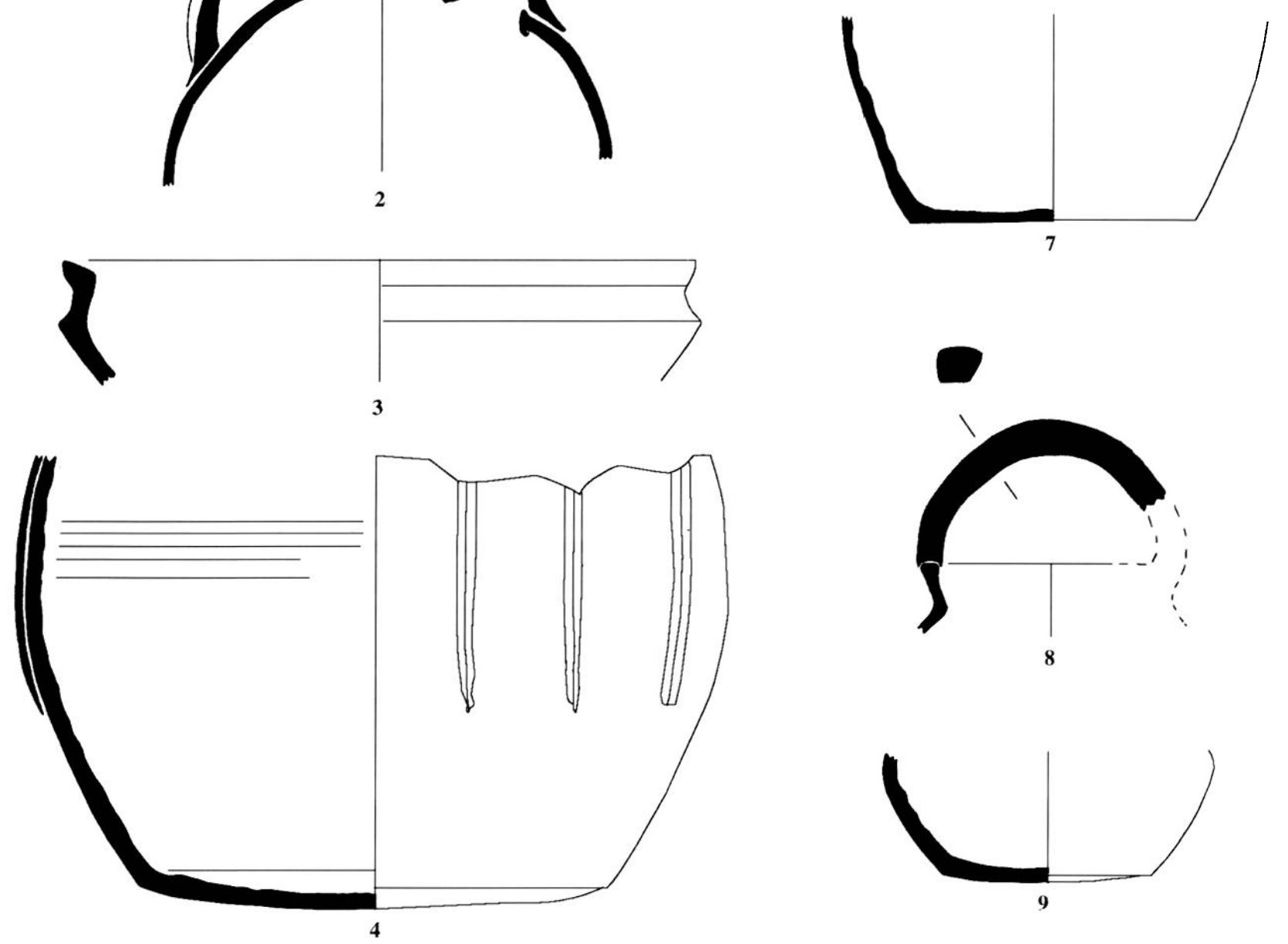

Fig. 8 : Céramiques grises issues de la couche 81 et céramique grise calcaire issue de la couche $72\left(n^{\circ} 4\right)$. M. Leenhardt. 

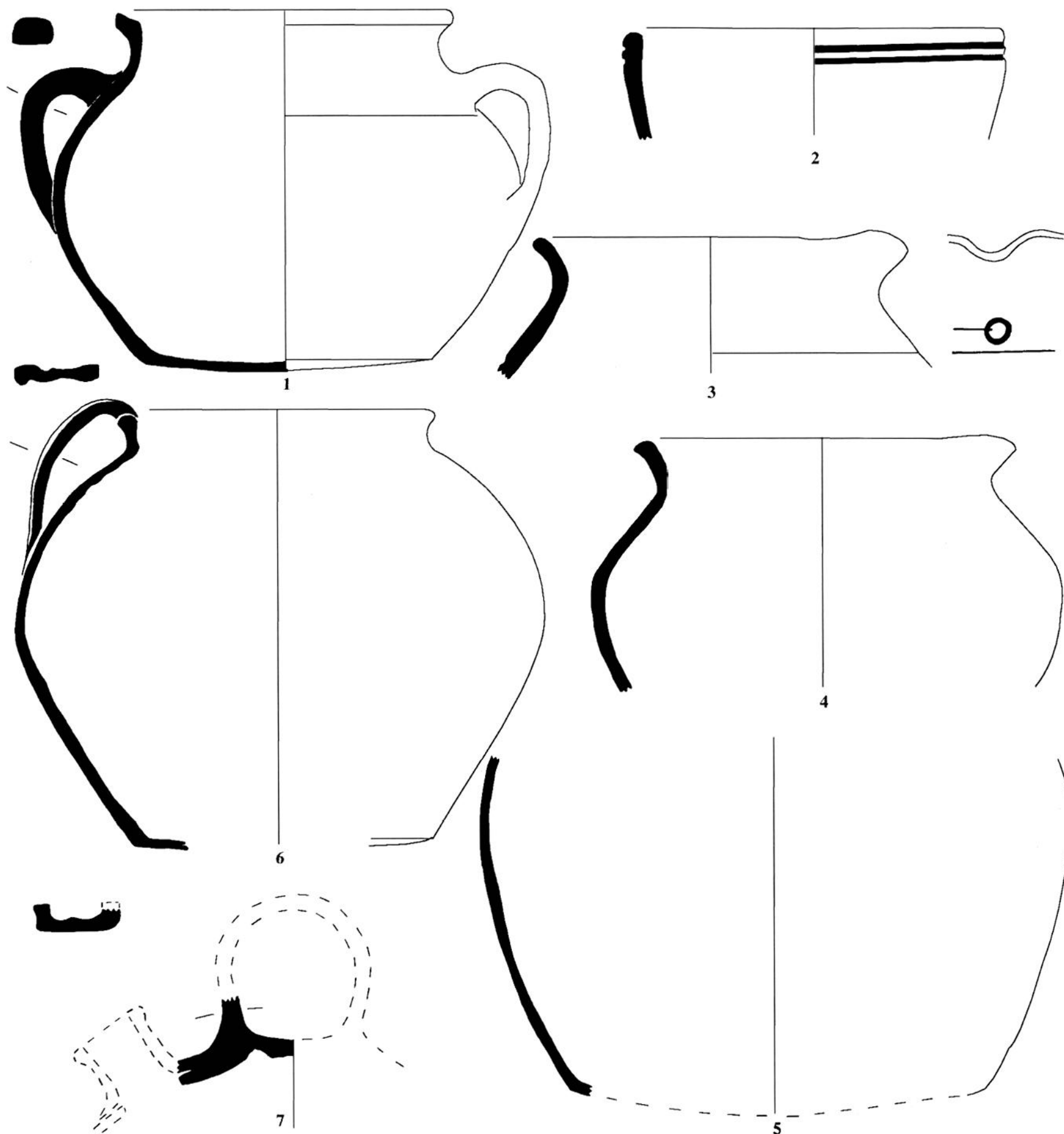

3
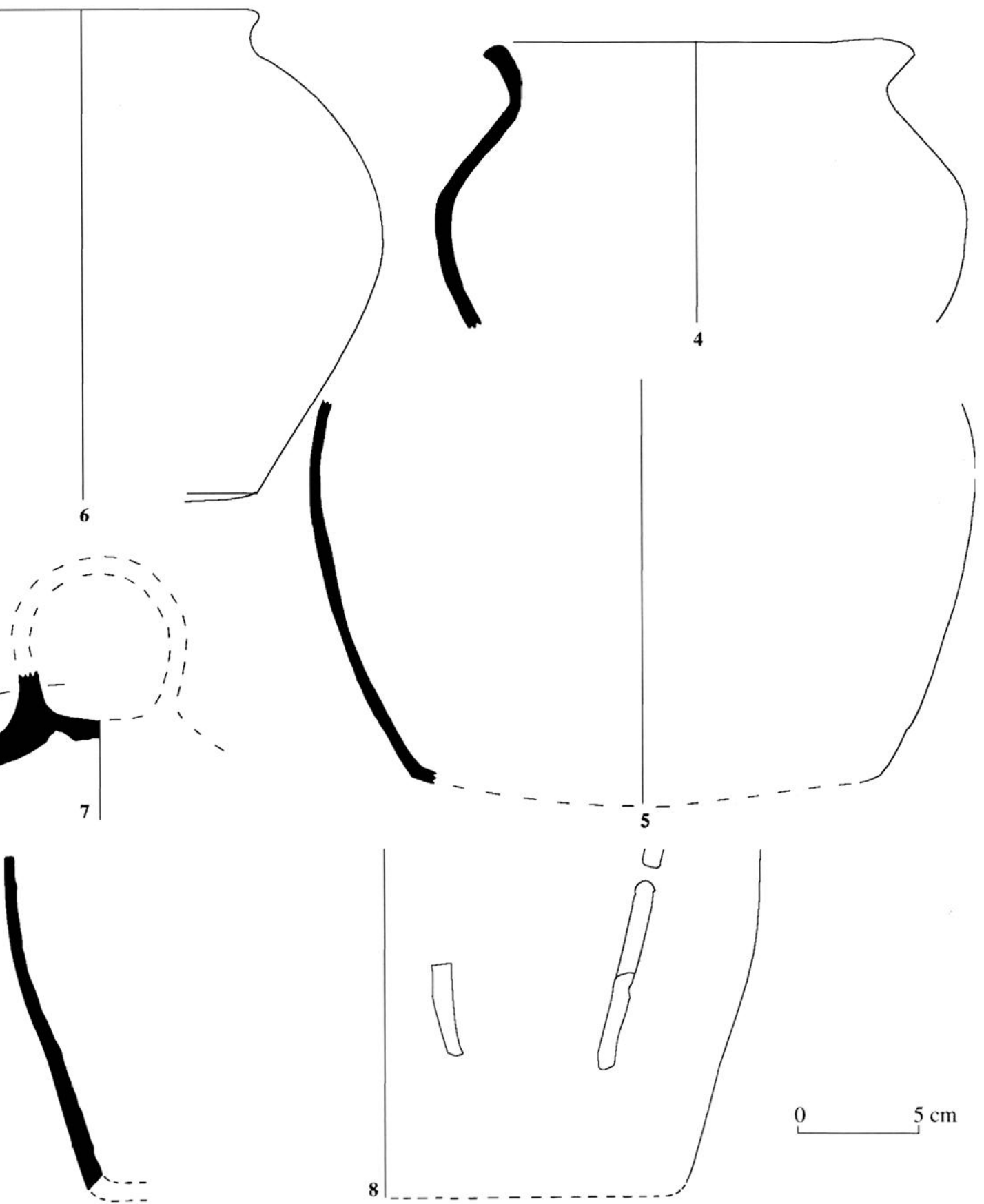

Fig. 9 : Céramiques en pâte rouge glaçurée $\left(n^{\circ} 1-2\right)$, céramiques brunes micacées $\left(n^{\circ} 3-5\right)$, autres céramiques rouges $\left(n^{\circ} 6-8\right)$ issues de la couche $81\left(n^{\circ} 1\right.$ 7) et de la couche $72\left(n^{\circ} 8\right)$. M. Leenhardt. 

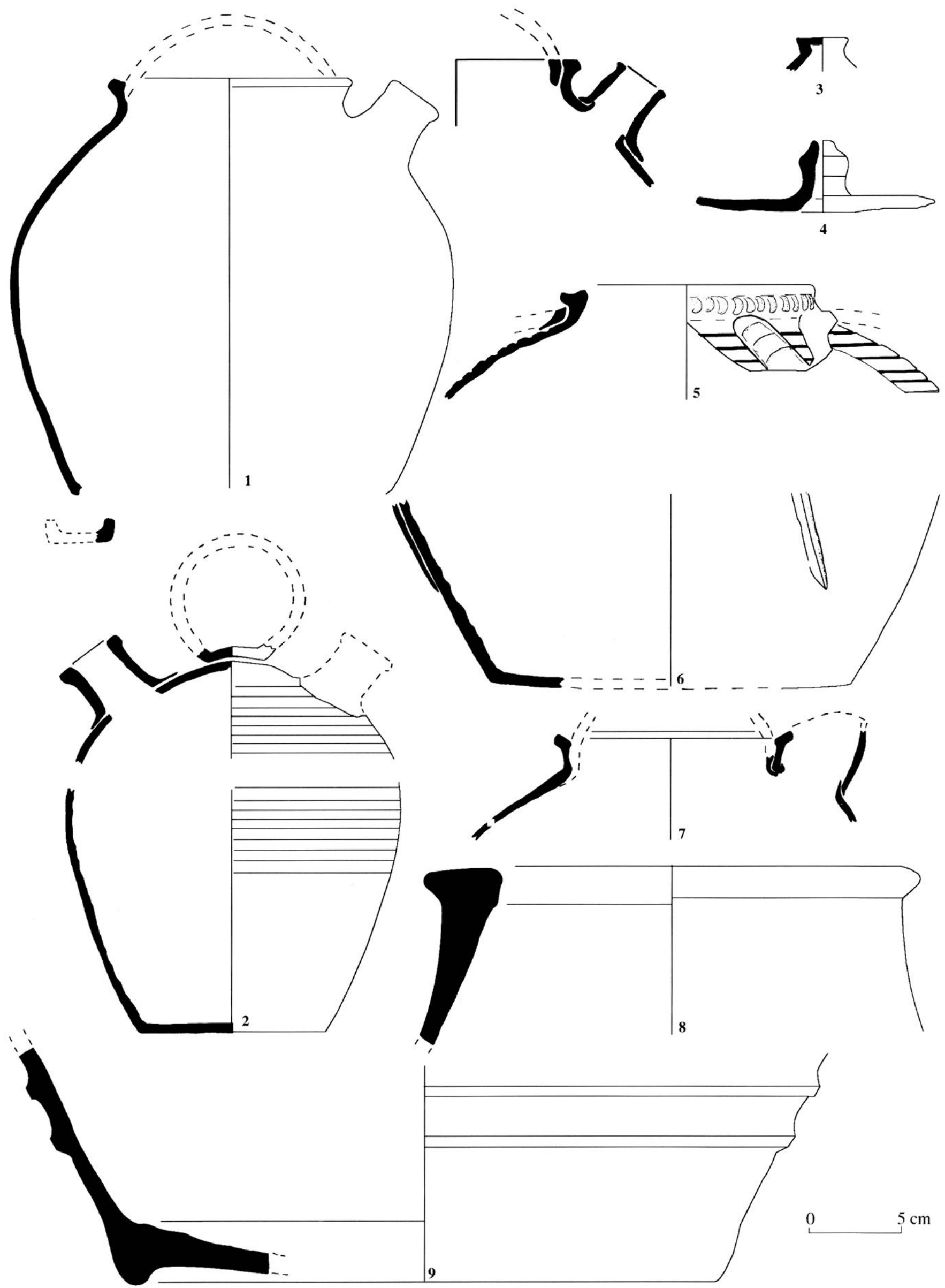

Fig. 10) Céramiques à pâte claire kaolinitique sans revêtement $\left(n^{\circ}\right.$ 1-7) et céramiques en pâte beige grossière ( $\mathrm{n}^{\circ}$ 8-9). M. Leenhardt. 
Saint-Gilles-du-Gard en activité au tournant des XIlle et XIVe s. ou inspirés par les mêmes modèles. De toute manière un approvisionnement privilégié dans cette officine, distante d'Arles d'une vingtaine de kilomètres seulement n'aurait rien d'étonnant.

Il faut enfin noter que les céramiques grises à pâte calcaire ne figurent que dans la couche 72 où elles demeurent exceptionnelles, vite supplantées par les vaisselles à cuisson oxydante, quasi-exclusives dans ce niveau. Le seul objet attesté est un grand vase à fond très légèrement lenticulaire, base large et cordons appliqués de section semi-circulaire (fig. $8 n^{\circ} 4$ ), reproduisant en pâte calcaire les modèles déjà connus dans d'autres productions grises.

\section{Les céramiques brunes micacées}

Les trois pots à bec pincé et sans anse de ce groupe (fig. $9 n^{\circ} 3-5$ ) sont aisément identifiables par leur pâte micacée de texture grossière, contenant de multiples inclusions de natures diverses, de couleur variant du gris brun au brunâtre. Le façonnage grossier, les formes lourdes et les bords mous et simplement déversés les caractérisent. Hormis un minuscule tesson résiduel dans la couche 72 , les pots de ce groupe sont attestés exclusivement dans le niveau de comblement le plus ancien (couche 81) et appartiennent à une production datée de la fin du XIIe s. et de la première moitié du XIIle s., observée sur plusieurs sites marseillais ainsi que sur la frange côtière à Fréjus, Hyères, Berre, Fos et Toulon, ou encore à Aix-en-Provence et même en Languedoc (Lattes) (Pelletier 1997 : fig. 43). Ces trois pots ne sont pas isolés à Arles : en effet diverses fouilles urbaines, aux Thermes puis à l'hôpital Van Gogh, ont mis au jour dans des contextes du XIIle s. de nombreux pots appartenant à l'évidence à cette production dont l'origine, peut-être de Provence orientale, n'est pas encore bien cernée. Pour diffuser ses produits aussi largement, cet atelier ne devait pas être d'importance négligeable ! La circulation de ces objets jusqu'à Arles, port sur le Rhône, n'a rien de surprenant, le fleuve constituant un axe privilégié pour la commercialisation de ces produits.

\section{Les vaisselles à pâte rouge siliceuse glaçurée}

Le groupe à pâte rouge siliceuse truffée de petites inclusions de type quartz est représenté seulement dans la couche 81 : il s'agit de deux récipients culinaires (fig. $9 \mathrm{n}^{\circ}$ 1-2), une marmite globulaire à fond lenticulaire, col très court et deux anses en boudin, sans revêtement et une cassole dont le bord simple est souligné par deux rainures et dont l'intérieur est couvert d'une glaçure plombifère jaune verdâtre. Du point de vue des pâtes et de la typologie, ces objets s'apparentent à ceux de deux productions bien représentées au XIIIe s., celle des ateliers de Sainte-Barbe à Marseille (Vallauri, Leenhardt 1997) et celle de l'aire montpelliéraine (Leenhardt 1995a). Par les détails de sa forme et faute d'analyses de laboratoire qui pourraient seules le prouver, la marmite est attribuée à la production languedocienne, alors que la cassole est une réplique exacte de celles de Marseille (Vallauri, Leenhardt 1997 : fig. 180). La rareté de ces objets en pâte rouge glaçurée dans le niveau ancien du comblement et leur absence dans les couches postérieures plaident en faveur d'une datation de la couche 81 vers la deuxième moitié du XIIIle s., période où le déclin et la disparition de ces productions sont clairement établis.

Les céramiques à pâte rouge-orangé sans revêtement.

Si la couleur et l'absence de revêtement isolent trois objets des autres productions identifiées, chacun appartient cependant à une catégorie de pâte particulière. Ils sont issus des niveaux anciens, (couche 81 , fig. $9 \mathrm{n}^{\circ}$ 6-7 et couche 72, fig. $9 \mathrm{n}^{\circ} 8$ ).

Le grand pot à base large, bord à gorge et anse rubanée dont l'attache supérieure englobe le bord (fig. $9 n^{\circ} 6$ ) est façonné dans une pâte grossière à nodules de quartz sans traitement de surface. Aucune trace d'usage n'est conservée. Ce récipient incomplet, avec ou sans bec, devait donc plutôt être affecté à la conservation des produits ou au stockage de liquide. De grands pots à bec pincé et anse rubanée, de formes et proportions comparables figurent dans diverses productions au XIIIe s. Citons de rares pots en pâte rouge glaçurée dans l'atelier de Marseille (Vallauri, Leenhardt 1997 : fig. 169), les pots de type A de SaintGilles-du-Gard au tournant des XIIIe s. et XIVe s. (Leenhardt, Thiriot $1989:$ fig. $4 \mathrm{n}^{\circ}$ 1) ou ceux en pâte claire non glaçurée de Saint-Victor des-Oules (Thiriot 1986 : fig. 31) à la fin du XIIIe s. Enfin un grand pot en pâte réfractaire de l'Uzège, de couleur violacée et revêtu à l'intérieur d'une glaçure plombifère jaunâtre, a été recensé à Arles, Van Gogh, dans le dépotoir de la fin du XIIIe s.. Pour cette période d'ailleurs on constate souvent la rareté de ces grands pots dans les différentes productions, de même que leur fréquente association avec de nombreux pégaus, de taille petite ou moyenne et parfois de rares marmites. Dans les séquences suivantes ils disparaissent.

Toujours dans la même couche 81 figure une cruche à anse en anneau (fig. $9 n^{\circ} 7$ ) et profil en U bien caractéristique réalisée dans une pâte rouge orangé très dure, contenant quelques points blancs. Elle possédait un bec tubulaire court, dont l'amorce est conservée mais peut-être aussi un second bec symétrique comme cela se rencontre fréquemment sur ce type de cruche-gargoulette destinée à conserver l'eau au frais (Vallauri, Leenhardt 1997 : fig. $229 n^{\circ} 1-3$ ). Cette forme, bien connue dans le répertoire hispanique, est attestée dans diverses productions régionales mais demeure plus rare en Provence qu'en Languedoc (cf. infra). Enfin cette pâte rouge à points blancs n'est pas sans rappeler celle qui caractérise les produits de l'atelier d'Argelliers, dans les garrigues nord-montpelliéraines aux XIe-XIIIe s. (Leenhardt et al. 1995).

Par sa pâte rouge siliceuse, avec parfois des traces de carburation dans l'épaisseur de la paroi, le pot à base large et bandes verticales rapportées (fig. $9 \mathrm{n}^{\circ} 8$ ) appartient à une autre production dont l'origine n'est pas encore identifiée.

\section{Les céramiques à pâte beige grossière}

Une jarre à conserves et un cuvier à lessive consolidé par de gros cordons horizontaux (fig. $10 n^{\circ} 8-9$ ) sont façonnés dans une pâte siliceuse beige, fortement dégraissée. 
Remarquables par l'épaisseur des parois et l'absence de revêtement, ces fragments proviennent des couches 65,54 et 56. Leur situation stratigraphique suggère donc de dater ces objets du XIVe s. Signalons qu'un fragment de jarre analogue a été recueilli lors des fouilles anciennes de la Tour des Mourgues. Si les cuviers sont inconnus en Provence aux XIIIe-XIVe s., de rares exemples de jarres à cordons digités sont recensés aussi bien dans le répertoire des vaisselles grises produites à Bonnieux dans le Vaucluse, au XIIIe s. (Bonhoure, Marchesi 1993 : fig. $8 \mathrm{n}^{\circ}$ 9) que parmi les poteries grises en pâte d'Ollières (Démians d'Archimbaud 1981 : fig. 263); de même des jarres de stockage ont été fabriquées en pâte rouge glaçurée et en pâte calcaire à Marseille, Sainte-Barbe (Vallauri, Leenhardt 1997 : fig. 224-226). En Languedoc, jarres et cuviers figurent en plus grand nombre. Si un pot à cordons digités analogue à celui de Bonnieux a été découvert à Pont-Saint-Esprit dans un contexte du début du XIVe s. (Leclaire 1992 : fig. IV n³), des jarres et cuviers ou bassins plus comparables aux récipients d'Arles comptent parmi les produits de l'atelier de Saint-Gilles-du-Gard au tournant des XIIIe et XIVe s. (Leenhardt, Thiriot 1989 : fig. $12 n^{\circ} 11-15$; fig.14 $n^{\circ} 8$ ). D'autres étaient utilisés dans la verrerie de la Seube, durant la première moitié du XIVe s. (Lambert 1982-1983; Leenhardt 1995 d : 104 et fig. 100-101). Celles découvertes dans la vallée de l'Hérault, à Cabrières et au Pouget (renseignements L. Schneider), ou encore à Aniane (Ollivier 1995 : 108) prouvent la fréquence de ces types au XIVe s. dans cette zone du Languedoc oriental. D'ailleurs les sources écrites mentionnent encore au XVe s. des cuviers et des jarres fabriqués à Saint-Jean-de-Fos (Vayssettes 1995 : 127).

\section{Céramiques à pâte claire de l'Uzège, avec ou sans revêtement glaçuré}

Les 136 récipients de cette catégorie sont définis par une pâte kaolinitique réfractaire, de structure souvent feuilletée, dure et bien cuite. La couleur varie du blanc au beige clair et au rose, devenant parfois violacée ou lie de vin. La texture présente diverses variantes : parfois, dans la couche 81 surtout, granuleuse et truffée d'inclusions de diverses tailles, plus souvent fine et compacte. L'exceptionnelle qualité technique du tournage, la finesse des parois, la brillance et la bonne adhérence des glaçures plombifères, caractérisent ces vaisselles. L'ensemble de ces traits conduit à attribuer tous ces objets aux ateliers de l'Uzège dont la circulation des produits sur les sites consommateurs de Provence et Languedoc n'est plus à démontrer. Certes tant que les officines elles-mêmes n'ont pas été localisées et fouillées et n'ont donc pas fourni le répertoire complet des formes produites, il reste difficile de certifier que ces poteries viennent exclusivement des centres de l'Uzège, si réputés et dans lesquels devait exister une concentration de savoir-faire tout à fait remarquable. La prudence impose en effet de mentionner que des gisements d'argile kaolinitique existent aussi dans la moyenne et basse vallée du Rhône, ayant pu favoriser l'installation d'autres potiers. Ainsi à Bédoin une tradition d'artisanat céramique est prouvée par l'archéologie dès l'époque an- tique, corroborée par les sources écrites à partir du XIVes. seulement (Amouric 1996) et par quelques analyses de laboratoire (M. Picon, Laboratoire de Céramologie de Lyon). Paradoxalement les découvertes archéologiques font encore défaut pour la période médiévale. En conséquence l'appellation "céramique de l'Uzège" reste convenable et adoptée par l'ensemble des chercheurs pour ces poteries au faciès si caractéristique.

L'importance de ces poteries, qui constituent $82,4 \%$ (tessons) ou $57,2 \%$ (NMI) du total des céramiques recueillies et $84 \%$ (tessons) ou 67,5\% (NMI) des vaisselles régionales, est remarquable. La différence constatée entre les pourcentages donnés en comptage tessons et en nombre d'objets s'explique par le fort taux de fragmentation des récipients de l'Uzège. Rares dans la couche 81 datée du XIIIe s. ces derniers sont devenus prédominants dès la séquence suivante (couches 72 et 65 ) qui représente, on l'a noté, le véritable comblement de la fosse.

Deux groupes sont reconnus selon que les vases sont exempts de tout revêtement ( 8 objets) ou, beaucoup plus souvent, couverts d'une glaçure plombifère (128 objets).

\section{Céramiques à pâte kaolinitique sans revêtement}

Les huit objets de ce groupe s'illustrent par l'absence de revêtement et de traces d'usage. Les deux ustensiles en pâte granuleuse, contenant de nombreuses inclusions brunes ou blanches sont les plus anciens (couche 81) : il s'agit d'un bouton de préhension d'un petit couvercle creux ou d'une tirelire en pâte rose (fig. $10 \mathrm{n}^{\circ} 3$ ) et d'un grand pot globulaire en pâte blanche à larges anses rubanées implantées sous le bord, dont la paroi est agrémentée de cannelures et de bandes digitées disposées verticalement (fig. $10 n^{\circ} 5$ ). Parmi les vases à liquide en pâte rose ou blanche et de texture fine, on note deux grandes "dourques" en pâte rosâtre (couche 72), cruches à bec tubulaire court et anse de panier surbaissée, dont la capacité atteint 6 litres (fig. $10 n^{\circ}$ 1), une cruche à anse en anneau, deux becs tubulaires et panse fermée (fig. $10 n^{\circ} 2$ ), en pâte blanche et de moindre capacité (3,5 litres) (couches 7261 ), un pot en pâte blanche et fine (fig. $10 n^{\circ} 7$ ), à large ouverture, bec ponté et anse de panier (couche 65) ; un dernier vase (fig. $10 n^{\circ} 6$ ) dont seule la base large et la panse décorée de bandes rapportées de section semi-circulaire sont conservées (couche 65), pourrait par sa forme et sa pâte blanche très fine et épurée appartenir au même groupe des vases à liquide. Enfin un couvercle plat de forme discoïde à bouton de préhension, en pâte blanche et fine (couche 65) complète ce lot (fig. $10 \mathrm{n}^{\circ} 4$ ).

Les "dourques" à anse de panier et bec tubulaire n'ont pas d'équivalent dans les productions en pâte grise de Provence et du Languedoc oriental aux XIIe et XIIIe s. En revanche ces récipients en pâte réfractaire trouvent des parallèles exacts dans les cruches en pâte calcaire de Marseille, Sainte-Barbe, au XIIIe s. (Vallauri, Leenhardt 1997 : fig. $229 n^{\circ} 4-5$ ) ou de la basse vallée du Rhône dans la première moitié du XIVes. (Schneider 1995).

Pour les pots à bec ponté et anse de panier, bien pratiques eux aussi pour puiser l'eau, la transporter et la 
conserver, de bons parallèles se trouvent dans diverses productions régionales du XIIe au XIVe s. L'exemple le plus ancien est sans doute celui de Cabasse qui daterait du XIe s. (Pelletier, Bérard 1997 : fig. 8). Un autre récipient, issu de l'atelier de Mimet, au tournant des XIIe-XIIIe s. pourrait sans doute en être rapproché, mais l'objet est trop fragmenté pour vérifier s'il possède ou non un bec (Pelletier, Vallauri 1992 : 237, fig. $8 n^{\circ}$ 5). Des récipients similaires sont mentionnés en Languedoc à partir du XIIIe s. : ils existent en pâte grise fine au sein du répertoire des formes de Saint-Gilles-du-Gard (Leenhardt, Thiriot 1989 : fig. $15 n^{\circ} 2$ ). Si par ailleurs de rares anses de panier sont comptabilisées parmi les produits de l'atelier de Bollène au XIIIe s., leur association avec les becs pontés n'a pu être prouvée (Thiriot 1987). Un rapprochement évident s'impose encore avec les grandes "dourques" en pâte calcaire grise, présentes au début du XIVe s. dans le comblement d'un puits à Lunel-Viel (Leenhardt, Raynaud 1995 : fig. 50). Enfin ces cruches à bec ponté et anse de panier sont absentes des répertoires en pâte calcaire et cuisson oxydante des ateliers provençaux en activité aux XIIIe-début XIVe s., notamment inconnues à Marseille, alors que quelques objets identiques sont dénombrés en pâte calcaire de couleur claire dans le comblement d'un puits de Montpellier (Leenhardt 1995b).

Les cruches à panse fermée, anse en anneau et un ou deux becs pour remplir l'eau et la verser, représentées à Arles dans différentes productions on l'a vu (fig. $9 \mathrm{n}^{\circ} 7$; fig. $10 n^{\circ} 2$ ), trouvent d'excellents équivalents en Provence et surtout en Languedoc, aussi bien en céramique grise, qu'en pâte calcaire sans revêtement ou en argile réfractaire glaçurée ou non. Parmi les exemples en céramique grise, le plus ancien provient de Mimet au tournant des XIIeXIIle s. (Pelletier, Vallauri 1992 : fig. $8 \mathrm{n}^{\circ}$ 5). Un seul est connu dans le Var en pâte d'Ollières (Démians d'Archimbaud 1981 : fig. $261 \mathrm{n}^{\circ}$ 6). En Languedoc, quelques-uns sont attestés au début du XIIle s. parmi les formes fabriquées au Garissou près de Béziers (Lécuyer 1995 : 40) ; ce type perdure encore dans l'atelier de Saint-Gilles-du-Gard au tournant des XIIIe-XIVe s. (Leenhardt, Thiriot 1989 : fig. $15 n^{\circ} 13$ et 15 ) et une petite cruchette trouvée à SaintFlorent dans le Gard, conservée au Musée archéologique de Nîmes, doit en être issue. Dans la première moitié du XIVe s. des récipients analogues sont reconnus autour de l'étang de Thau, à Loupian et à Agde (Poteries d'Oc 1995 : fig. 96). Cette même forme fait également partie du répertoire des officines pratiquant la cuisson oxydante. On recense ainsi trois exemples en pâte calcaire à Marseille (Vallauri, Leenhardt 1997 : fig. $229 n^{\circ} 1-3$ ). En Languedoc, des vases semblables figurent parmi les produits de divers centres. Citons les grandes cruches en pâte calcaire agrémentées d'un décor plastique exubérant de l'atelier implanté à Aniane dans la seconde moitié du XIVe s. (Ollivier 1995 : fig.113). Mais les plus beaux spécimens sont originaires de l'Uzège au XIVe s., comme le montrent des poteries recueillies à Avignon, sans revêtement (Boiron et al. 1991), ou bien émaillées et peintes en vert et brun (Poteries d'Oc 1995 : fig. 95) ; ce type s'est perpétué au XVIe s. et cette fois les récipients étaient ornés de décors d'ap- pliques et revêtus de glaçure plombifère (Carru 1989 : 209, fig. $12 \mathrm{n}^{\circ} 2$; Poteries d'Oc 1995 : fig. 113).

\section{Céramiques à glaçure plombifère}

Ces vaisselles revêtues de glaçure plombifère rassemblent bon nombre de pots culinaires, prépondérants ( 89 objets) et une série conséquente de vases à liquide (39). Au sein du premier groupe les marmites dominent (63), suivies par les pégaus (13), les jattes (7), les poêles (4) et de rares couvercles (2). Dans le second, 30 cruches côtoient 8 pichets gargoulettes à bec tubulaire et un unique pichet à bec pincé. Des glaçures dont la brillance et la qualité sont remarquables couvrent la surface interne des récipients culinaires assurant leur étanchéité et agrémentent l'aspect extérieur des autres (Vallauri, Leenhardt à paraître). Les teintes varient du jaune or ou miel, parfois moucheté de brun, au brun et au vert pâle, plus rarement au vert moucheté.

\section{Marmites}

Les marmites sont définies par une large ouverture, un col très court, une panse globulaire ou piriforme, un fond bombé et deux anses rubanées. Elles constituent l'équivalent des faitouts et cocottes-minute modernes. Trois groupes sont distingués selon le mode d'implantation des anses.

Les marmites à anses horizontales et rubanées directement implantées sur un bord de profil rectangulaire sont les plus anciennes (fig. 11 et 12). Ces dix objets proviennent des couches 81 et surtout 72 .

L'antériorité de l'unique exemplaire de la couche 81 est certaine. Ce récipient se singularise par l'absence de col (fig. $11 \mathrm{n}^{\circ} 2$ ). Il rappelle des objets de même forme en pâte grise : l'un figure dans la même couche (fig. $7 \mathrm{n}^{\circ} 8$ ), d'autres étaient fabriqués à Saint-Gilles-du-Gard (voir supra) ; il évoque également les marmites 6 en pâte calcaire et en forme de sac de la seconde phase de l'atelier de Sainte-Barbe (Vallauri, Leenhardt 1997 fig. $176 n^{\circ}$ 6-7). Les autres marmites de ce groupe appartiennent toutes à la couche 72 (fig. $11 n^{\circ} 1$ et $3-7$; fig. 12). Elles ont toujours un bord rectangulaire formant un léger bourrelet interne mais se séparent de la précédente par la présence systématique d'un col court et légèrement renflé et d'une panse globulaire ou surtout piriforme. Il existe différents modules comme le montrent les variations de capacité ( 3 litres à 11,5 litres). Le décor à la molette figure sur un seul objet (fig. $11 \mathrm{n}^{\circ} 5$ ).

A Arles même, la fosse de l'hôpital Van Gogh (cf supra) a livré une série de marmites de typologie identique, les unes en pâte blanche très épurée, d'autres en pâte beige clair ou rosâtre. Glaçurées ou non, quelques-unes semblent n'avoir jamais servi ; l'une d'elles conserve sur le bord les traces de collage d'un autre objet, confirmant ainsi que les accidents de cuisson n'empêchaient pas forcément la commercialisation des pots et témoignant surtout des modalités d'empilement des marmites dans le four pour la cuisson. 


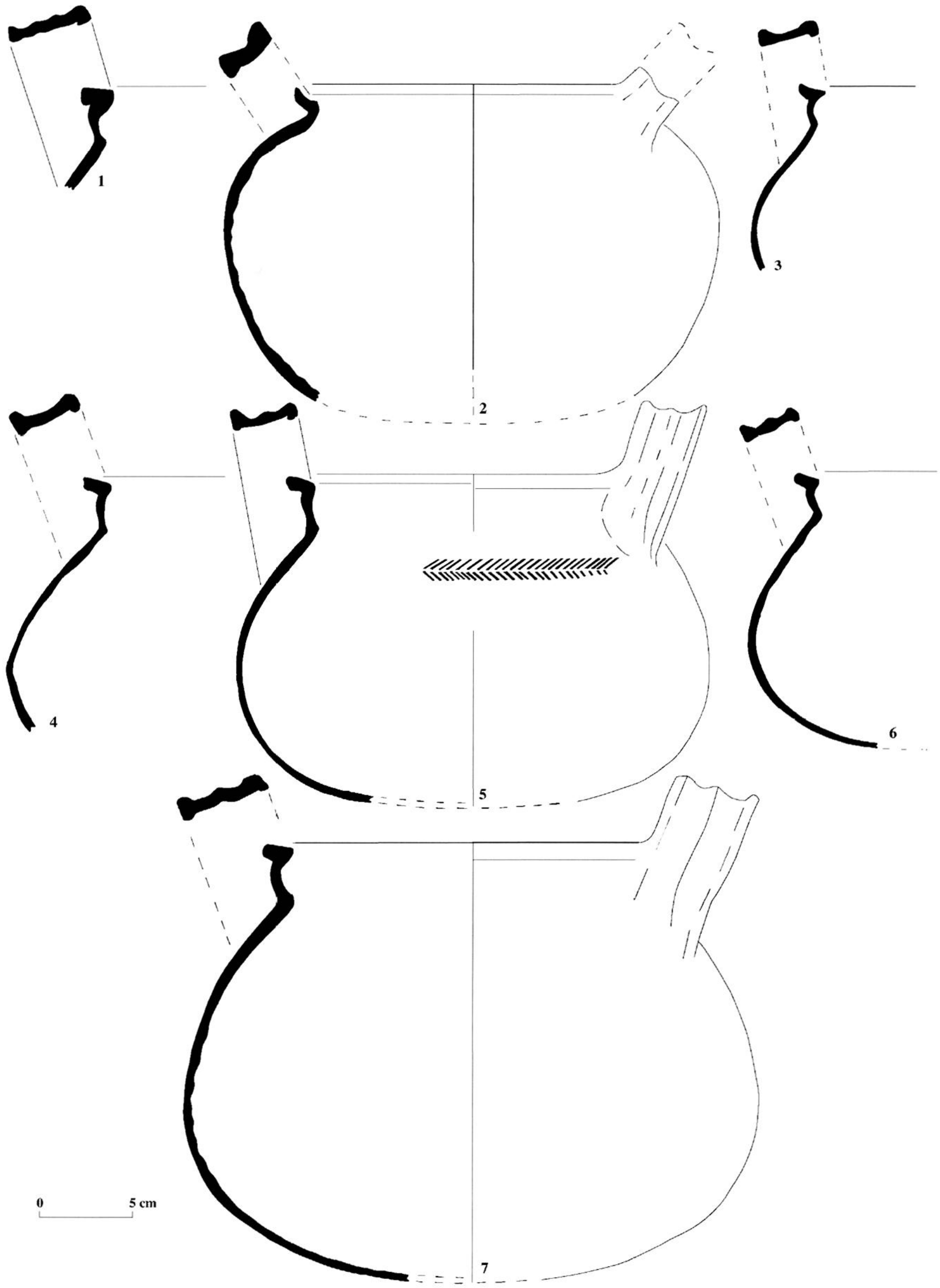

Fig. 11 : Céramiques en pâte claire glaçurée : marmites à anses horizontales sur le bord. M. Leenhardt. 


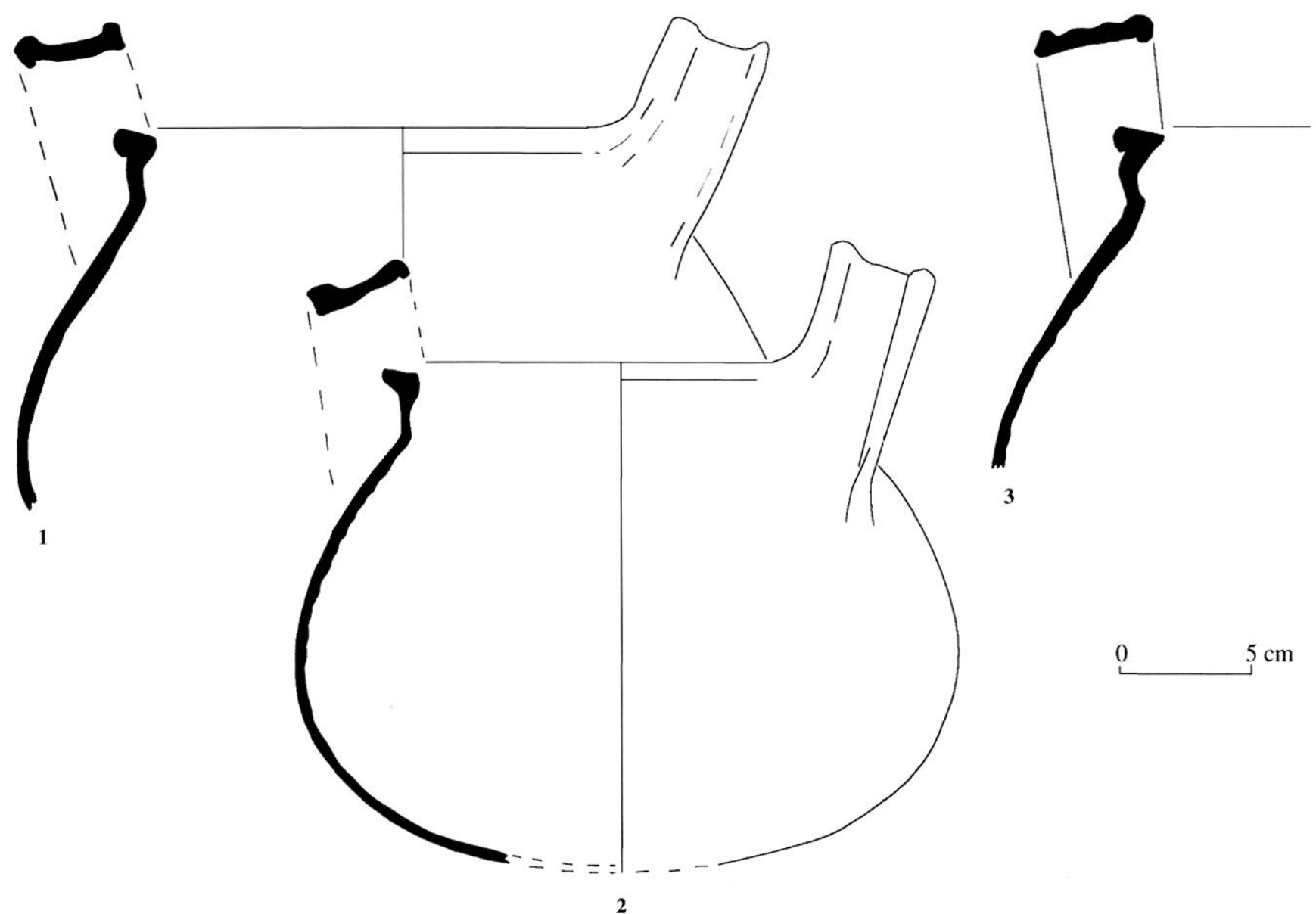

Fig. 12 : Céramiques en pâte claire glaçurée : marmites à anses horizontales sur le bord. M. Leenhardt.

On l'a noté, cette forme à anses horizontales sur le bord était déjà attestée, quoique peu fréquente, dans les productions languedociennes à pâte grise. En revanche elle demeure absente du répertoire des vaisselles en pâte rouge glaçurée de Marseille ou de l'aire montpelliéraine au XIIle s. C'est en réalité parmi les productions en pâte claire glaçurée de l'Uzège, dès leur apparition, qu'elle se trouve le mieux représentée sur divers sites languedociens. Ainsi au château de Beaucaire de telles marmites, glaçurées et souvent décorées à la molette figurent dans des niveaux bien datés de la seconde moitié du XIIIe s. (Leenhardt 1995c : fig. 59); sur ce même site, dans les contextes du début du XIVe s., elles ont disparu au profit des marmites à anses verticales. Des exemplaires analogues à ceux d'Arles et Beaucaire mais sans décor sont recensés aussi à Nîmes, rue Nationale (fouilles Genty), au Bouquet près d'Alès ; un récipient unique figure encore à Pont-Saint-Esprit au tout début du XIVe s. (Leclaire 1992 : fig. $9 \mathrm{n}^{\circ}$ 1). Dans la basse vallée du Rhône, en Avignon, quelques objets semblables sont signalés au tournant des XIIIe-XIVe s. (Carru 1995a : fig. 68 ; Gaday et al. 1995 : fig. 48). En revanche sur les sites provençaux occupés durant la première moitié du XIVe s. et sur lesquels la diffusion des productions de l'Uzège est largement vérifiée, ces marmites à anses horizontales sur le bord restent inconnues, ce qui suggère leur abandon après le tournant du XIVe $s$. au profit d'autres modèles à anses verticales (Richarté 1991; Michel 1989;
Hesnard et al 199 ; Parent 1991 ; Cartron 1992 ; Leenhardt 1996).

\section{Marmites à anses horizontales sur l'épaulement}

Les sept récipients de cette série proviennent eux aussi de la couche 72 (fig. 13). Ils s'isolent aisément car l'implantation des anses horizontales et rubanées se situe cette fois sur l'épaulement. Un seul cas de décor à la molette est répertorié (fig. $13 \mathrm{n}^{\circ} 6$ ). Leur taille reste généralement modeste, leur contenance se situant autour de 3,5 litres. Ces marmites à anses horizontales sur l'épaulement restent rares en Languedoc tant en céramique grise (Leenhardt, Thiriot 1989) que parmi les productions à pâte claire kaolinitique du XIVe s. (Leenhardt 1997 : fig. 50 n $^{\circ} 27$ ). En Provence, au contraire, elles caractérisent les productions grises des ateliers varois et vauclusiens de la fin du XIIle et du XIIIe s. (voir supra). Elles sont également fréquentes dans les séries à pâte claire glaçurée du groupe B2A à Rougiers dans la seconde moitié du XIIle et au début du XIVe s. puis disparaissent, tandis qu'elles figurent dans les productions rouges glaçurées de l'atelier d'Ollières à partir du début du XIVe s., progressivement remplacées pourtant par les marmites à anses verticales (Démians d'Archimbaud 1981 : fig. 277 et fig. 290-293).

\section{Marmites à anses verticales}

Elles se différencient des précédentes par la présence de deux anses verticales et rubanées dont les attaches su- 

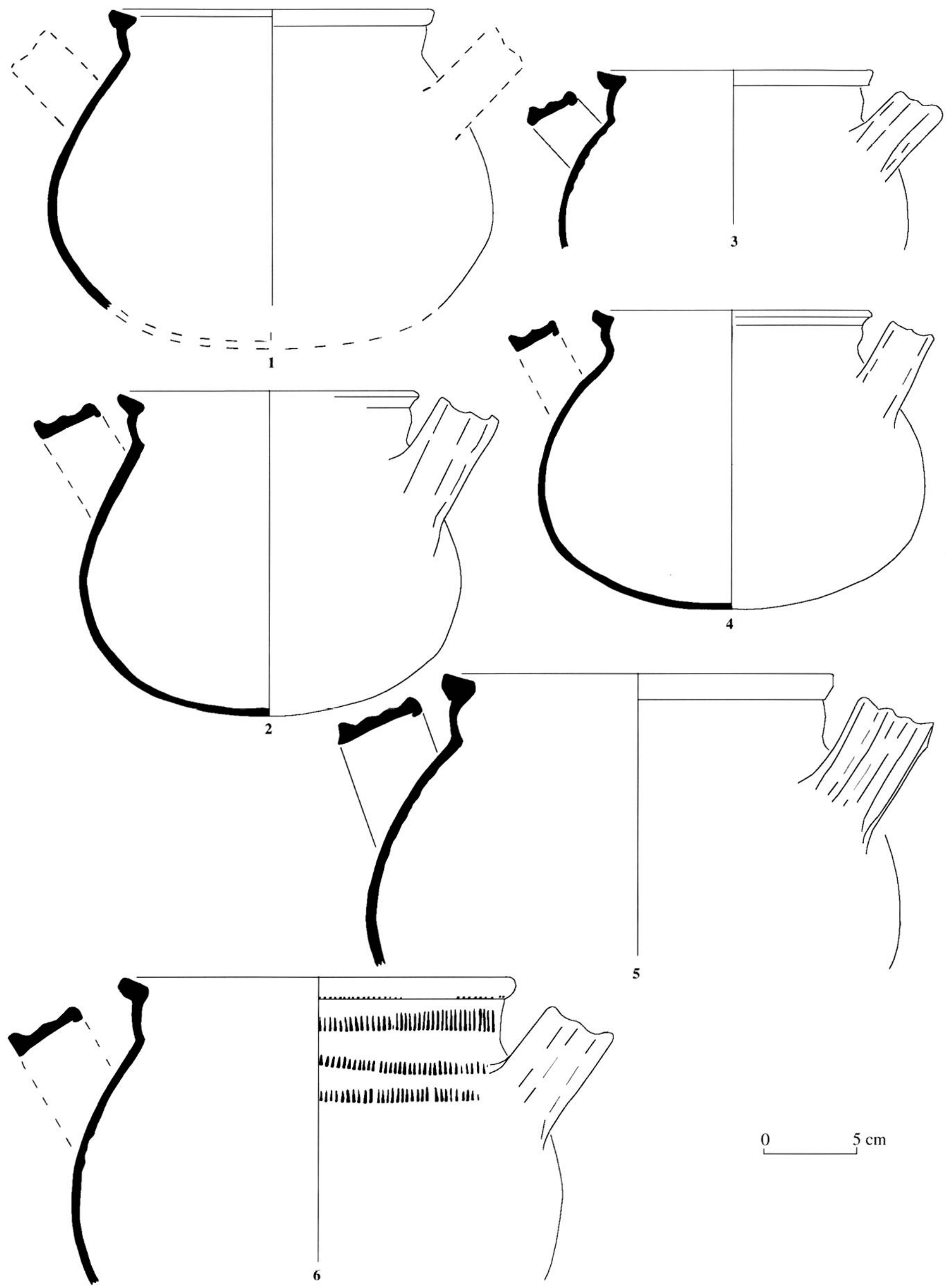

Fig. 1.3 : Céramiques en pâte claire glaçurée : marmites à anses horizontales sur l'épaulement. M. Leenhardt. 
périeure et inférieure se situent respectivement sous le bord ou à mi-hauteur du col et au niveau de plus grande largeur de la panse. Ce groupe, de loin le plus conséquent, compte 46 objets dont 40 se trouvent dans les couches $72-$ 65 et seulement 6 dans les couches supérieures.

La forme globale, souvent piriforme (fig. $14 n^{\circ} 1,4,6$ ) devient parfois globulaire ou ovoïde (fig. $14 n^{\circ} 5$ et 8 ). Quelques bords de profil rectangulaire demeurent (fig. 14 $\mathrm{n}^{\circ}$ 2-4 et 7) mais la tendance vers le bord carré ou triangulaire s'affirme (fig. $14 n^{\circ} 5$ et 9 ; fig. $16 n^{\circ} 4$ et 6 ; fig. 17 $\mathrm{n}^{\circ} 6$ et 12 ), notamment dans les marmites de plus petite taille. Simultanément les cols légèrement bombés cèdent la place à d'autres au profil droit et parfois plus haut. $\mathrm{Ce}$ changement, amorcé sur les marmites recensées dans la couche 72 se confirme pour celles de la couche 65 . L'évolution se poursuit ensuite comme le révèlent les rares marmites de la dernière séquence (couches $61,56,54)$ : les bords rectangulaires ont totalement disparu, seuls existent des bords carrés (fig. $18 \mathrm{n}^{\circ} \mathrm{l}$ et 3 ) ou franchement triangulaires et soulignés par un petit bourrelet (fig. $18 n^{\circ} 4$ et 6).

Ces marmites sont de différents modules. La capacité des plus grandes est égale ou supérieure à 10 litres. C'est d'ailleurs à cette série qu'il convient de rattacher le seul exemplaire à quatre anses rubanées (fig. 15). Les récipients du groupe intermédiaire peuvent contenir de 3 à 7,5 litres. Enfin quelques-uns ont une capacité réduite, moins de 2 litres. Les ustensiles de taille moyenne ou faible apparaissent dès la couche 72 mais se multiplient surtout dans la couche 65 .

En Languedoc des marmites de l'Uzège à anses verticales et bord triangulaire ou en amande sont répertoriées au château de Beaucaire dans les niveaux de la première moitié du XIVe s. où elles remplacent celles à anses horizontales sur le bord, typiques du siècle précédent (Schneider 1990 et 1995 ; Leenhardt 1995c). A la même époque à Pont-Saint-Esprit elles sont définies par des bords triangulaires ou carrés, plus rarement en amande (Leclaire 1992). En Provence aussi, dans la première moitié du XIVe s., sur la côte varoise à Fréjus et à Hyères, à Marseille, Aix-enProvence, Avignon comme dans les Alpes, les marmites de l'Uzège diffusées en abondance ont systématiquement des anses verticales : si une relative variété des lèvres est manifeste, les bords rectangulaires et les cols renflés disparaissent au profit de bords triangulaires, carrés ou en amande (Parent 1991 ; Michel 1989 ; Hesnard et al. 1993 ; Richarté 1991 ; Cartron 1992 ; Carru 1995a ; Gaday et al. 1995 ; Leenhardt 1996 ; Démians d'Archimbaud, Vallauri à paraître).

Ainsi l'étude des marmites de l'Uzège découvertes à Arles apporte de précieux renseignements sur les formes les plus anciennes de ces pots culinaires, qui disparaissent au début du XIVes. Elle fournit d'utiles jalons pour préciser ou compléter l'évolution typologique intervenue pour ces produits depuis la seconde moitié du XIIIe s. jusqu'à la fin du XIVe s. Elle confirme aussi l'exceptionnelle diffusion de ces récipients et leur renommée dont les sources écrites se faisaient d'ailleurs l'écho (Amouric 1995a).

\section{Pégaus}

Ces 13 petits pots globulaires à fond généralement plat et anse rubanée dont l'attache supérieure inclut le bord, ont souvent un bec pincé diamétralement opposé à l'anse (fig. 19). Revêtus en surface interne d'une glaçure plombifère jaunâtre, parfois mate et mal cuite, ils présentent une paroi externe fortement noircie en raison de leur emploi pour cuire ou tenir au chaud les préparations alimentaires. Ces objets, inconnus dans la couche ancienne, figurent surtout dans les couches 72-65 ; deux seulement viennent des niveaux tardifs (fig. $19 \mathrm{n}^{\circ} 10-11$ ). Généralement la hauteur n'excède pas $10 \mathrm{~cm}$ et la capacité ne dépasse pas 1 litre, mais la contenance de quelques rares pots atteint le double, soit 2 litres (fig. $19 \mathrm{n}^{\circ} 9$ ). Dans la séquence récente, le pégau prend une forme étirée et allongée (fig. $19 n^{\circ} 11$ ) mais on voit aussi apparaître des ustensiles de taille réduite (fig. $\left.19 n^{\circ} 10\right)$.

Des pégaus attribués à une origine uzégeoise étaient déjà bien répertoriés dès la seconde moitié du XIIle et encore au XIVe s. sur les sites consommateurs languedociens et provençaux et même dans les nécropoles où ils étaient fréquemment utilisés comme vases funéraires (Leenhardt, Vallauri 1988). Mais l'originalité du groupe d'Arles réside dans la présence fréquente d'un bec pincé. En effet jusqu'ici ces éléments verseurs caractéristiques des pégaus languedociens en pâte grise (Leenhardt, Thiriot 1989 : fig. 5 et 6) ou en pâte rouge glaçurée (Leenhardt 1995a ; Leenhardt, Raynaud 1995) ne semblaient pas associés aux pégaus fabriqués en Uzège. Enfin la faible proportion de ces petits pots à anse et bec pincé par rapport aux marmites prédominantes confirme les constatations similaires effectuées sur de nombreux sites de la région et révèle l'usage envahissant de ces dernières dès la première moitié du XIVe s., sans doute en raison de profondes transformations des modes alimentaires.

\section{Jattes}

Caractérisées par leur forme basse à large ouverture, la présence de deux anses et d'un bec verseur, elles sont moins nombreuses que les pégaus et apparaissent seulement à partir de la couche 65 ; une seule, très fragmentaire d'ailleurs, appartient à la couche 54 . Toujours revêtues à l'intérieur d'une glaçure plombifère, elles servaient surtout à la cuisson des plats en sauce comme en témoignent les fonds systématiquement noircis. Les plus anciennes ont un bord rentrant bien incurvé (fig. $20 n^{\circ} 1-3$ ) ou rarement en amande (fig. $20 n^{\circ} 4$ ). L'unique objet de la couche 54 se distingue par son aspect plus lourd et surtout le bord en amande et très redressé (fig. $20 \mathrm{n}^{\circ} 5$ ).

Des récipients similaires sont connus dès le XIIIe s. parmi les vaisselles en pâte rouge glaçurée de Marseille, Sainte-Barbe (Vallauri, Leenhardt 1997 : fig. 181-182) et de Montpellier (Leenhardt 1995a : fig. 35). C'est toutefois dans les productions à pâte claire glaçurée de l'Uzège que l'on a inventorié les plus belles séries. Déjà représentées au château de Beaucaire dans la seconde moitié du XIIIe s., où elles sont associées à des marmites à anses horizontales, elles ont un bord bien incurvé, rentrant ou redressé et sur- 


$$
\begin{aligned}
& \sum \bar{l} \bar{l}- \\
& \bar{l} \bar{q}< \\
& \bar{l} \bar{q}
\end{aligned}
$$



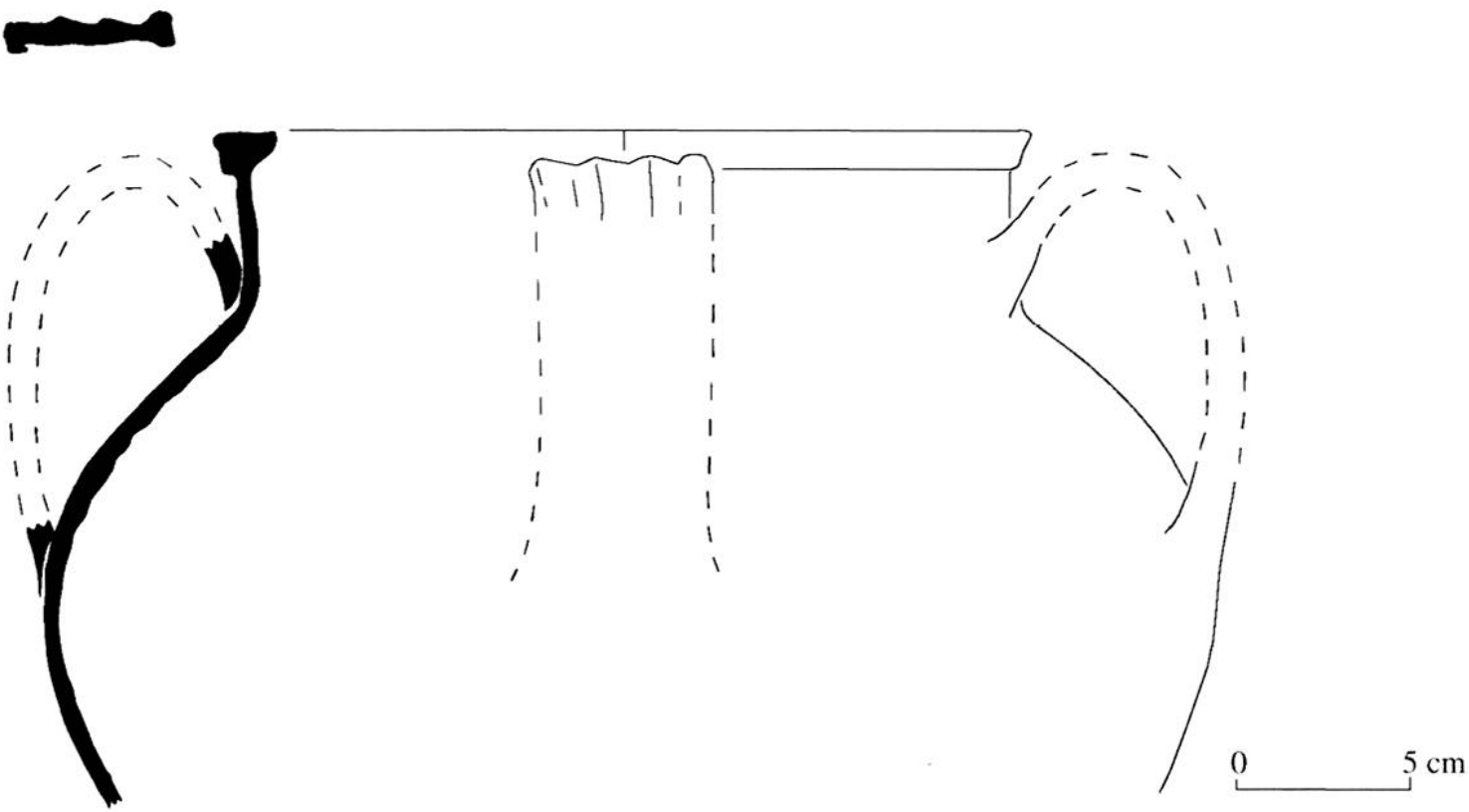

Fig. 15: Céramiques en pâte claire glaçurée : marmites à anses verticales issues des couches 72-65. M. Leenhardt.

tout des anses attachées à la base du bord ; mais dans les niveaux de la première et de la seconde moitié du siècle suivant les bords en amande deviennent exclusifs et souvent redressés (Schneider 1990 et 1995 ; Leenhardt 1995c). Si les deux types de bords semblent coexister à Arles durant la première moitié du XIVe s., sur nombre de sites provençaux l'évolution typologique des bords et de l'implantation des anses est déjà réalisée à cette période (Richarté 1991 : fig. 21 n 9-16; Gaday et al. 1995 : fig. 56 ; Leenhardt 1997 : fig. $51 \mathrm{n}^{\circ} 33$ et 36 ; Démians d'Archimbaud, Vallauri à paraître : fig. $45 n^{\circ} 5$ ) sans que de nouveaux changements se manifestent après le milieu du siècle (Konaté 1980 : pl. 64 ; Démians d'Archimbaud et al. 1980 : fig.51 ; Carru 1995a).

\section{Pốles}

Plus rares encore sont les poêles puisque quatre seulement furent dénombrées (fig. $20 n^{\circ} 8-11$ ). Provenant toutes de la couche 65 , elles sont attribuables à la première moitié du XIVes.

Deux ont conservé leur manche, partiellement écrasé et ovalisé lors de leur application sur le bord. Tous les fonds sont noircis, prouvant l'usage culinaire de ces ustensiles, toujours glaçurés en surface interne pour accroître l'étanchéité et empêcher que les aliments n'accrochent au fond lors de la cuisson.

La fosse de l'hôpital Van Gogh, déjà citée, recelait un poêlon de forme proche, plus creux et muni d'un bec pincé, pratique pour servir de saucière ou verseuse.

Ce type d'ustensile paraît toujours rare, quelles que soient les productions. Cette faible fréquence ne peut surprendre et résulte sans doute de l'existence simultanée de nombreuses poêles en métal, non conservées ou récupérées. Ces dernières sont souvent mentionnées dans les sources écrites de la fin du Moyen Age et rendent compte de l'importance des fritures dans la cuisine médiévale (Stouff 1970 ; Coulet 1991). En tous les cas si quelques poêles figurent parmi les vaisselles en pâte rouge glaçurée au XIIIe s. aussi bien à Marseille, Sainte-Barbe (Vallauri, Leenhardt 1997 : fig. $179 \mathrm{n}^{\circ}$ 1-2) que dans l'aire montpelliéraine (Leenhardt 1995a : fig. 35), les exemplaires les mieux connus sont issus des productions uzégeoises aux qualités réfractaires bien appropriées pour les fritures à forte chaleur. Citons par exemple les types recensés à Marseille, Sainte-Barbe, dans les niveaux de consommation contemporains de la seconde phase de l'atelier (Leenhardt 1997 : fig. $51 \mathrm{n}^{\circ}$ 38) mais aussi d'autres attestés dès la première moitié du XIVe s. à Aix-en-Provence (Richarté 1991 : fig. $20 n^{\circ} 6$ à 8) ou encore à Pont-Saint-Esprit (Leclaire 1992 : fig. $8 n^{\circ} 24$ ). Après le milieu du XIVe s. des objets analogues figurent dans les vaisseliers retrouvés sur les sites avignonnais (notamment Konaté 1980 : pl.72; Démians d'Archimbaud et al. 1980 : fig. 52 n 1-2).

\section{Couvercles}

Deux couvercles sont issus de la couche 65 , datée de la première moitié du XIVe s. (fig. $20 n^{\circ}$ 6-7 ; Poteries d'Oc 1995 : fig. 51 ). De forme discoïde plate à bords redressés et à bouchon de préhension central, revêtus de glaçure jaune miel ou mouchetée de brun, ils ont une taille modeste, trop réduite pour s'adapter sur les jattes conservées dans le même lot. L'un d'eux est percé de trous destinés à faciliter l'évacuation de la vapeur d'eau et à réguler la cuisson. Des exemples similaires ne manquent pas sur les sites languedociens ou provençaux occupés au XIVe s. (Leclaire 1992 : fig. n 20-21 ; Guyonnet 1992 : pl. 4 n 14 ; Démians d'Archimbaud et al. 1980 : fig. $51 \mathrm{n}^{\circ} 5-7$; Poteries d'Oc 1995 : fig. 71 et 74).

\section{Vases à liquide}

Ce groupe rassemble 30 cruches à col large, prédominantes, 8 pichets-gargoulettes à bec tubulaire et un pichet à bec pincé. Avec 39 objets cet ensemble, à peine deux fois moins important que celui des pots culinaires, prouve une fois encore que la circulation des produits de l'Uzège ne se 


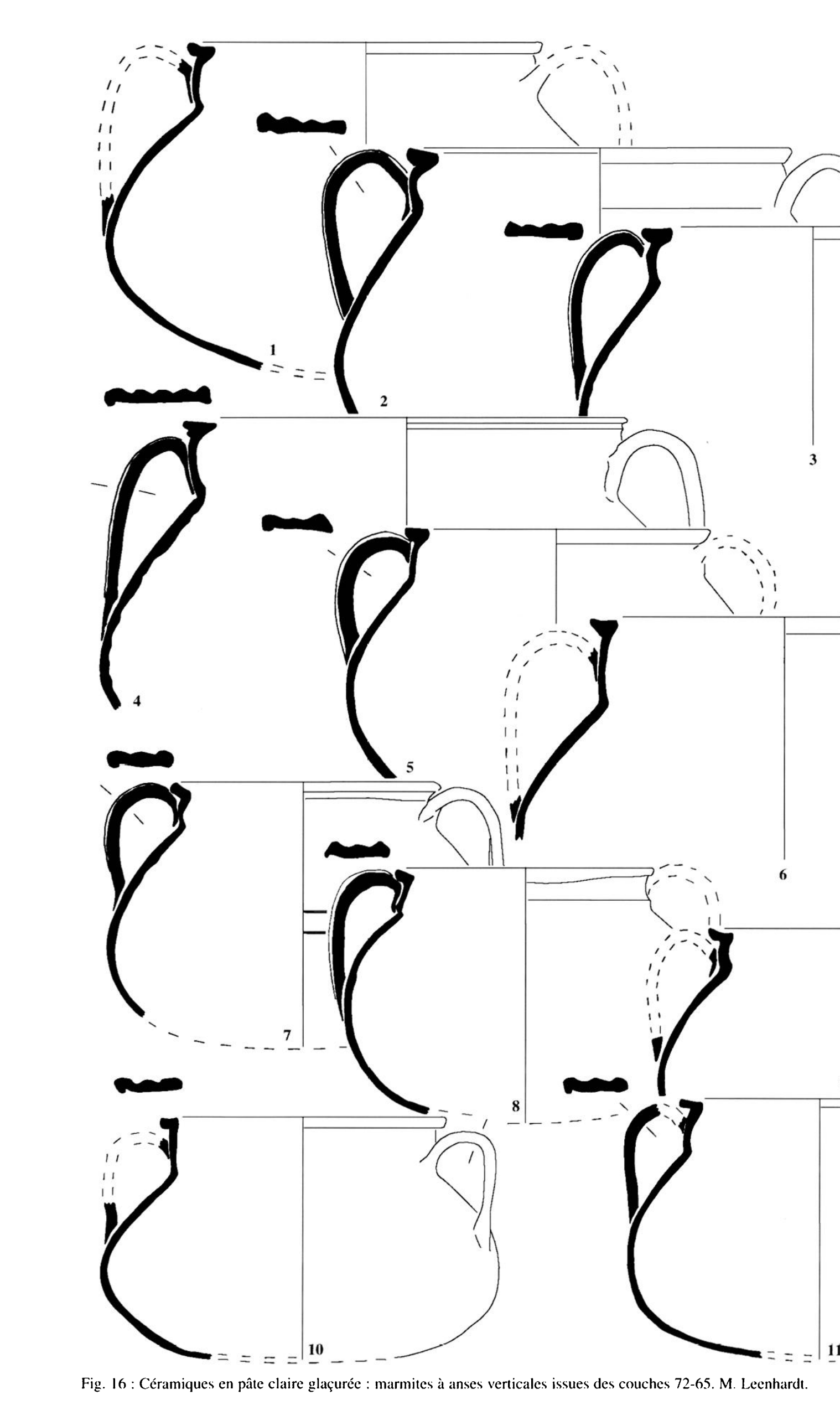




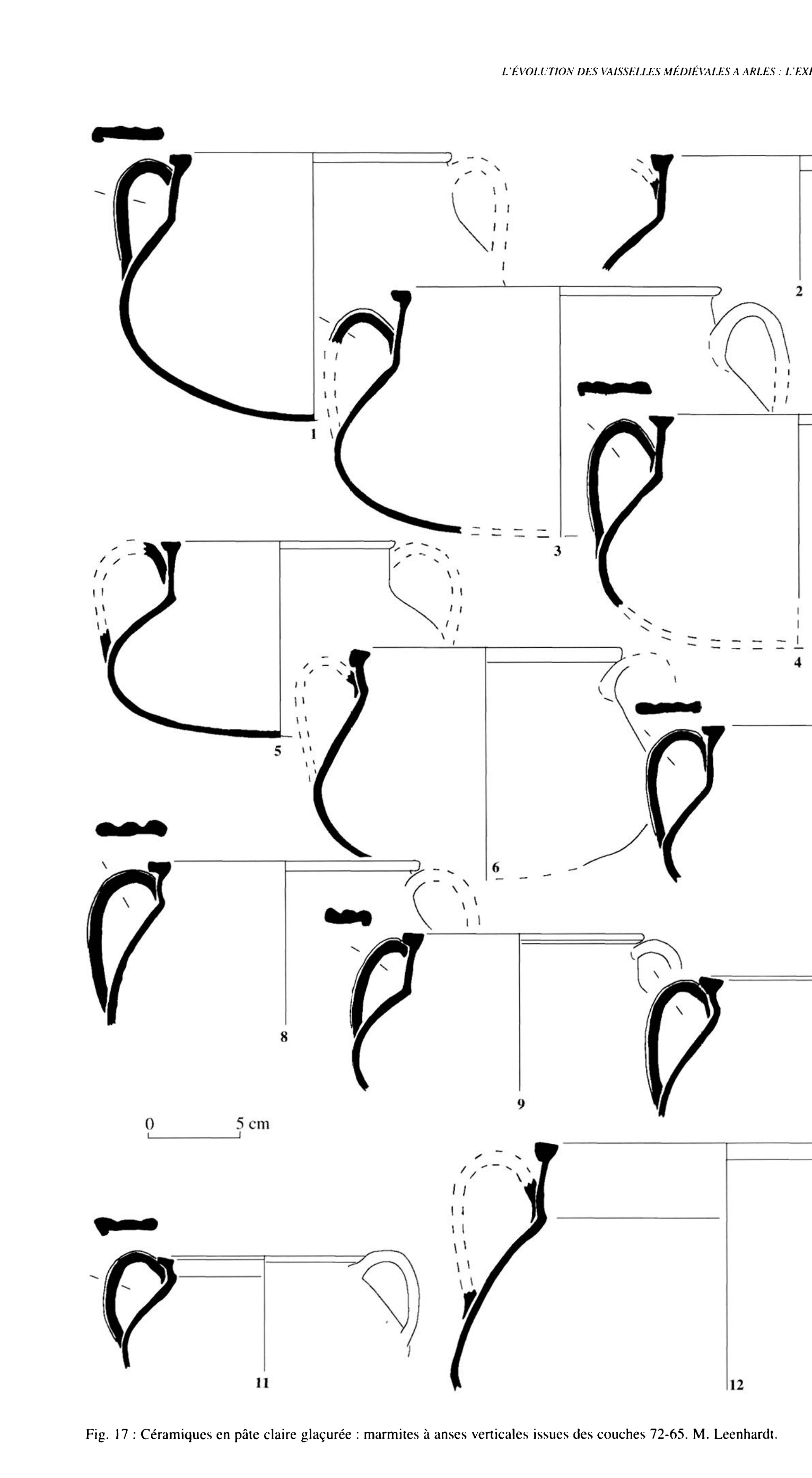




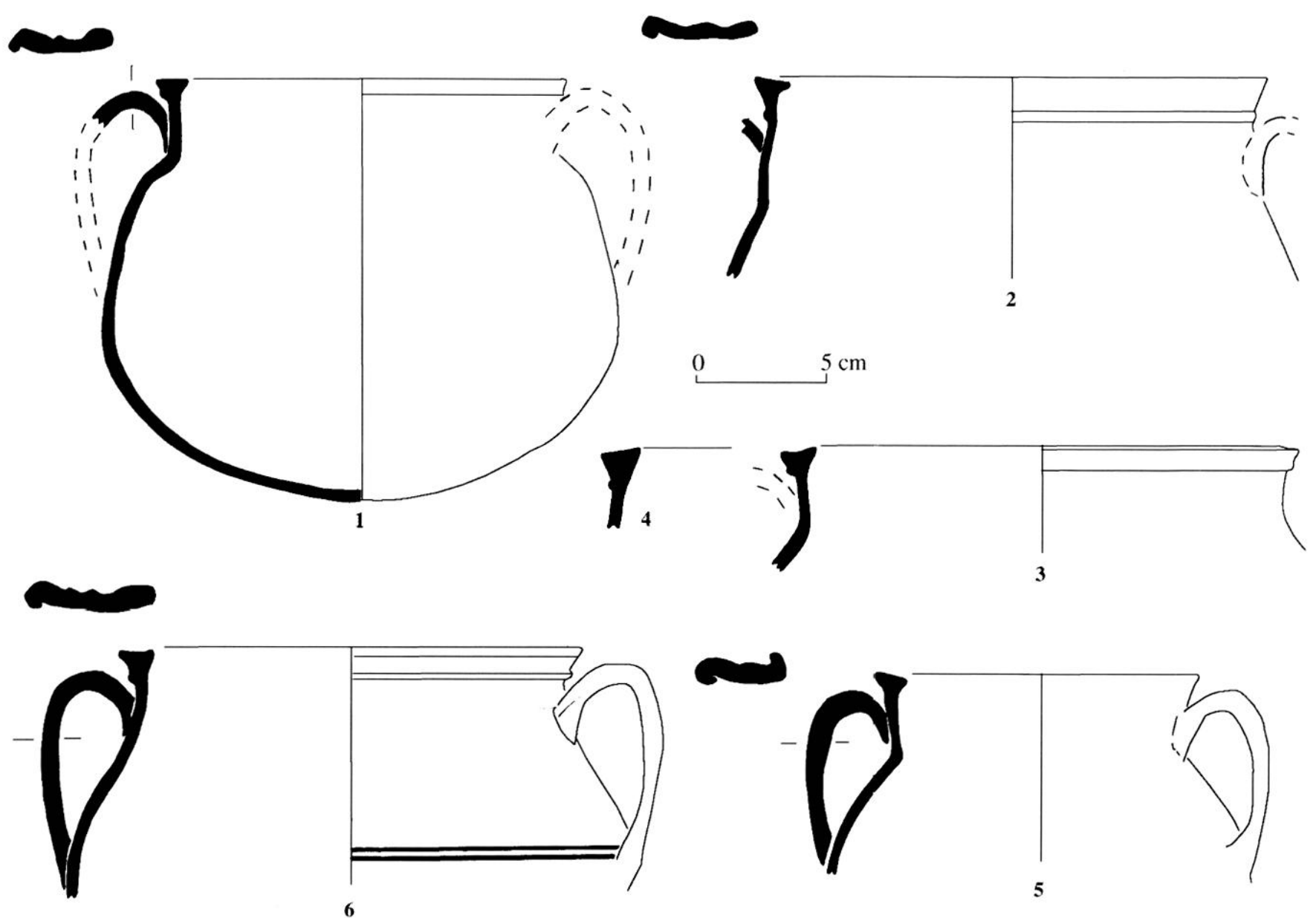

Fig. 18 : Céramiques en pâte claire glaçurée : marmites à anses verticales issues des couches 61-56-54. M. Leenhardt.

limitait pas, de loin, à ces derniers même s'ils étaient les plus réputés.

Les cruches sont définies par un col large et très haut (fig. $21 \mathrm{n}^{\circ} 4,5$ et 9), une panse globulaire de profil souvent surbaissé (fig. $21 \mathrm{n}^{\circ} 9$; fig. $22 \mathrm{n}^{\circ} 7$ ) et un pied bien dégagé dont la largeur est sensiblement égale à celle de l'embouchure du vase. Toujours munies d'une anse verticale rubanée et cannelée, elles possèdent en général un bec pincé. Un cas exceptionnel, sans verseur doit cependant être mentionné (fig. $21 n^{\circ} 6$ ). La capacité de ces récipients se situe entre 1,2 et 1,5 litres mais de rares modèles de moindre contenance existent (fig. $22 n^{\circ} 8-9$ ). A l'exception de deux minuscules fragments recueillis dans la couche 81 , ces cruches proviennent du dépotoir formé par les couches 72-65 sans que l'on puisse discerner de différences typologiques entre les objets issus de l'une ou l'autre couche. Signalons la qualité exceptionnelle des glaçures, leur bonne adhérence et leur brillance. Les teintes courantes sont le jaune or, le brun-jaune ou le brun moucheté, plus rarement le vert pâle ou le vert foncé moucheté (fig. $21 \mathrm{n}^{\circ} 3$ ).

Deux cruches issues de la couche 72 se séparent du reste du lot. La première (fig. $21 n^{\circ}$ 2) est caractérisée par sa grande taille et surtout sa base très large et par sa contenance qui atteint 5 litres; en outre sa pâte rosâtre se rapproche par sa texture des pâtes calcaires sans pouvoir cependant être véritablement identifiée à elles. La seconde (fig. $21 \mathrm{n}^{\circ}$ ) se démarque du groupe par son décor excep- tionnel. Sous la glaçure jaune or en effet, une série de bandes brunes rapportées et moletées ornent la panse et l'ensemble procure un effet de polychromie.

Pour l'essentiel toutes ces cruches rappellent des modèles en pâte claire de l'Uzège déjà bien répertoriés sur les sites régionaux. Les parallèles les plus proches, présentant les mêmes profil surbaissé et col haut se trouvent à PontSaint-Esprit dans des niveaux de la première moitié du XIVe s. (Leclaire 1992 : fig. $8 n^{\circ} 7$ ) et surtout à Marseille dans un dépotoir comblant un puits et daté du premier tiers du XIVe s. (Poteries d'Oc 1995 : fig. 65 et 66 ; Hesnard et al. 1993 ; Démians d'Archimbaud, Vallauri à paraître). La cruche à bandes moletées, quant à elle, renvoie à un petit nombre d'objets identiques, réalisés eux aussi en pâte claire de l'Uzège. Ils proviennent du même puits marseillais (Poteries d'Oc 1995 : fig. 61), mais aussi du château de Beaucaire où ils furent recueillis dans des niveaux de la seconde moitié du XIIIe s. (Leenhardt 1995c : fig. 60), ou encore de Pont-Saint-Esprit dans la première moitié du XIVe s. (Leclaire 1992 : fig. $10 n^{\circ} 4$ ). Cette fantaisie décorative ne semble pas s'être perpétuée dans les productions uzégeoises ultérieures. Peut-être fait-elle référence au goût prononcé pour les "céramiques très décorées" qui se manifestait couramment à la même époque dans les régions plus septentrionales et dont les exemples les plus méridionaux ont été recensés sur des cruches ovoïdes en pâte rouge glaçurée datées de la seconde moitié du XIIIe s. dans le 

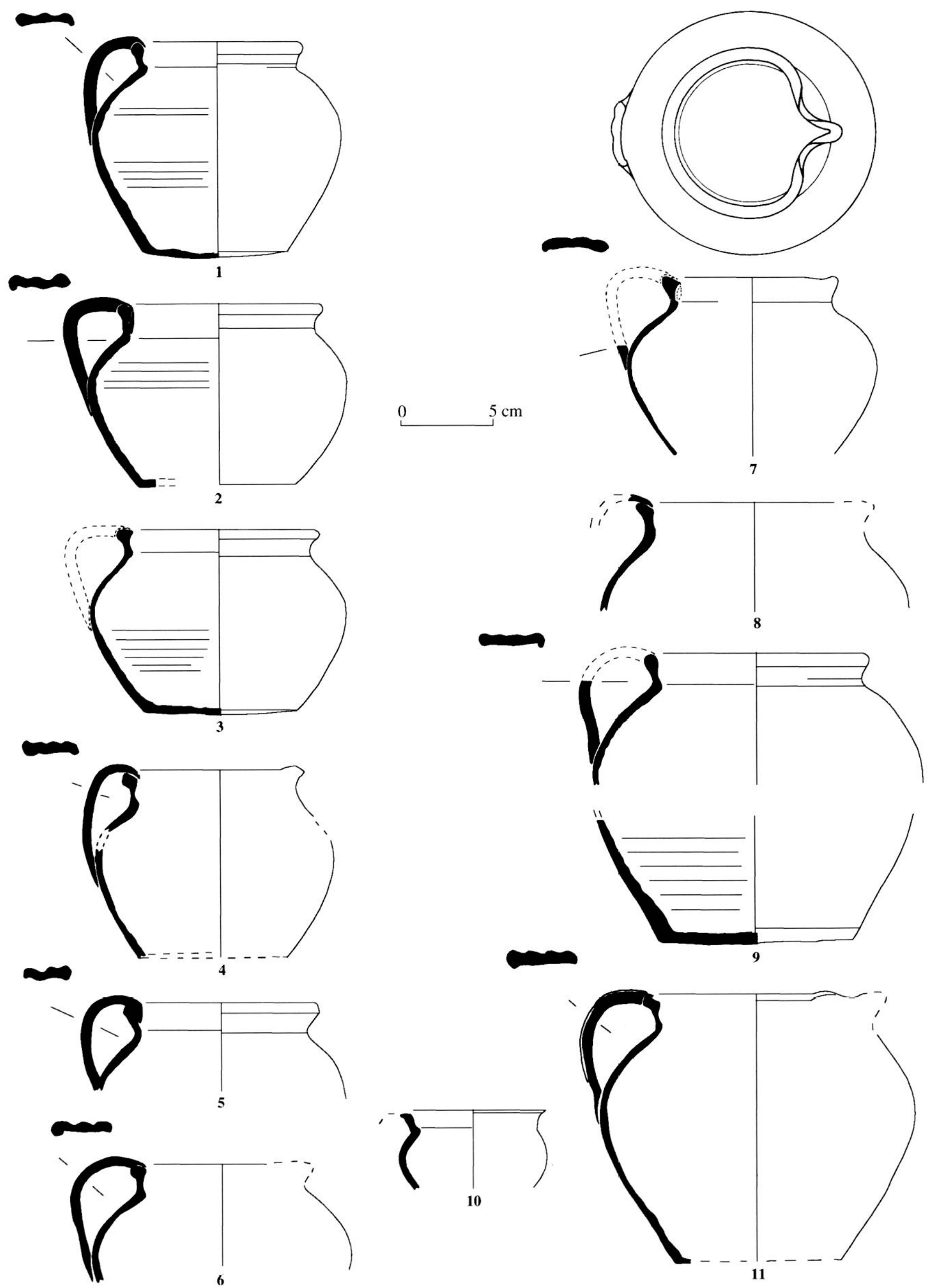

Fig. 19 : Céramiques en pâte claire glaçurée : pégaus issus des couches 61-56-54. M. Leenhardt et A. Alliaoui. 

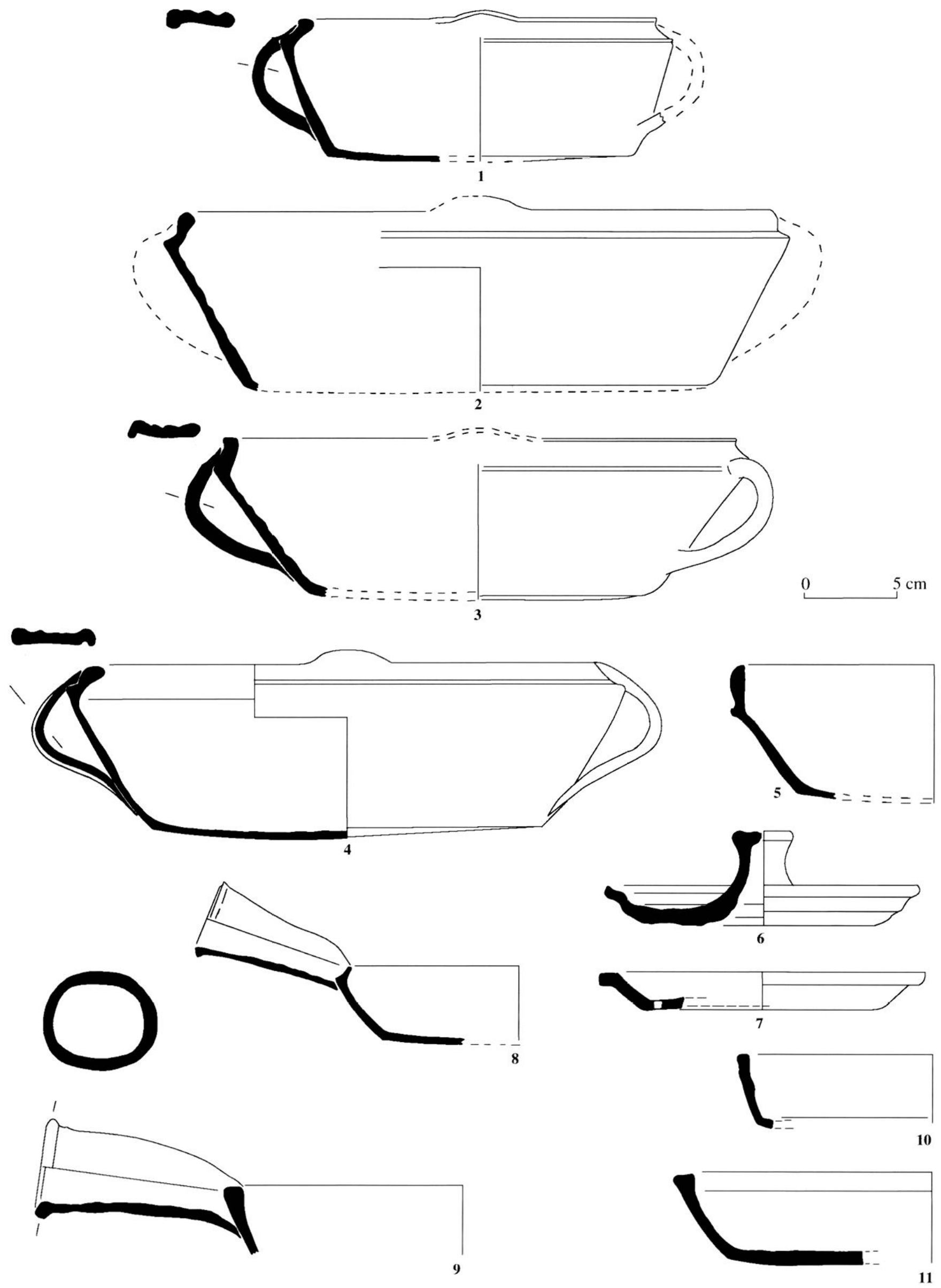

Fig. 20 : Céramiques en pâte claire glaçurée : jattes $\left(n^{\circ} \mid-2\right)$, couvercles $\left(n^{\circ} 6-7\right)$, poêles $\left(n^{\circ} 8-11\right)$. A. Alliaoui. 


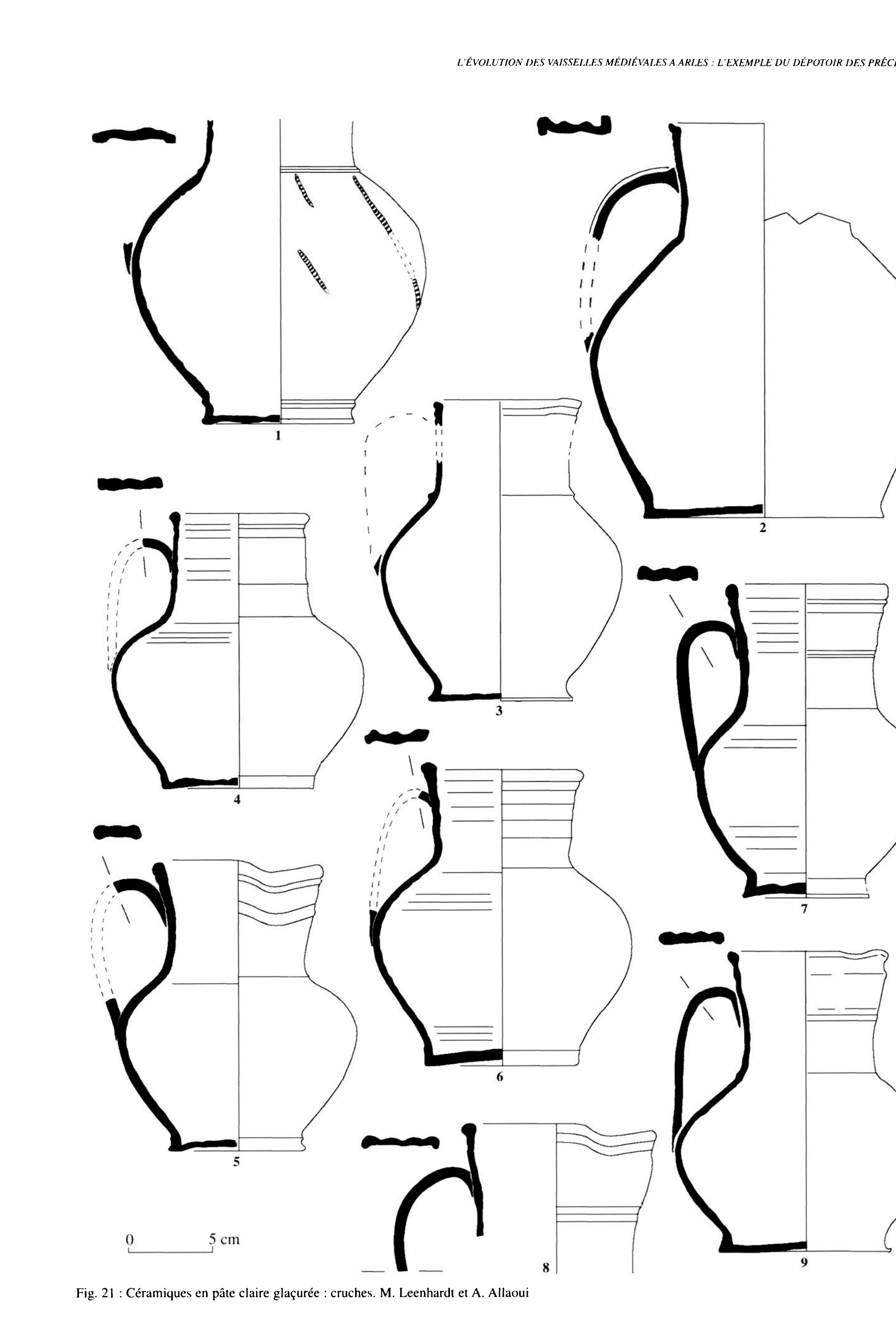




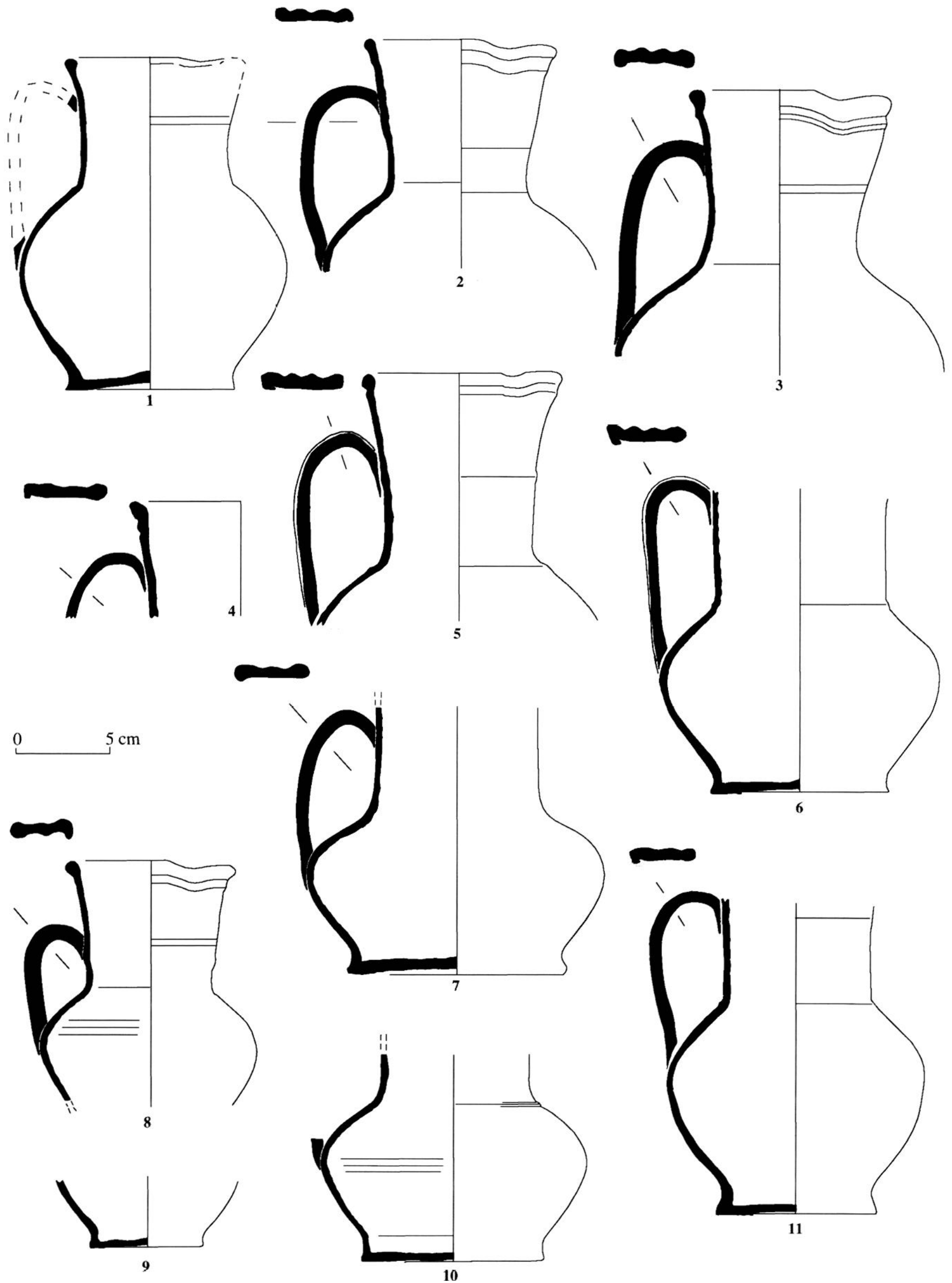

Fig. 22 : Céramiques en pâte claire glaçurée : cruches. A. Alliaoui. 
Lyonnais au château d'Anse (Faure-Boucharlat et al. 1996 : fig. 122) ou du XIVe s. dans la nécropole de Viviers (Leenhardt, Vallauri 1988 : fig. $69 \mathrm{n}^{\circ}$ 16).

Les huit pichets-gargoulettes (fig. 23) sont aisément identifiables par leur forme haute à panse ovoïde, leur col étroit et leur bec tubulaire diamétralement opposé à une anse rubanée et cannelée. Les glaçures présentent les mêmes brillance et variations de teintes que les cruches.

Ces gargoulettes sont issues des couches 72-65 à l'exception d'un objet très fragmenté (fig. $23 n^{\circ} 6$ ) qui provient de la couche 61 , postérieure ; il se différencie par sa paroi épaisse et son bord de profil carré.

Signalons enfin la présence d'un seul pichet à bec pincé et col étroit, identifié grâce à un minuscule fragment de col. Il rappelle les pichets similaires, toujours de petite taille recensés sur les sites consommateurs languedociens et provençaux contemporains (Poteries d'Oc 1995 : fig. 48 et 62 ; Richarté 1991 : fig. $20 n^{\circ} 10$ ).

Les gargoulettes à bec tubulaire s'apparentent aux modèles uzégeois recueillis dans des niveaux de la première moitié du XIVe s. aussi bien au château de Beaucaire (Schneider 1995 ; Leenhardt 1995c) qu'à Aix-en-Provence (Richarté 1991 : fig. $20 n^{\circ} 4-5$ et 11 ) ou sur de nombreux sites avignonnais occupés au milieu et dans la seconde moitié du XIVe s. (Konaté 1980 : pl. 71 ; Démians d'Archimbaud et al. 1980 : fig. $52 \mathrm{n}^{\circ}$ 3-4 ; Carru 1995a ; Poteries d'Oc 1995 : fig. 72).

\section{Les faïences en pâte claire de l'Uzège}

Les 10 tessons en pâte claire émaillée de l'Uzège retrouvés uniquement dans les contextes 72-65 ne représentent au total que deux vases à liquide très incomplets. L'un deux est bien identifiable par un bec tubulaire accolé au niveau du diamètre maximum de la panse (fig. $23 n^{\circ} 3$ ). Sous le bec un décor géométrique est composé de taches horizontales vertes encadrées par deux panneaux striés de brun. Le second qui comporte une panse globulaire a conservé son anse large et rubanée. Cette cruche est soigneusement décorée d'un motif floral vert et brun bordé par des bandes verticales brun-violacé faites de manganèse dilué selon un procédé fréquent dans les productions languedociennes. Si le profil de cette cruche semble classique, le décor principal n'est pas sans évoquer les élégantes fleurs de lis intercalées de tiges bouletées, représentées sur les premiers carreaux de pavements en pâte réfractaire : tels ceux de Châteauneuf-du-Pape datés du premiers tiers du XIVe s. (Démians d'Archimbaud, Gagnière 1995 : fig. 41-42) ou ceux de la Chapelle Saint-Jean du Palais des Papes antérieurs à 1336 (Carru 1995c : fig. 217). La similitude de ce motif utilisé sur les céramiques architecturales comme sur les vaisselles conforte l'origine uzègeoise de la cruche. Cette production émaillée bien attestée par les commandes de carreaux dans la seconde décennie du XIVe siècle ne semble pas se poursuivre au-delà du milieu ou du troisième quart du XIVe siècle comme en témoigne la raréfaction des comptes pontificaux (Amouric 1995b, Amouric et al. 1995b). Le répertoire plus marginal des vaisselles, connu par un petit nombre d'exemplaires souvent uniques et dans des contextes de la première moitié du XIVe siècle, montre toute l'originalité de cette production de qualité et dont les formes sont imprévisibles (Le Vert et le Brun $1995: n^{\circ}$ 276-280). On est cependant étonné d'en trouver si peu sur ce site dominé par les productions culinaires et les vases glaçurés de l'Uzège.

\section{Les productions calcaires}

Les céramiques calcaires sans revêtement

Cette catégorie, réalisée dans une argile calcaire de même nature que celle utilisée pour les faïences, n'était jusque-là connue qu'à la fin du XIVe siècle. Elle était réservée à deux types d'objets : les tirelires et les petites coupelles à épices (Démians d'Archimbaud et al. 1980 : fig. 26). Depuis la découverte des officines de Marseille, on sait que les potiers ont produit depuis le XIIIe siècle de nombreux vases à usages multiples en pâte calcaire sans revêtement, entre autres des chopes-mesures, filtres, tirelires, bassins, pots de fleurs et jarres de stockage. Des cruches à anses de panier ont été rejetées dans les derniers dépotoirs de l'atelier soit au premier tiers du XIVe siècle (Vallauri, Leenhardt 1997 : fig. 229, $\mathrm{n}^{\circ} 4,5$ ). C'est cette dernière forme que l'on retrouve à Arles. Elle est concentrée exclusivement dans les couches 72-65 (fig. 24) et correspond en tous points à d'autres exemples identifiés dans le château de Beaucaire, toujours dans des contextes du début du XIVe siècle (Schneider 1995). Le nombre d'individus est quantifiable par trois cols à rebord simple déversé, munis d'une large anse surbaissée, deux courts goulots tubulaires à embouchure évasée et dix fonds plats aux parois épaisses (fig. 24, $\mathrm{n}^{\circ} 1$ à 8 ). L'ensemble du profil peut être reconstitué suivant le proche modèle marseillais retrouvé sur un site de consommation dans les fouilles de la place Jules-Verne (Vallauri, Leenhardt 1997 : fig 276, $n^{\circ} 1$ ). Cette forme haute et globulaire, à verseur unique placé sur le haut de la panse, est particulièrement bien adaptée au puisage et au transport de l'eau. Elle prolonge un type plus archaïque réalisé en céramique grise et associé à des becs pontés qui se retrouve aussi bien dans les productions languedociennes que provençales ( $c f$. supra). Dans cette catégorie sans revêtement, un autre goulot plus mince et parfaitement cylindrique (fig. $24, \mathrm{n}^{\circ}$ 9) pourrait évoquer le verseur d'une cruche cette fois refermée à son sommet et munie d'un anneau de préhension. Cet autre récipient pour l'eau, bien connu dans les productions kaolinitiques, est aussi présent en argile calcaire dans le dépotoir de Van Gogh. Si le col cylindrique $n^{\circ} 10$ est difficile à relier à une forme précise (cruche ou mesure ?), le petit bouton, associé à des fragments de panse piriforme percée d'une fente verticale, renvoie à la traditionnelle tirelire. Celle en usage à la fin du XIVe siècle est bien datée par un trésor mónétaire (Aujourd'hui le Moyen Age 1981 : fig. 324 ; Démians d'Archimbaud et al. 1980 : fig. 26).

L'identification sur les sites arlésiens et à Beaucaire d'un groupe conséquent de céramiques communes sans revêtement, au sein des productions calcaires de la vallée du Rhône, fournit un indice supplémentaire sur la polyvalence qui devait exister dans la plupart des ateliers dès le début du XIVe siècle. A ces derniers encore non localisés 

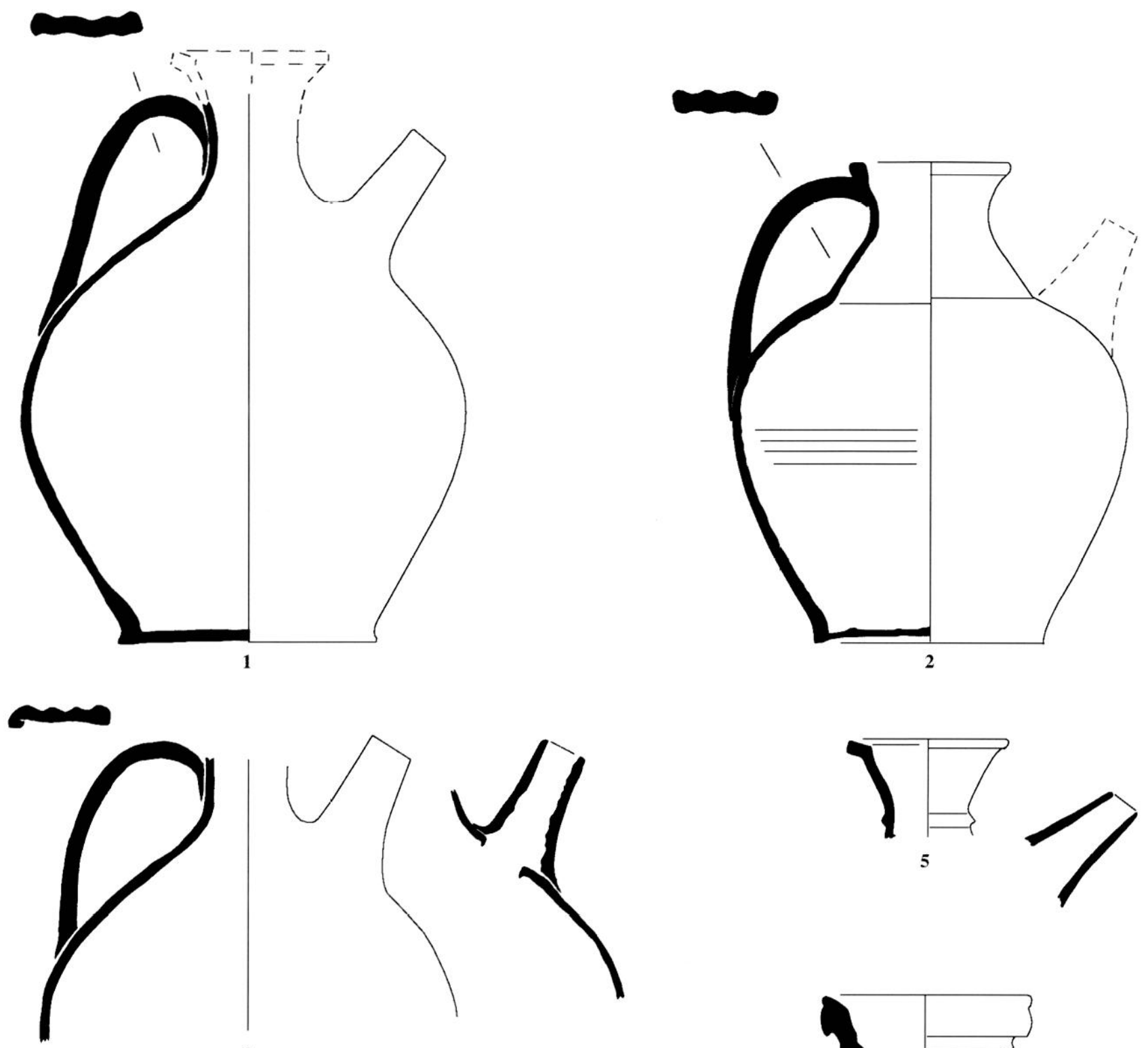

3
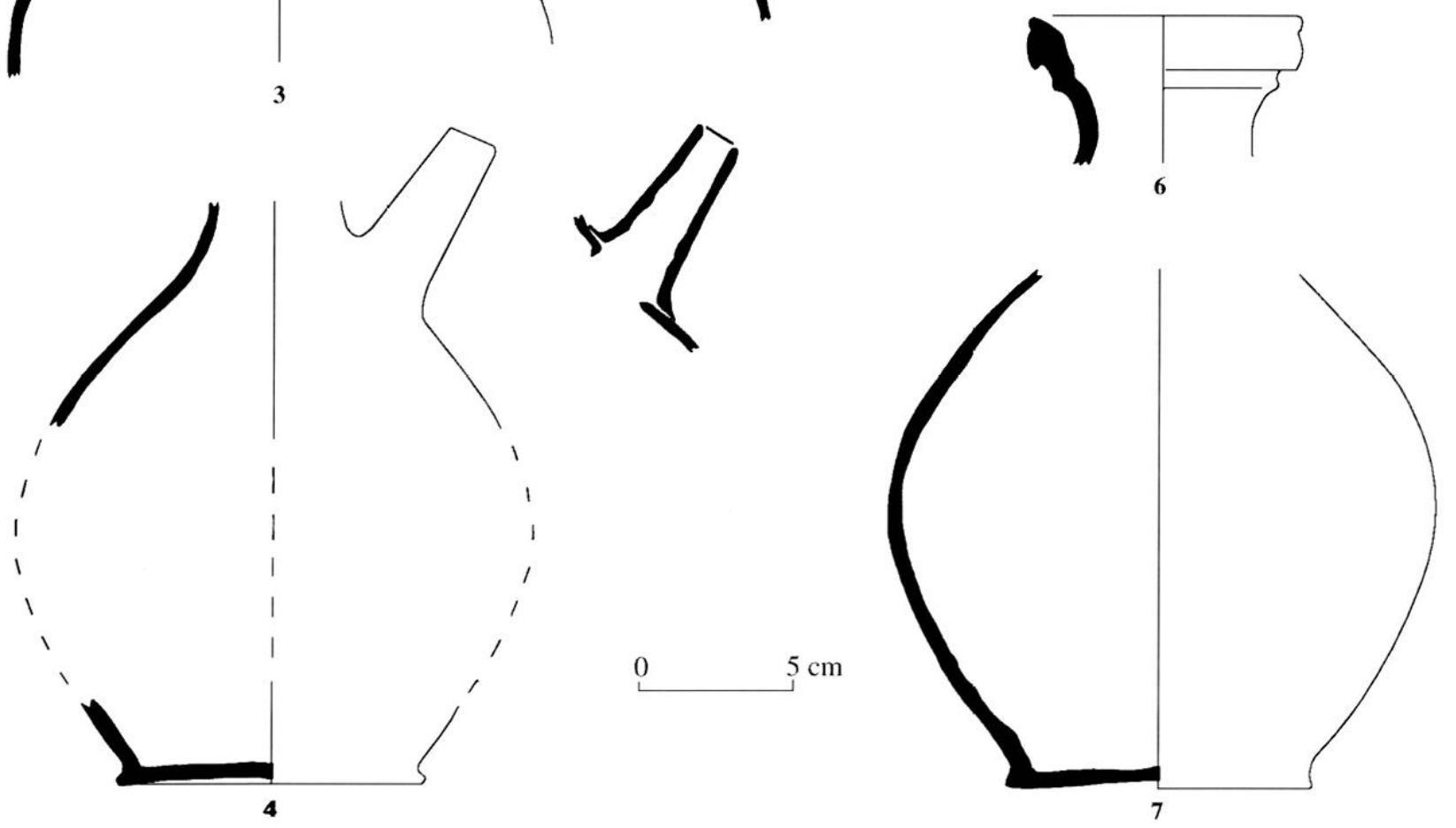

Fig. 23 : Céramiques en pâte claire glaçurée : pichets gargoulettes. M. Leenhardt et A. Alliaoui. 

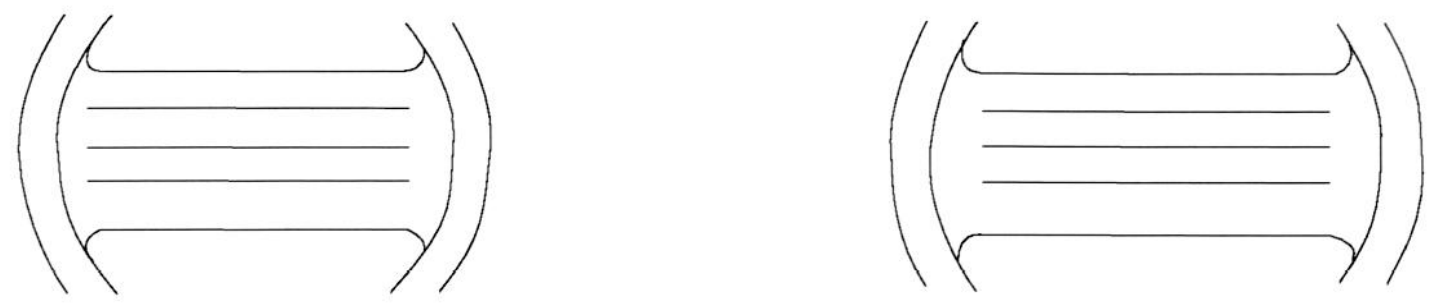
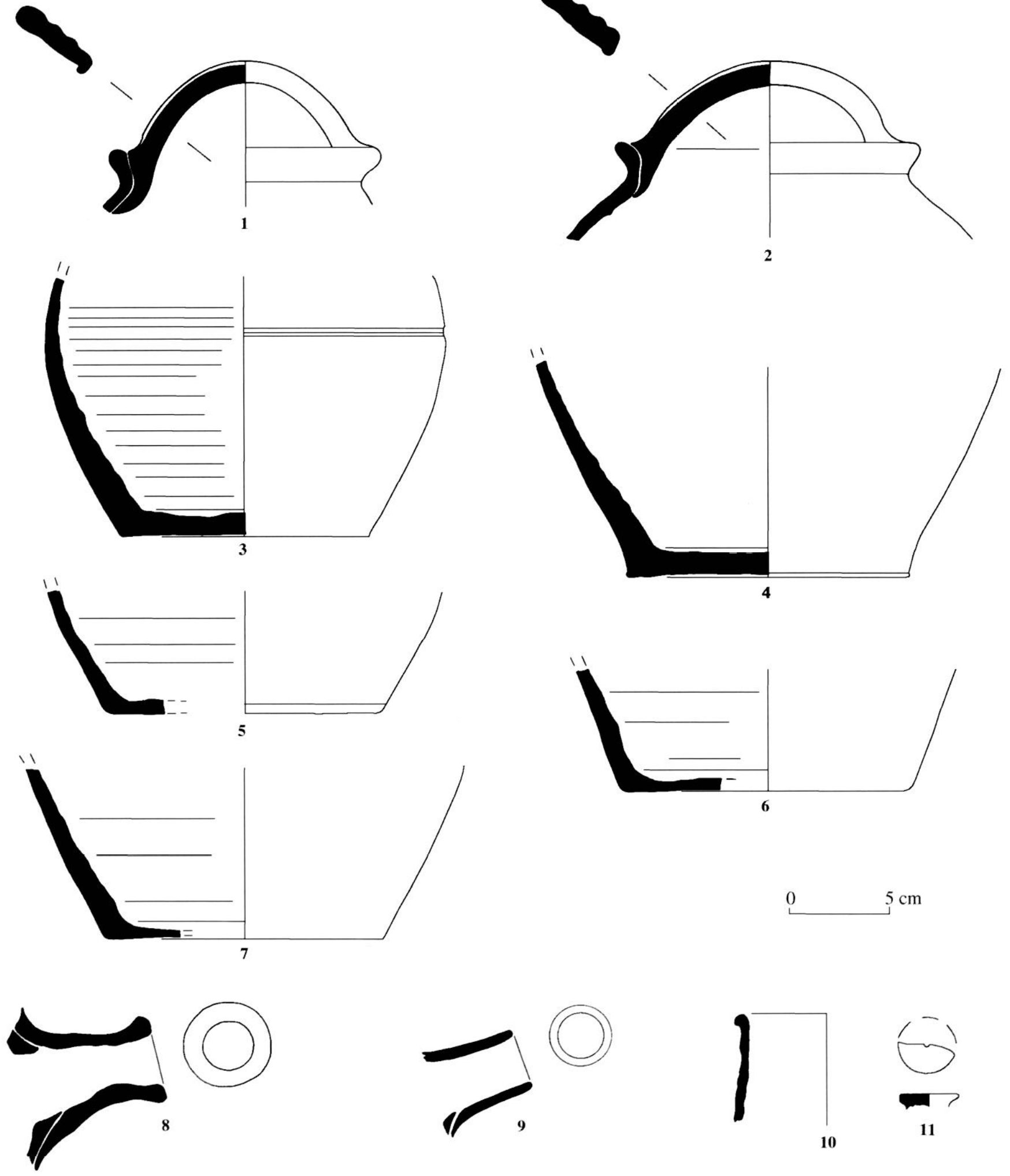

Fig. 24 : Céramiques en pâte calcaire sans revêtement : cruches à anse de panier $\left(n^{\circ} 1-7\right)$, col $\left(n^{\circ} 10\right)$, tirelire $\left(n^{\circ} 11\right)$. A. Alliaoui. 
avec précision, on n'attribue généralement que les produits faïencés plus luxueux identifiés dans ce dépotoir dans des proportions comparables.

\section{Les céramiques calcaires émaillées}

Cette catégorie en argile fluviale qui caractérise les productions de faïence de la vallée du Rhône, est bien reconnue depuis les premières études typologiques ct confirmée par les analyses de laboratoire. Les productions de ce groupe d'ateliers sont, malgré l'absence de découverte archéologique, attestées dès la fin du XIIIe siècle et perdurent jusqu'au début du XVe siècle (Amouric et al. 1995). A Arles on les suit dans toute la stratigraphie, avec cependant une évolution dans les traitements de surface comme dans les formes.

Les céramiques à couverte monochrome sont présentes dès le premier niveau 81 . Les plus anciennes concernent une seule forme fermée recouverte par une glaçure monochrome verte, sans glaçure interne et une petite coupelle blanche (fig. $25, n^{\circ} 1$ et 2 ). Les deux cruches hautes et pansues sont surmontées par un col court cylindrique, peutêtre pincé et munies d'une anse en boudin épaisse. Ce prototype qui n'est pas associé à des formes équivalentes vertes et brunes, correspond à un type produit en Languedoc dans le courant du XIIIe siècle aussi bien en pâte rouge glaçurée qu'en pâte calcaire (Poteries d'Oc 1995 : fig. 46,39 et 111 ). Elle est très proche aussi des premières productions émaillées de l'atelier marseillais, blanches ou colorées en vert (Vallauri, Leenhardt 1997 : cruche 1, fig. 214). Les suivantes, présentes dans les niveaux 61,56 et 54 sont d'un tout autre esprit. Ce sont des fragments d'un bassin, d'un bol (fig. $25, n^{\circ} 3$ ) et de quatre cruches basses à glaçure interne et externe blanche épaisse ornées parfois d'un motif, (monogramme ou croix), peint en brun de manganèse sur le devant de la panse. Cette réapparition massive des formes non peintes ou peu décorées, de plus en plus simplifiées, est bien notée dans les stratigraphies de la région avignonnaise, à la fin du XIVe et au début du XVe siècle (Démians d'Archimbaud et al. 1980 : 48-73 ; Carru 1995e ; Gaday et al. 1995).

Les vaisselles décorées en vert et brun témoignent de la même évolution. La qualité des pièces anciennes est indéniable. Elles apparaissent dans les couches 72-65 et sont constituées par une petite série de cinq vases à liquide à glaçure plombifère jaune interne (fig. $25, n^{\circ} 6$ à 11 ). La typologie comme les décors sont originaux. Un col droit à lèvre aplatie (fig. $25 \mathrm{n}^{\circ} 6$ ) rappelle des types languedociens trouvés à Montpellier et Gigean (Leenhardt 1995b ; Broecker 1982 : fig. $11, n^{\circ} 25$ et fig. 20). Le vase avec départ de manche de préhension tubulaire est sans correspondant direct (fig. $25 n^{\circ} 7$ ). La panse couverte de motifs en spirales semble se refermer ou se terminer par un goulot très étroit. La forme générale tronconique ainsi que l'usage de la glaçure plombifère à l'intérieur rappellent toutefois des cruches produites au début du XIVe siècle en pâte calcaire à Marseille, en Languedoc ou en pâte réfractaire de l'Uzège (Le Vert et le Brun $\left.1995: n^{\circ} 232,280,267\right)$. Une autre panse globulaire (fig. $25 \mathrm{n}^{\circ} 8$ ), percée par un bec tubulaire est décorée d'une fine tresse pointée tandis que d'autres fragments de panse ( $\mathrm{n}^{\circ} 9$ et 10 ) sont couverts par des réseaux de $S$ emboîtés ou cordiformes. Toujours dans les mêmes niveaux, deux cruches sans glaçure interne au profil plus banal (fig. $25 \mathrm{n}^{\circ} 12$ ) sont d'une grande finesse d'exécution avec un jeu de triangles opposés remplis d'écailles pointées. La même précision dans le tracé des décors se retrouve sur les deux formes ouvertes issues du contexte 65 (fig. $25 n^{\circ} 13$ et 14). La première petite coupe tronconique sur pied plat dégagé à la base, au décor rayonnant de fuseaux verts surmontés de polylobes est particulière par ses dimensions. Mais par sa forme haute et son style géométrique, elle rappelle les coupes plus grandes d'Olbia et de Rougiers de la première moitié du XIVe siècle (Démians d'Archimbaud 1980 : fig. 349 n 1-2). La seconde à fond plat percé de trous de suspension a un départ de panse plus concave. Le décor de cette coupe creuse ou bol, disposé en médaillon quadrillé et pointé, reste très original.

Cet ensemble ancien de faïences vertes et brunes, aux formes et décors peu stéréotypés, pourrait être le témoin des premiers ateliers de la vallée du Rhône, de Beaucaire ou de la région avignonnaise dont le répertoire est encore mal connu. La grande pièce (fig. 26) retrouvée dans le niveau suivant 61 témoigne d'un nouvel esprit (Le Vert et le Brun $1995: n^{\circ} 289$ ). Ce plat bas à marli oblique, de 34,5 $\mathrm{cm}$ d'ouverture et $5 \mathrm{~cm}$ de haut, est couvert sur le fond par un décor naturaliste. La frise en $\mathrm{S}$ sur le marli et les deux amples palmettes à enroulements entre lesquelles s'inscrivent des spirales, sont spécifiques des dernières productions avignonnaises de la fin du XIVe siècle et du début du XVe siècle peintes avec fantaisie et liberté (Démians d'Archimbaud et al. 1980 : 93-99, fig. 37, 40).

\subsection{Les importations}

L'origine de ces céramiques méditerranéennes coïncide le plus souvent avec chaque séquence stratigraphique du dépotoir.

\section{Les céramiques importées rares}

Les trois premières céramiques de la couche 81 ont une origine lointaine ou inconnue. Un petit fond (fig. $27, n^{\circ}$ ) en pâte rouge peu homogène contenant des grains blancs, présente une petite carène basse. Il est tournassé à l'extérieur et sous le pied et couvert à l'intérieur par un engobe (?) ou une couche jaunâtre tachetée de vert. Il reste à ce jour non identifié et a été classé en importation en fonction de l'engobe qui pourrait évoquer à la limite des productions de Méditerranée orientale. Les deux faïences associées sont décorées en bleu et brun. Le petit bol à marli évoque les protomajoliques du sud de l'Italie (fig. $27, \mathrm{n}^{\circ} 2$ ) tandis que le gros bassin tronconique en pâte granuleuse jaune, à lèvre épaissie, renvoie aux productions de Tunisie de l'époque almohade (Couleurs de Tunisie 1994 : 106107). Ces importations sont caractéristiques des contextes provençaux de la seconde moitié du XIIle siècle et quasi absentes au siècle suivant (Démians d'Archimbaud, Picon 1980 : Pl. VIII ; Moliner 1990 : 208, 212-216 ; Vallauri 1997 : fig. 57). Elles sont par contre souvent associées à d'autres catégories qui apparaissent ici seulement dans le 

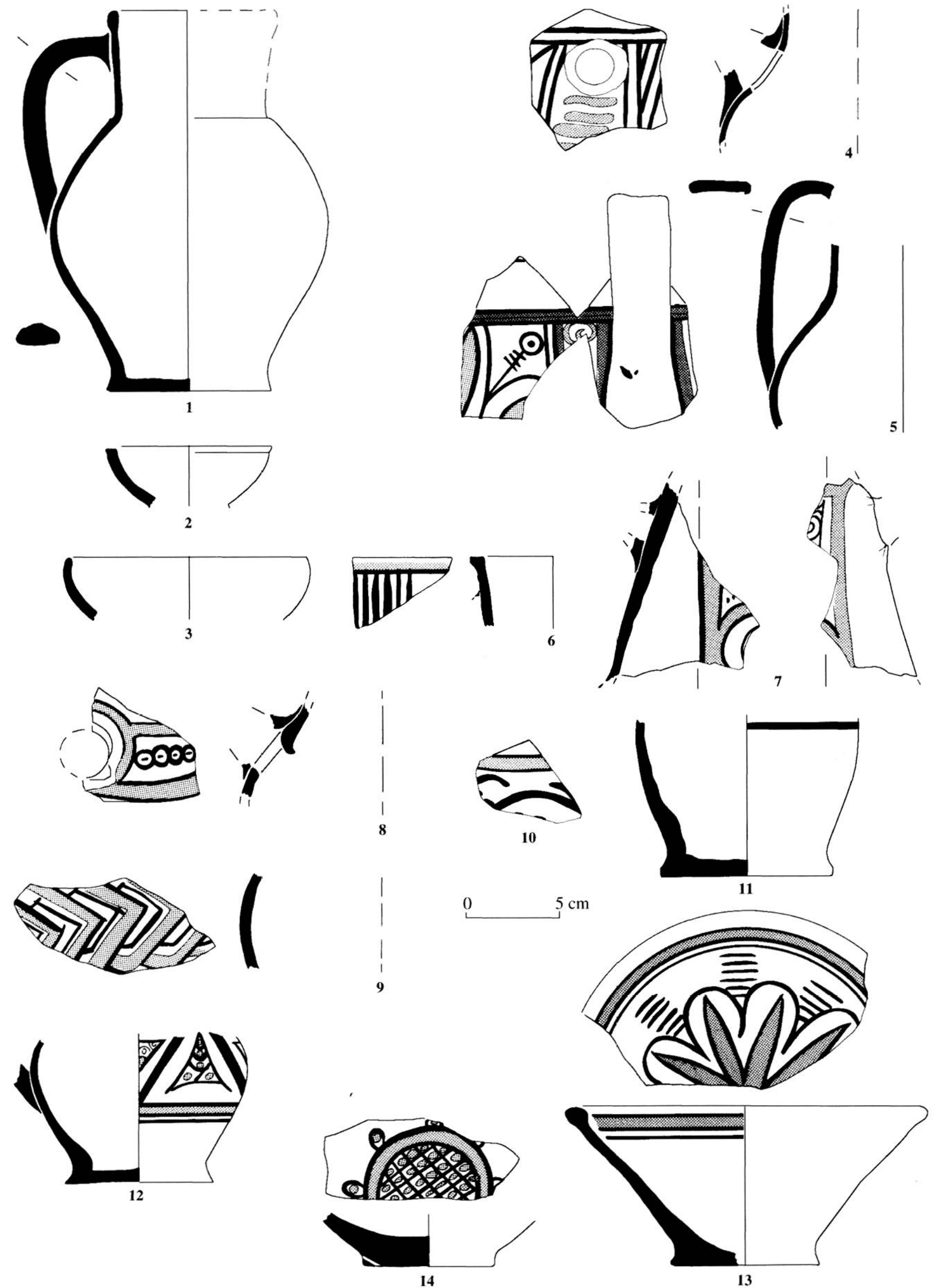

Fig. 25 : Céramiques émaillées en pâte kaolinitique ( ${ }^{\circ} 4$ et 5 ) et en pâte calcaire ( $n^{\circ} 1$ à 3 et $n^{\circ} 6$ à 12$)$. 1 cruche monochrome verte (81) :2-3 coupelle et bol monochromes blancs $(72$ et 54$): 6-11$ vases à liquide à glaçure interne jaune et décor vert et brun ; 12 cruche sans revêtement interne et décor vert et brun ; 13-14 coupes à décor vert et brun. L. Vallauri. 


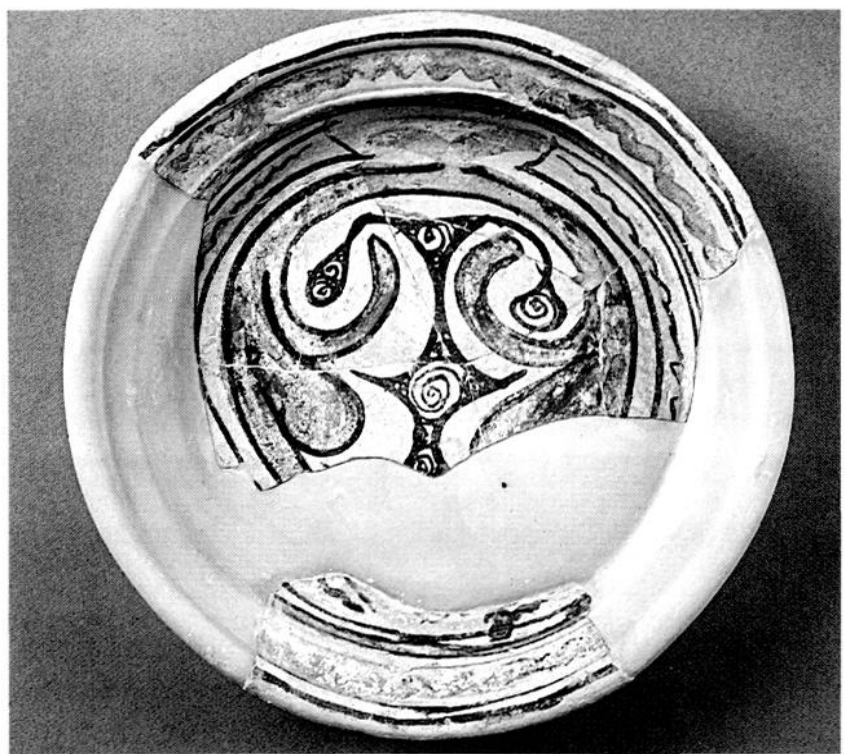

Fig. 26 : Plat à marli en pâte calcaire et décor vert et brun. Cl. Y. Rigoir.

niveau 72. C'est le cas d'un fragment de coupelle à marli en pâte rouge et glaçure monochrome verte (fig. $27 n^{\circ} 4$ ) qui se rattache à toute une série d'origine maghrébine ou sicilienne, bien mise en évidence sur la côte provençale, en Corse et jusqu'en Catalogne au XIIIe siècle (Vallauri 1995 ; Vallauri 1997 : fig. 53 ; Istria 1996) ou des céramiques catalanes, ligures et pisanes.

\section{La céramique catalane}

Elle est bien représentée à Arles et constitue un bon pourcentage des importations après celles de Ligurie. Deux types de productions coexistent. Les premières qui apparaissent dans la couche 72 sont des céramiques communes simplement glaçurées, parfois décorées qui perdurent dans le niveau 65 , associées cette fois à de la véritable faïence verte et brune. Les 9 formes rencontrées sont dans les deux cas en argile rouge vacuolaire, parsemée de nodules ferrugineux qui suggère une origine commune (9). Les grands bassins tronconiques (lebrillo) aux parois épaisses et au bord épaissi en crochet caractérisent cette production commune ancienne (fig. $27, \mathrm{n}^{\circ} 5$ à 8 ). Ces grandes pièces à glaçure plombifère jaune ou miel, très diffusées sur le pourtour de la côte languedocienne et provençale et jusqu'à l'intérieur des terres, sont présentes dès le XIIle siècle à Marseille jusqu'au début du XIVe siècle comme à Aix-en-Provence (Démians d'Archimbaud, Vallauri à paraître). Elles sont parfois ornées de frises remplies de spirales, tracées au brun de manganèse en large traits (fig. $27 \mathrm{n}^{\circ} 5$ et 6 ) mais aussi en vert bleuté (fig. $27 \mathrm{n}^{\circ}$ 7) sur un fond légèrement opacifié à l'étain. Ces coupes aux décors simplifiés sur fond blanc sont bien attestées à Marseille sur plusieurs sites, dans des contextes de la seconde moitié du XIIIe siècle (Moliner 1990) : fig. 14 ; Vallauri 1997 : fig. $59 \mathrm{n}^{\circ}$ 13). On les repère aussi à Montpellier (Broecker 1979: 201, pl. 37), Collioure (Verdié 1971: photo XII), Fontvieille, Hyères (Brien et al. 1992 : fig. 28 $\mathrm{n}^{\circ} 11$ et jusqu'en Ligurie sur une forme de cruche (Cabona et al. $1986: 122$, fig. 37). La présence répétée de ces sortes de "protomajoliques" grossières témoigne à l'évidence d'une production conséquente jusque-là peu repérée. On note aussi dans cette catégorie de céramique commune glaçurée d'autres formes moins répandues, un petit fond de cruche (fig. $27 \mathrm{n}^{\circ}$ 9), une coupe (fig. $27 \mathrm{n}^{\circ} 11$ ) et un col de jarre (fig. $27 \mathrm{n}^{\circ} 10$ ). Ce dernier est très proche d'un exemplaire vert, décoré de stries au peigne, découvert à Arles dans la fouille des Thermes. Ces diverses formes de céramiques qualifiées de populaires sont bien connues aux XIVe et XVe siècles sur les sites de consommation catalans (Montréal, Barrachina 1983 : 177-194 ; Amigo et al. 1988) et pour leur réutilisation dans le remplissage des voûtes des édifices religieux (Bassegoda Nonell 1978 ; Riu de Martin 1995).

Le fond de coupe en véritable faïence peinte en vert et brun tout comme la petite coupelle blanche (fig. $27 \mathrm{n}^{\circ} 12$ et 13) font partie du traditionnel répertoire catalan aux formes et décors stéréotypés, diffusé en Provence dans la première moitié du XIVe siècle. (Démians d'Archimbaud 1981 : 379-386; Le Vert et le Brun : ${ }^{\circ} 171$ ).

\section{La céramique verte et brune pisane}

Cette catégorie de vaisselle émaillée est quasiment inexistante à Arles par opposition avec la Provence centrale et orientale bien alimentée par les produits toscans au XIVe siècle (Picon, Démians d'Archimbaud 1980). La situation est en fait comparable en Languedoc (Vallauri, Leenhardt 1995) et dans la cité avignonnaise où les faïences pisanes constituent de très faibles pourcentages (Alonso, Thiriot 1995 ; Carru 1995e ; Carru à paraître). La seule cruche retrouvée dans le contexte 72 est d'une grande finesse d'exécution (fig. $27 \mathrm{n}^{\circ} 14$ ) dans le décor comme dans le tournage. La pâte rouge brique dure est couverte à l'intérieur par une glaçure plombifère transparente, tandis qu'à l'extérieur un décor en réseau serré est peint en vert et brun sur l'émail stannifère. Cette belle pièce malheureusement incomplète renvoie à des productions anciennes attestées à partir de la première moitié du XIIIe siècle à Pise et bien diffusées jusqu'au milieu du XIVe siècle (Berti, Gelichi 1995). Des exemples comparables sont présents par exemple à Fréjus dans le dépotoir de l'évêque daté de la fin du premicrs ticrs du XIVc sic̀clc (Michel 1989).

\section{La céramique glaçurée ligure}

A l'inverse, les produits ligures issus du même contexte sont relativement abondants puisqu'ils constituent le premier apport extérieur. Deux catégories sont présentes. La première est de la céramique commune glaçurée en pâte granuleuse rouge-orangé, tournée grossièrement (fig. 28 $\mathrm{n}^{\circ} 13$ ). Une jatte basse à usage culinaire est pourvue de doubles tenons de préhension appliqués en boudin et perforés de petits trous pour assurer le collage suivant une technique observée dans de nombreux cas à Marseille. Ces vaisselles communes originaires de la région de Savone

(9) Quelques échantillons de céramiques catalanes glaçurées et décorées de Collioure ont été confrontés au large groupe de faïences découvertes en Provence et Languedo (Vallauri et al 1980 : pl. 1 : Broceker 1979 : 201. pl. 37). Les résultats des analyses effectuées par M. Picon montrent une composition proche malgré l'absence de localisattion précise des ateliers (AMA 329 à 331 . 531 à 534 ). 



4
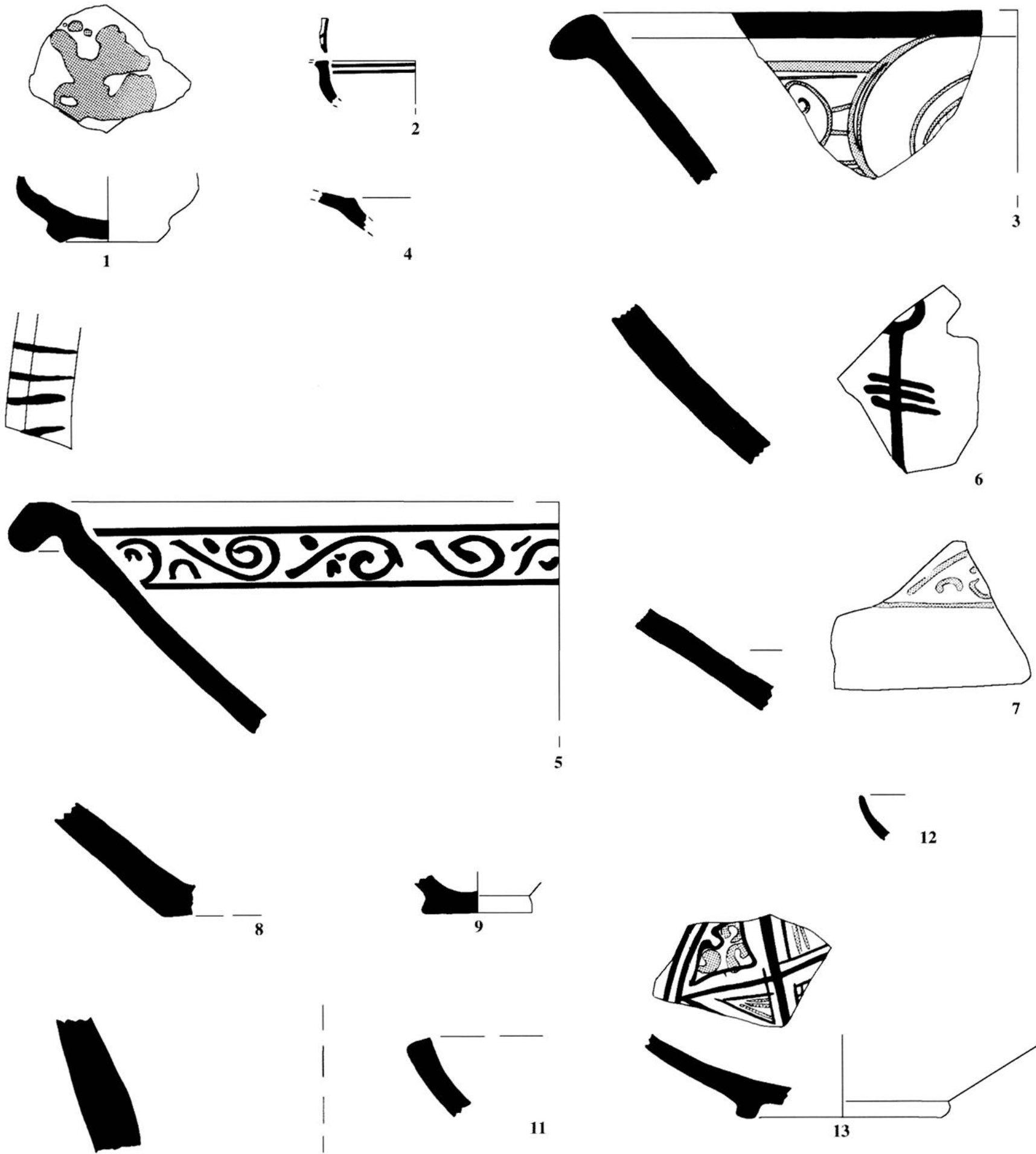

11

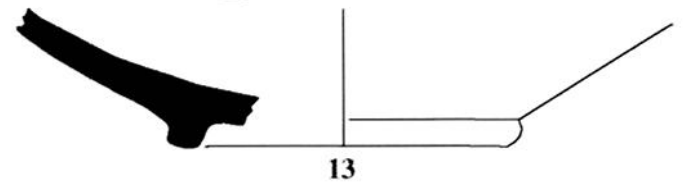

10
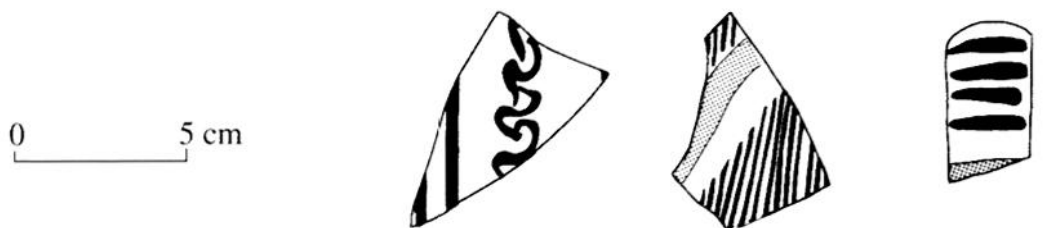

14

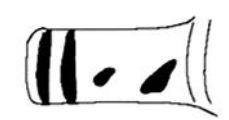

Fig. 27 : Céramiques importées. 1 fond à taches vertes sur engobe glaçuré, provenance indéterminée (81): 2 et 3 protomajoliques d'Italie du Sud et du Maghreb à décor bleu et brun (81): 4 coupelle à marli à glaçure verte. Sicile ? (72) :5-13 céramiques catalanes glaçurées et émaillées (72-65) : 14 cruche pisane émaillée à décor vert et brun. L. Vallauri. 

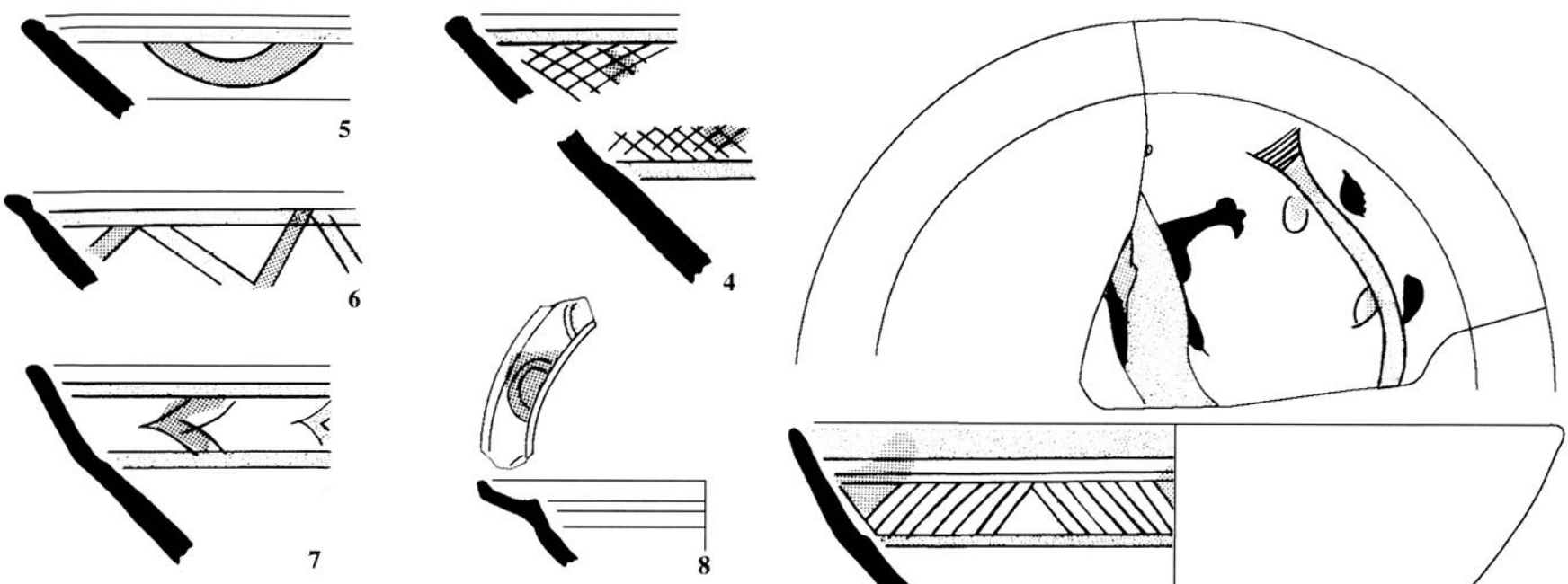

6
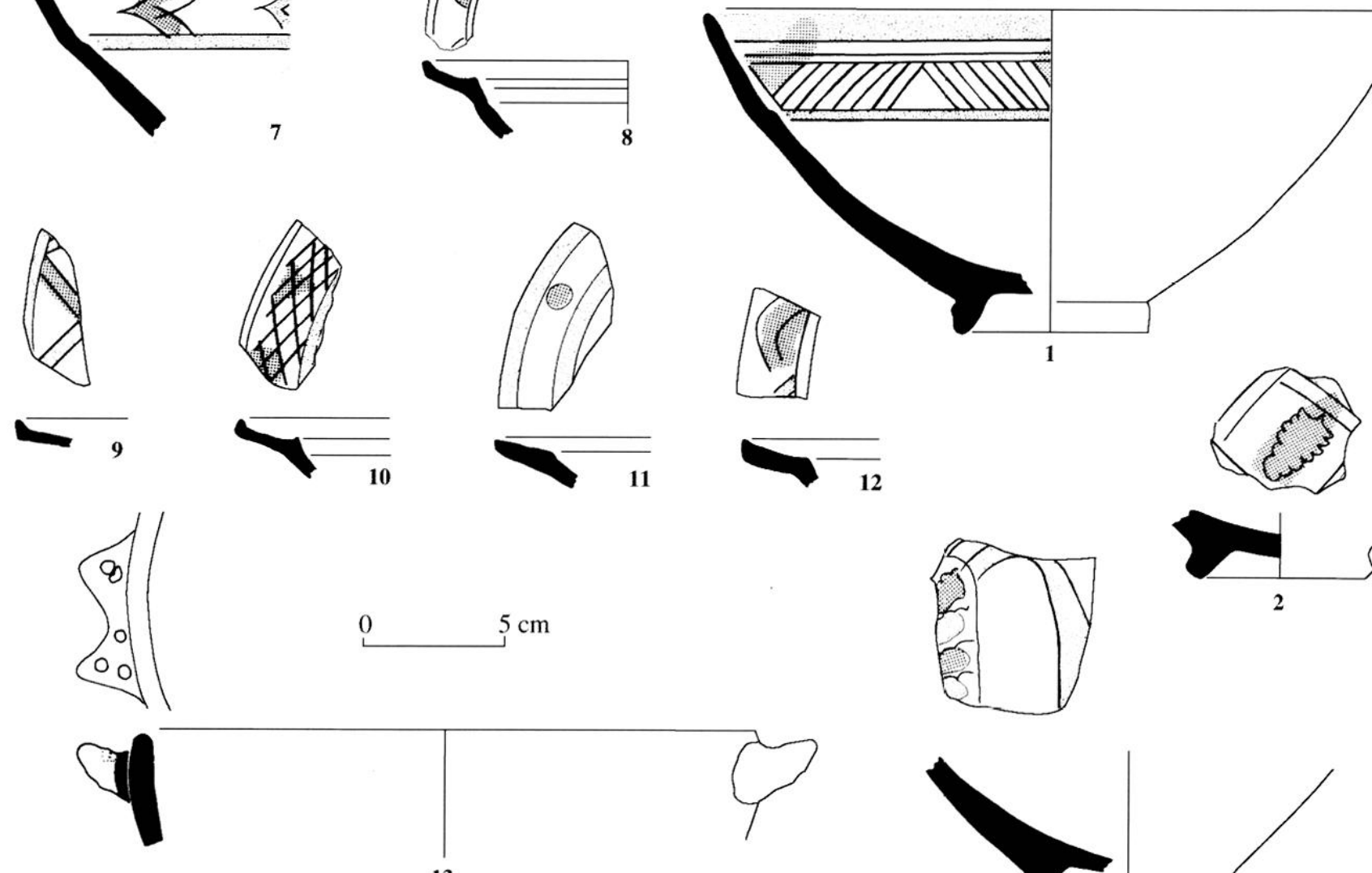

13
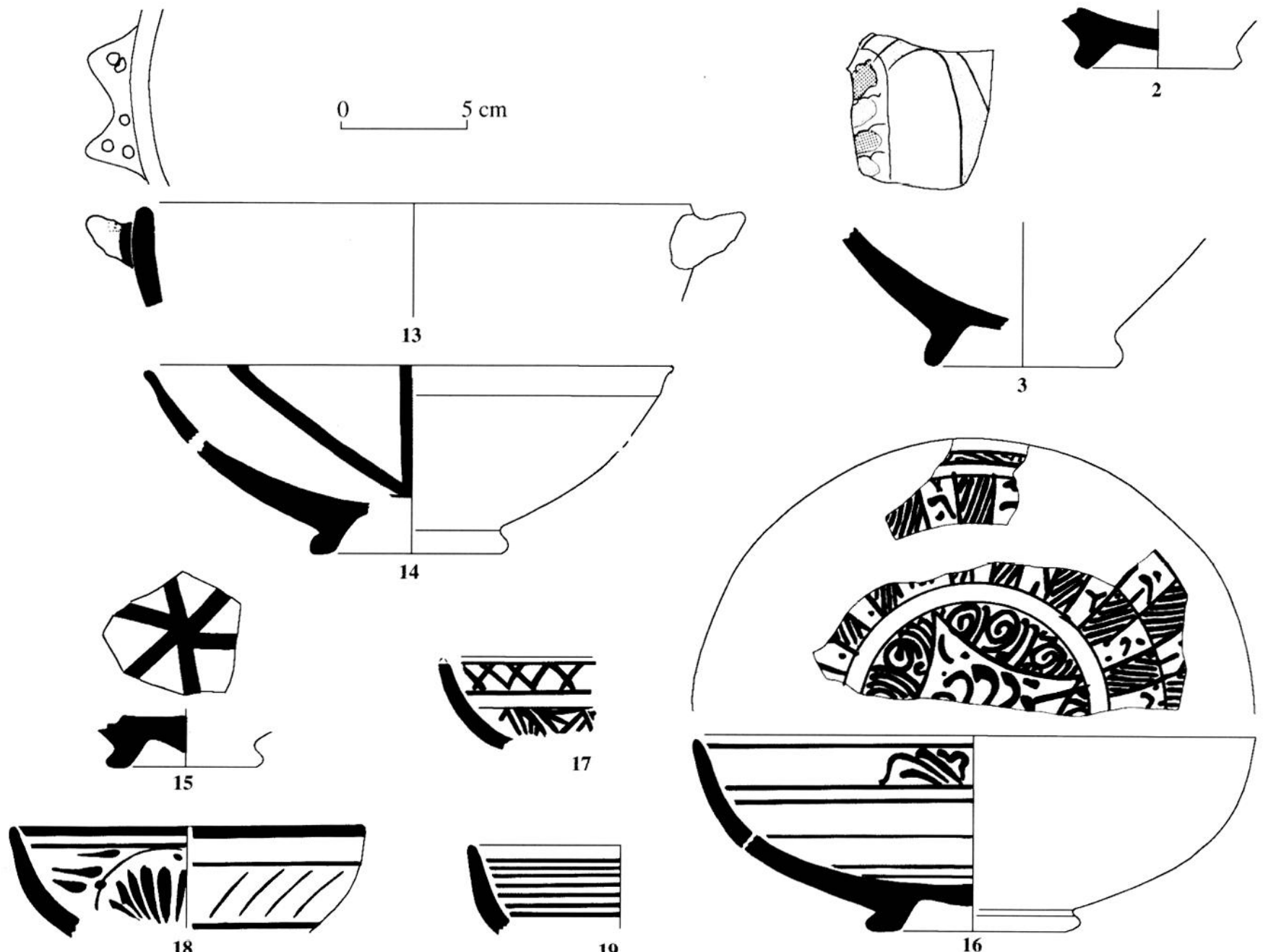

17
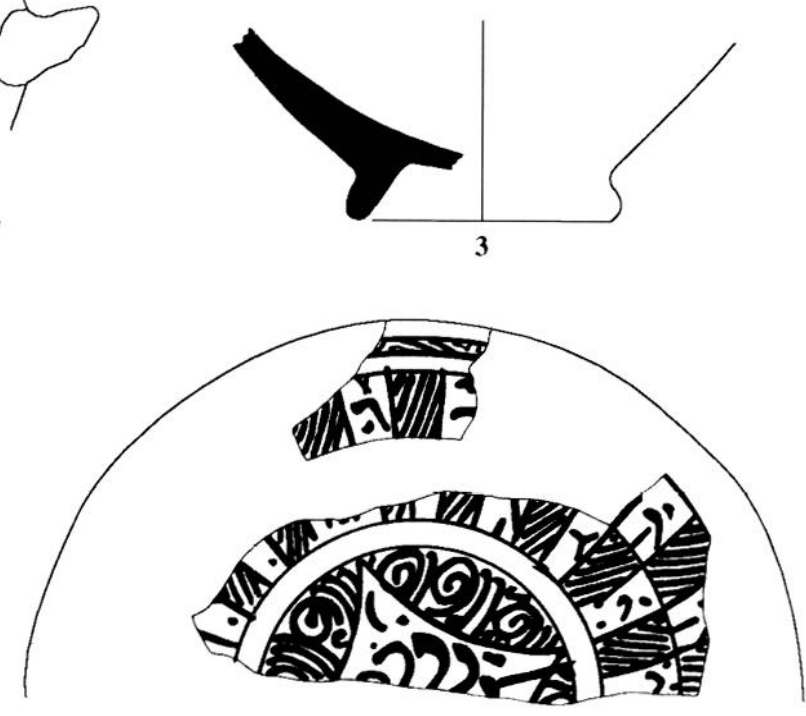

Fig. 28 : Céramiques importées. 1 à 12 coupes et coupelles en sgraffito archaïque ligure (72-65) : 13 jatte glaçurée ligure (72); 14-17 bols valenciens à décor bleu (61-65) ; 18-19 bols valenciens à décor de lustre et à décor bleu (54). L. Vallauri. 
(Mannoni 1975), fréquentes sur les côtes provençales mais aussi languedociennes ainsi que dans la vallée du Rhône, caractérisent les niveaux de la seconde moitié du XIIIe siècle bien qu'elles perdurent au début du siècle suivant (Vallauri 1997 : fig. 59 n 1-11 ; Démians d'Archimbaud, Vallauri à paraître).

La catégorie de vaisselles de table de même origine qui coexiste dans les niveaux contemporains, est reconnue depuis plus longtemps dans le sud de la France (Picon, Démians d'Archimbaud 1980). Quatorze formes ouvertes en pâte orangée engobée, glaçurée, incisée et rehaussée de taches vertes et brun jaune, sont bien représentatives des productions de sgraffito archaïque ou graffita arcaïca tirrenica (G.A.T.) dont la technique s'inspire du monde byzantin. Les classifications réalisées à partir du site producteur de Savone et des sites de consommation en Provence montrent une grande répétitivité dans les décors et formes (Varaldo à paraître ; Démians d'Archimbaud 1981 : 354-363 ; Moliner 1993 ; Michel 1989). Les bols hémisphériques, légèrement carénés (fig. $28 \mathrm{n}^{\circ} 1$ à 7 ) portent en bordure des frises géométriques d'arceaux, chevrons et quadrillages serrés identiques à ceux figurés sur le marli des petites coupelles (fig. $28 n^{\circ} 8$ à 12). Les motifs centraux bien conservés sur les fonds annulaires hauts, sont soit zoomorphes comme cet oiseau, gravé en partie en champlevé, qui tient un rameau (fig. $28 n^{\circ}$ 1), soit végétaux (fig. $28 n^{\circ}$ 2 et 3) (Varaldo à paraître : fig. 6 et 7). Une petite coupelle qui n'a pas été incisée ( $\left.n^{\circ} 11\right)$ est peinte sur le marli de pois verts cernés par deux bandes jaunes comme l'exemplaire trouvé à Rougiers (Démians d'Archimbaud 1981 : fig. $\left.342 n^{\circ} 7\right)$.

\section{La céramique émaillée valencienne}

En nombre aussi conséquent que les céramiques catalanes, les faïences valenciennes apparaissent cependant plus tardivement, à partir seulement du niveau 65 et sont concentrées surtout dans le dernier remblai 54. Les plus anciennes sont des grands bols au profil fin, décorés seulement en bleu avec soit des motifs rayonnants, soit des classiques jeux de damiers et médaillon central, soit des palmettes (fig. $28 \mathrm{n}^{\circ} 14$ à 17). Les exemplaires plus tardifs sont des bols à décor de palmettes en lustre métallique seul, ou à décor de cercles concentriques bleus, (fig. $28 n^{\circ}$ 18-19) ou encore un bec triangulaire de cruche. L'évolution observée dans les décors est confortée par la stratigraphie. D'autre part elle concorde avec celle notée dans les découvertes provençales et avignonnaises. Dès la seconde moitié du XIVe siècle et surtout au XVe siècle les produits valenciens fabriqués en masse et de plus en plus hâtivement (Amigues, Garcia Mesquida 1993) inondent les marchés provençaux et languedociens (Démians d'Archimbaud, Lemoine 1980 ; Richarté 1991 ; Carru 1995c ; Vallauri, Leenhardt 1995).

\section{Les verres}

Un lot de verres comprenant un minimum de 35 pièces était amoncelé à la base des couches 54-56. Quatre de ces objets ont été restaurés, publiés et présentés au public peu après leur découverte (A Travers le Verre 1989 : notices
$185,189,198$, et 209). Plusieurs types de verreries peuvent être distingués.

Les gobelets qui comptent 25 individus constituent le groupe le plus important (fig. 29). Ils sont tous réalisés dans une matière incolore, très fine. Ils ont aujourd'hui un aspect irisé. Les profils complets ou restitués sont le plus souvent évasés, mais tous les gobelets ont une hauteur supérieure à leur largeur ; aucun ne semble avoir l'aspect trapu des verres jusqu'à maintenant retrouvés uniquement dans les fouilles du Petit Palais d'Avignon (Foy 1988 : fig. $68, \mathrm{n}^{\circ} 1$ et 3 ). Quelques pièces ont au contraire des parois verticales donnant à l'objet un corps presque cylindrique. La plupart de ces verreries portent un décor géométrique dû à un moule. Le verrier a soufflé le verre dans un moule ouvert pour obtenir une ornementation imprimée. La pièce a ensuite été soufflée une seconde fois à l'air libre et le rebord a été façonné ; ainsi s'explique l'irrégularité du décor en particulier dans les parties hautes où les motifs apparaissent comme emboîtés. L'ornementation n'atteint jamais le rebord, ce qui est habituel ; en revanche il est étonnant de ne jamais pouvoir observer un estampage sous les fonds, comme on peut le voir dans la plupart des gobelets de ce type (Foy 1988 : fig. 73 à 75). Le motif le plus fréquent est celui de pastilles rondes de taille relativement importante (pastilles de 1 à $1,5 \mathrm{~mm}$ de diamètre), disposées quelques fois en quinconce (fig. $29, \mathrm{n}^{\circ} 7$ et 8 ). Beaucoup plus rare est le décor de très grosses pastilles imprimées sur seulement deux rangs (fig. $29, \mathrm{n}^{\circ} 9$ ) ; c'est la première fois que nous le rencontrons. Viennent ensuite, par ordre d'importance numérique, les gobelets aux parois ornées d'un réseau serré de petites alvéoles hexagonales, ou de "grains de riz" plus séparés (fig. 29, n 3 à 5). Enfin, il faut signaler l'ornementation originale faite de petits cercles concentriques formant des pastilles ombiliquées. La forme complète de deux gobelets aux parois dépourvues de tout décor, a pu être restituée.

Ces gobelets sont les verres à boire les plus communément utilisés dans le Midi de la France durant tout le XIVe siècle. Ils sont reconnus de Montauban (Foy 1986) à Fréjus et dans de nombreux sites italiens (Mendera 1989 et 1991). Les exemplaires les plus précoces datent de la première moitié du siècle comme en témoignent les découvertes des ateliers de Rougiers et de la Seube (Lambert 1972 et 1982-1983). Dans le troisième quart du XIVe siècle, ce mobilier est toujours fabriqué dans l'atelier de Cadrix en Provence (Foy 1988). A l'extrême fin du XIVe siècle et au début du XVe siècle, les rares gobelets provenant de la verrerie ligure du Monte Lecco (Fossati, Mannoni 1975) ou de fosses dépotoirs de Tarquinia (Whitehouse 1987) ne sont généralement pas décorés. Les seuls décors qui semblent subsister sur les gobelets de cette époque sont les nervures verticales.

Une demi douzaine de verres sont ornementés de filets rapportés, de teinte bleu cobalt. Seules deux formes sont définies (fig. 32).

La coupelle (fig. 30, $\mathrm{n}^{\circ} 1$; A Travers le verre 1989: notice 209), cylindrique à sa base, s'évase ensuite largement. Un réseau de filets et de taches bleus couvre les deux-tiers 

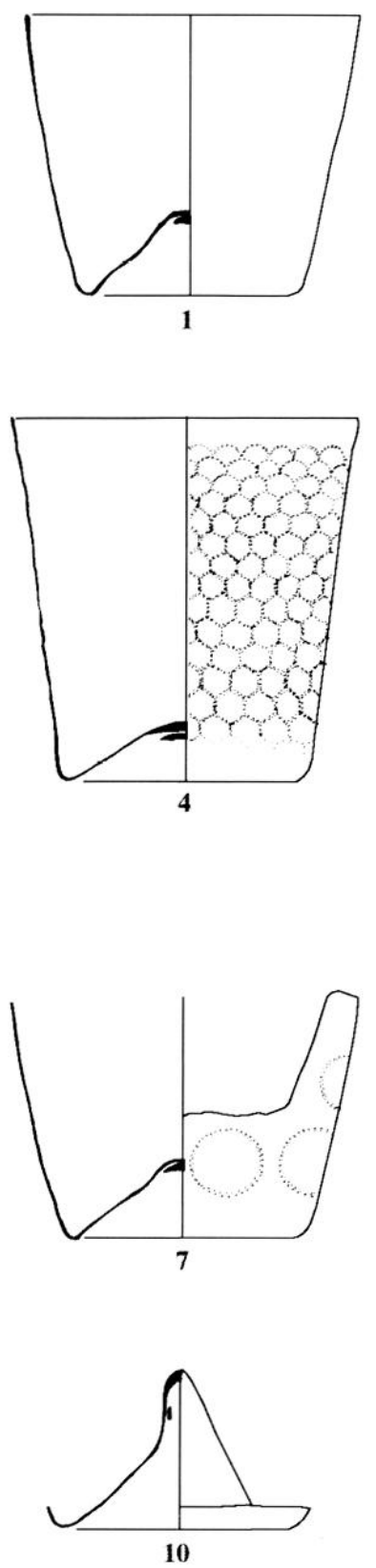

Fig. 29 : 1-9 Gobelets ; 10-11 Fonds de fioles. D. Foy.
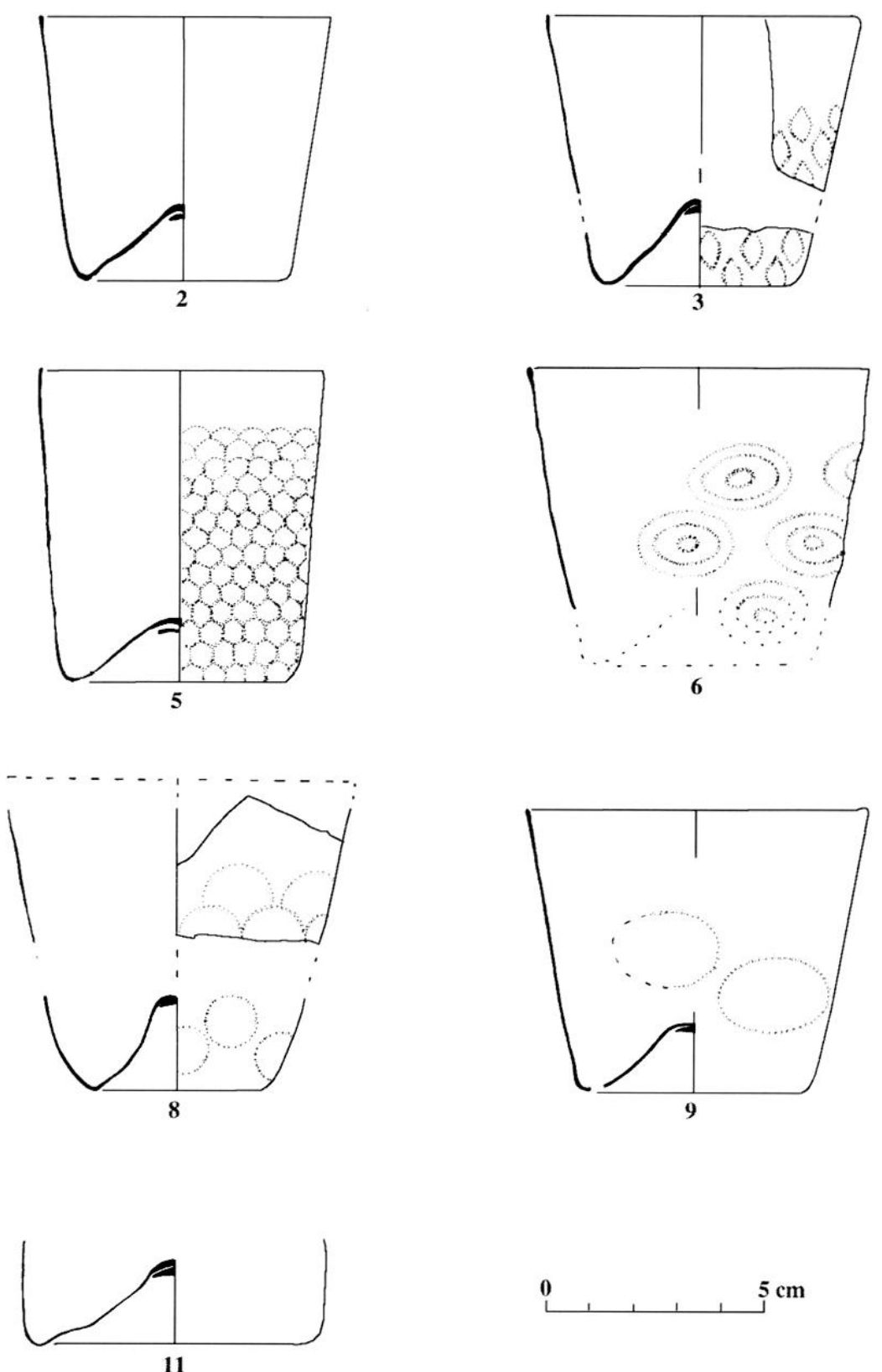

inférieurs des parois et se poursuit sous le fond. Ce décor "informel" est à rapprocher de l'ornementation d'arabesques bien connu sur ce type d'objet. Un cordon de verre a été rapporté, puis incisé, autour du fond; il recouvre en partie les filets de verre bleus. La fonction de ces pièces fragiles retrouvées en grand nombre sur les sites du XIVe siècle, reste encore hypothétique. Elles devaient être utilisées comme luminaire, leur profil, en particulier le décrochement bien marqué entre la moitié supérieure élargie et la base cylindrique, est en effet tout à fait comparable à la partie haute des lampes à pied tubulaire creux. Ces verreries sont presque aussi banales que les gobelets précédents, et leur datation est similaire. Les coupelles les plus simples, sans cordon pincé à la base, parfois décorées des mêmes motifs moulés que les gobelets, sont sans doute les plus précoces (exemplaires de Roujan, Fréjus, Jouques, A Travers le verre 1989 : notices 202 à 204), mais dès la pre- mière moitié du XIVe siècle, les pièces avec décor pincé à la base coexistent. Produits par les ateliers méridionaux, en France et en Italie, ces objets ne sont pas exceptionnels au nord des Alpes (A Travers le verre 1989: notice 205; Baumgartner, Krueger 1988 : notice 320).

Un très beau gobelet presque cylindrique, possède, en commun avec la pièce précédente, le décor de cordon pincé qui cercle le fond et le décor de filets bleus (fig. $30, n^{\circ} 2$ et fig. 32 ; A Travers le verre 1989 : notice 198). Toute l'ornementation est concentrée dans la moitié inférieure. Les filets bleus, entrecroisés, déterminent une frise de losanges allongés. Cette résille est limitée par un simple fil bleu horizontal, déposé juste au-dessus. L'exemplaire le plus comparable, tant par sa forme que son décor, est un gobelet provenant des fouilles de l'hôtel de Brion à Avignon (A Travers le verre 1989 : notice 199); le contexte de découverte ne permet malheureusement pas de dater la pièce 

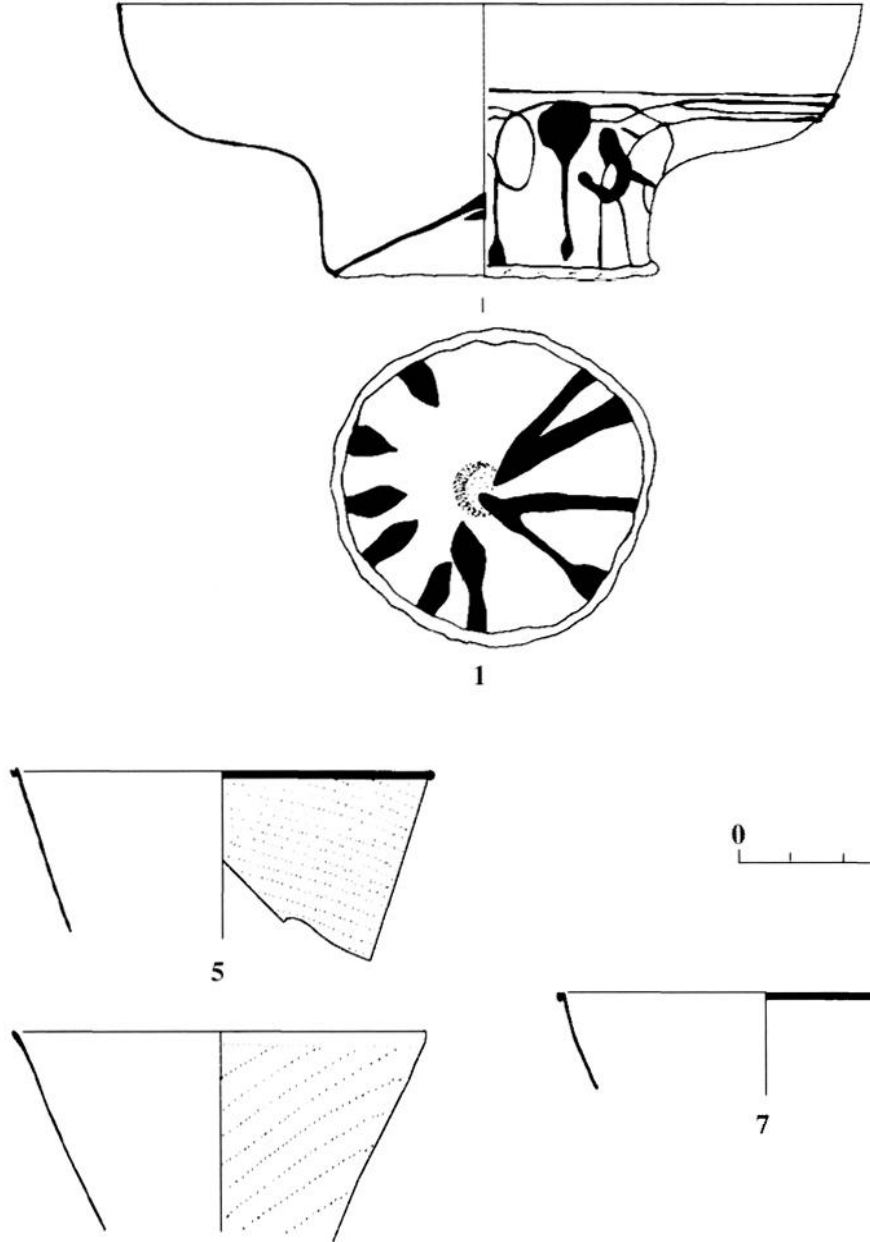

6
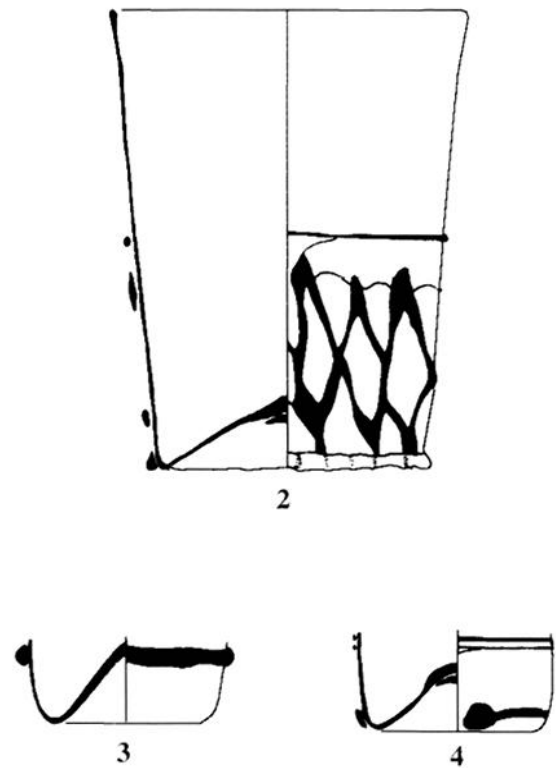

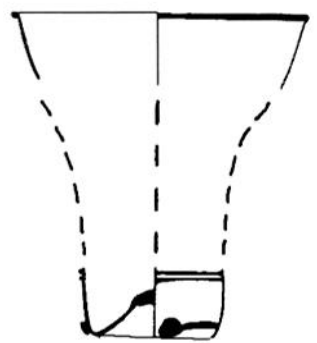

Fig. 30 : 1-4 Verreries à décor bleu rapporté : 5-7 Rebords moulés ou à fil bleu ; 8 Hypothèsc de restitution d’un gobelet à partir du fond 4 et du rebord. D. Foy.

avec précision. Un autre décor de résille bleue comparable apparaît sur une coupelle exhumée lors des fouilles de l'abbaye de Farfa (Whitehouse 1983).

Deux fonds étroits sont cerclés par des cordons de verre bleu. Nous ne savons pas à quelle forme ils se rapportent. Le diamètre réduit des fonds, la verticalité des parois évoquent cependant les rares gobelets au corps cylindrique et au rebord évasé caractéristiques de la seconde moitié du XIIIe siècle et du début du XIVe siècle (Baumgartner, Krueger 1988 : notices 160 à 165). Si l'hypothèse est recevable, il conviendrait alors d'associer à l'un de ces fonds un rebord évasé et décoré d'un fil bleu rapporté en guise de lèvre (fig. $30, \mathrm{n}^{\circ} 7$ et restitution $\mathrm{n}^{\circ} 8$ ). Deux autres rebords décorés de côtes hélicoïdales et parfois d'un fil bleu peuvent tout aussi bien appartenir à des gobelets qu'à des embouchures de récipients (fig. $30, \mathrm{n}^{\circ} 5$ et 6 ).

On remarque que l'ensemble des verreries sont des verres à boire et non des contenants. Les seuls débris qui pourraient faire partie de fioles, bouteilles ou autres contenants à liquide seraient, outre les deux rebords cités ci-dessus, deux fonds. L'un, par l'importance de son diamètre, pourrait être attribué à une bouteille (fig. 29, $\mathrm{n}^{\circ} 11$ ); l'autre, profondément rentrant à l'intérieur du vase, est caractéristique de bien des pièces du XVe siècle, en particulier des fioles à panse globulaire et col allongé, fréquentes en Italie (Visser Travagli 1985 et 1996) mais aussi des gobelets de la même époque (Lang 1991).

Ce fond et les quatre verres suivants sont vraisemblablement les pièces les plus tardives du lot. Les pieds tronconiques refoulés, faits dans la même masse de verre que le restant de l'objet appartiennent aux verres à boire les plus répandus à la fin du XVe siècle et au XVIe siècle (fig. 31). La coupe tronconique, haute, est nettement séparée du pied. De nombreux objets peuvent porter, à l'instar d'un des fonds retrouvés à Arles (fig. 31, n ${ }^{\circ} 4$ ), un décor au moule. Cette forme largement répandue dans toute la France vient d'Italie. Quelques pièces peuvent être des importations mais la plupart sont l'œuvre des artisans italiens immigrés (en particulier les altaristes, originaires de la ville d'Altare) qui l'ont imposée, créant ainsi une uniformité dans toutes les productions régionales (on trouvera dans $\mathrm{A}$ travers le verre, notices 266 à 285 , de nombreux exemplaires provenant de diverses régions).

L'examen des verreries provenant des fouilles des Prêcheurs d'Arles montre donc que l'ensemble n'est pas homogène. Deux pièces pourraient dater de la fin du XIIle ou du début du XIVe siècle : les gobelets au corps étroit et au rebord évasé (fig. 30, $\mathrm{n}^{\circ} 3,4$ et 7). La forme que nous suggérons demeure cependant hypothétique. Il n'en reste pas moins une disparité entre, d'une part, le groupe formé par 


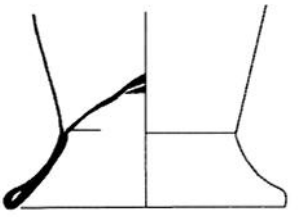

1

0
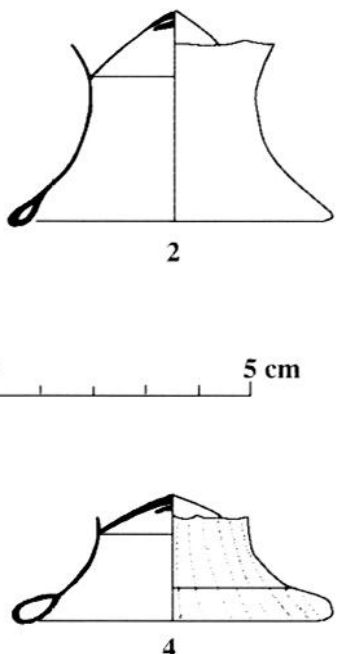

4

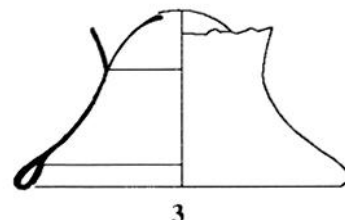

Fig. 31 : Pieds de verres à boire tronconiques. D. Foy.

la majorité des gobelets et les verreries à décor bleu rapporté et d'autre part, les quatre verres à pied tronconique. Bien que nous ne puissions préciser la date exacte d'utilisation du premier lot, nous devons le situer, sans hésitation, dans le courant du XIVe siècle. En revanche, les supports des verres tronconiques ne peuvent être antérieurs à la deuxième moitié du XVe siècle. Ce petit ensemble, exceptionnel par sa conservation, enrichit en particulier le répertoire décoratif des gobelets.

\section{Conclusion}

La diversité des céramiques découvertes associées à des verres et des restes de faune, témoigne bien de la vie

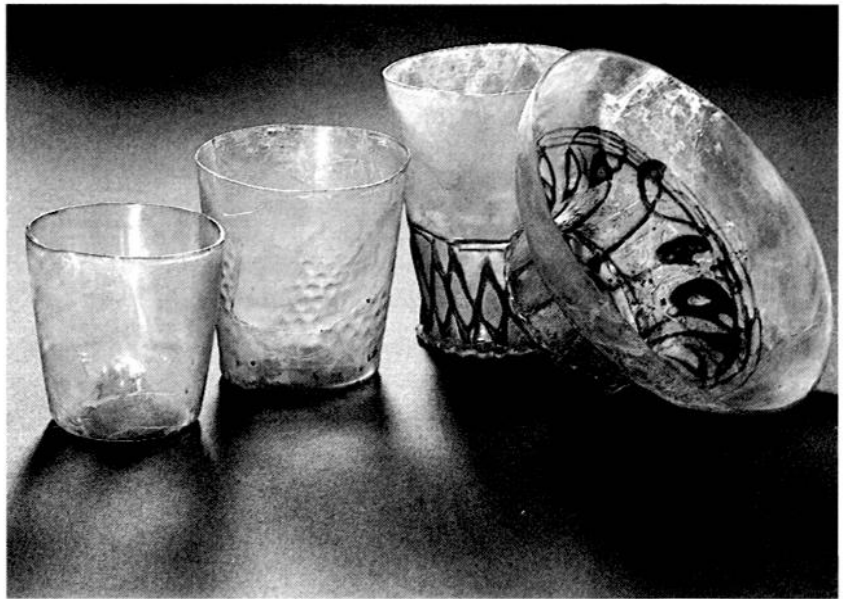

Fig. 32 : Gobelets et coupelle . Cl. Y. Rigoir

quotidienne dans un quartier arlésien au Moyen Age. Les différentes catégories de vaisselles communes régionales et de faïences locales ou importées font percevoir une évolution dans les techniques, dans les formes, et dans l'approvisionnement en liaison avec la périodisation. Celle-ci s'étale depuis le milieu du XIIle jusqu'au milieu du XVe, sur près de deux cents ans, avec un temps fort de l'extrême fin du XIIIe siècle jusqu'au milieu du siècle suivant. L'apport le plus neuf apparaît dans l'étude des céramiques communes, en particulier celles de l'Uzège, qui par leur abondance et leur très bonne qualité de conservation fixent de nouveaux jalons typochronologiques. Le catalogue des marmites en constitue le meilleur exemple et suggère des

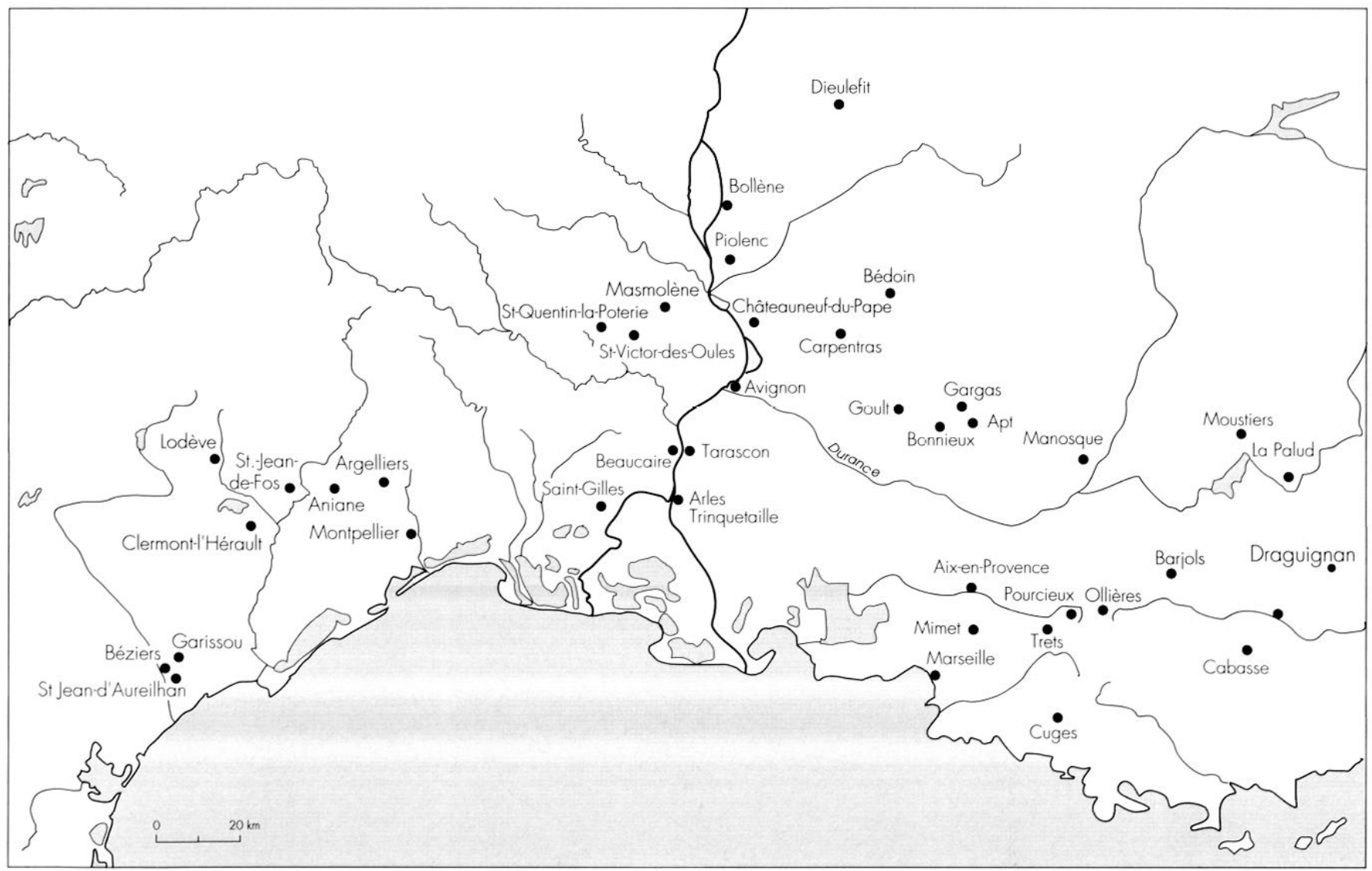

Fig. 33 : Localisation des ateliers de céramiques repérés par l'archéologie et les sources écrites au Moyen Age. F. Gillet del. 
ateliers et des artisans très actifs et innovants. L'apparition des faïences régionales de la vallée du Rhône constitue un phénomène remarquable, de par la qualité et l'originalité de ces premières réalisations encore mal connues. La succession des importations confirme les observations faites en Provence et dans le Comtat. La forte proportion des céramiques régionales n'a rien de surprenant, dans une ville située au cœur de grandes zones productrices et ressemble d'ailleurs à celle observée à Avignon. Si les importations sont peu nombreuses, elles témoignent cependant d'une ouverture sur la Méditerranée, aisément accessible par le Rhône, et des fluctuations du marché. Ce port constitue un observatoire exceptionnel pour l'étude d'un vaisselier médiéval au sein duquel il est possible de quantifier la part relative des différentes officines tant rhodaniennes que languedociennes suivant les époques (fig. 33). Arles est alimenté par les ateliers proches du Languedoc oriental comme celui de Saint-Gilles et par d'autres pressentis dans la vallée de l'Hérault ou dans les garrigues au nord de Montpellier. Si ccux dc l'Uzc̀gc prédominent ensuite, cela résulte autant de la notoriété de ce centre que de sa proximité. Il n'est pas surprenant de trouver aussi la diffusion des produits calcaires de la basse vallée du Rhône.

En définitive, Arles semble plus tournée vers le Languedoc que vers la Provence, mêmes si des rapprochements typologiques ont pu être tentés avec certaines formes marseillaises de chronologie comparable.

\section{BIBLIOGRAPHIE}

A Travers le verre 1989 : A Travers le verre du Moyen Age à la Renaissance. Catalogue d'exposition, Musée des Antiquités de la Seine Maritime, Rouen, 1989.

Alonso, Thiriot 1996 : ALONSO (I.), THIRIOT (J.). Faïences du Petit-Palais en Avignon. In : 1500 ans de céramique en Vaucluse. Ateliers et productions de poteries du Ve siècle au début du XXe siècle. Catalogue d'exposition, Musée des faïences, Château de la Tour d'Aigues, 1996, p. 57-60.

Amigo et al. 1988 : AMIGO (J.), BARBERA (J.), CORTADELLA (J.), GUASCH (D.), SOLIAS (J.-M.), MARIA CORTES (M. del). El bullidor, jaciment medieval. estudi de materials i documentació. Quaderns d'estudis santjustencs, III, 1988

Amigues, Garcia Mesquida 1993 : AMIGUES (F.), GARCIA MESQUIDA (M.). Les ateliers et la céramique des ateliers de Paterna (XIIIe-XVe siècles). Béziers : Musée SaintJacques, 1993.

Amouric 1995a : AMOURIC (H.). La marmite de l'évêque, la gloire de Saint-Quintin. In : LEENHARDT (M.) dir. Poteries d'Oc, céramiques languedociennes VIIe-XVIIe siècles, catalogue d'exposition, Nîmes, Musée archéologique, 1995, éd. Narration, p. 25

Amouric 1995b : AMOURIC (H.). Les commandes pontificales. Au fil des comptes... In : Petits carrés d'histoire : Pavements et revêtements muraux dans le Midi méditerranéen du Moyen Age à l'époque moderne, catalogue d'exposition,
Avignon, 1995, p. 23-35.

Amouric 1996 : AMOURIC (H.). Les textes prêchent dans le désert. Bédoin-Apt XIVe-XVIe siècles. In : 1500 ans de céramique en Vaucluse. Ateliers et productions de poteries du Ve siècle au début du XXe siècle, catalogue d'exposition, La Tour d'Aigues, 1996, p. 63-70.

Amouric et al. 1995b : AMOURIC (H.), DEMIANS D'ARCHIMBAUD (G.), VALLAURI (L.). De Marseille au Languedoc et au Comtat Venaissin : les chemins du vert et du brun. In : Le Vert et le Brun, de Kairouan à Avignon, céramiques du Xe au XVe siècle, catalogue d'exposition, Marseille, La Vieille Charité, 1995, R.M.N., p. 185-201.

Amouric et al. 1995a : AMOURIC (H.), DEMIANS D'ARCHIMBAUD (G.), PICON (M.), VALLAURI (L.). Zones de production céramique et ateliers de potiers en Provence du haut moyen âge à l'époque moderne. In : Ve Colloque international de la céramique médiévale en Méditerranée occidentale, Rabat, 1991, p. 35- 48.

Aujourd'hui le Moyen Age 1981 : DEMIANS D'ARCHIMBAUD (G.) dir. Aujourd'hui le Moyen Age : archéologie et vie quotidienne en France méridionale. Catalogue d'exposition, Sénanque-Gap, 1981-1983, Aix-en-Provence, 1981, $125 \mathrm{p}$.

Archéologie et vie quotidienne 1990 : Archéologie et vie quotidienne aux XIIIe XIVe siècles en Midi-Pyrénées. Catalogue d'exposition, Musée des Augustins, Toulouse, 7 mai -31 mai 1990, $351 \mathrm{p}$.

Bassagoda Nonell 1978 : BASSAGODA NONELL (J.). La cerámica popular en la arquitectura gótica. Barcelona, 1978.

Baumgartner, Krueger 1988 : BAUMGARTNER (E.), KRUEGER (I.). Phönix aus Sand und Asche, Glas des Mittelalters, München, 1988.

Benoît 1944 : BENOIT (F.). Fouilles mineures et informations, Gallia II, 1944, p. 256.

Berti, Gelichi 1995 : BERTI (G.), GELICHI (S.). Mille chemins ouverts en Italie. In : Le Vert et le Brun, de Kairouan à Avignon, céramiques du Xe au XVe siècle, catalogue d'exposition, Marseille. La Vieille Charité, 1995, R.M.N., p. 129-163.

Boiron 1991 : BOIRON (R.). Avignon, fouilles de l'Oratoire. Bilan Scientifique du Service Régional de l'Archéologie PACA. 1991, p.183-185.

Bonhoure, Marchesi 1993 : BONHOURE (I.), MARCHESI (H.). Le site archéologique du Pont-Julien à Bonnieux, premiers résultats. Archéologie du Midi Médiéval, 11, 1993, p. 99-110.

Brien et al. 1992 : BRIEN (F.), LAGRUE (J.-P.), LAURIER (F.), PASQUALINI (M.), VECCHIONE (M.). Hyères, fouilles de l'église Saint-Pierre et de ses abords. Archéologie du Midi Médiéval, X, 1992, 22 p.

Broecker 1979 : BROECKER (R.). Céramiques médiévales découvertes en Languedoc méditerranéen. (Thèse de doctorat 3e cycle. Université d'Aix-Marseille I), 1979.

Broecker 1982 : BROECKER (R.). Céramiques émaillées de Saint-Félix-de-Montceau en Languedoc méditerranéen. Archéologie Médiévale, XII, 1982, p. 209-274.

Cabona et al. 1986 : CABONA (D.), GARDINI (A.), PIZZOLO (O.). Nuovi dati sulla circolazione delle ceramiche mediterranee dallo scavo di palazzo Ducale a Genova (sec. XII- 
XIV). In : La ceramica medievale nel Mediterraneo Occidentale : Atti del III congresso Internazionale, Siena-Faenza, 1984. Firenze, 1986, p. 453-482.

Carru 1989 : CARRU (D.). Céramiques d'un dépotoir du XVIe siècle à Avignon. Archéologie du Midi Médiéval, 7, 1989, p. 187-210.

Carru 1995a : CARRU (D.). Avignon au temps des Papes : un marché privilégié pour l'Uzège. In : LEENHARDT (M.) dir. Poteries d'Oc, céramiques languedociennes VIle-XVIIe siècles, catalogue d'exposition, Nimes, Musée archéologique, 1995, éd. Narration, p. 61-63

Carru 1995b : CARRU (D.). Avignon à l'époque moderne : encore et toujours de l'Uzège. In : LEENHARDT (M.) dir. - Poteries d'Oc, céramiques languedociennes VIIe-XVIle siècles, catalogue d'exposition, Nimes, Musée archéologique, 1995, éd. Narration p. 124-125.

Carru 1995c : CARRU (D.) dir. De l'Orient à la table du Pape. L'importation des céramiques méditerranéennes dans la région d'Avignon aux XIVe-XVIe siècles, Documents d'Archéologie Vauclusienne, 5, Service d'Archéologie de Vaucluse, Avignon 1995, 78 p. : ill.

Carru 1995d : CARRU (D.). Nouvelles investigations, nouveaux apports, la Chapelle Saint-Jean. In : Petits carrés d'histoire : Pavements et revêtements muraux dans le midi méditerranéen du Moyen Age à l'époque moderne, catalogue d'exposition, Avignon, 1995, p. 72-73

Carru 1995e : CARRU (D.). Aperçu sur les céramiques d'Avignon à la fin du Moyen Age. In : 1500 ans de céramique en Vaucluse. Ateliers et productions de poteries du Ve siècle au début du XXe siècle, catalogue d'exposition, La Tour d'Aigues, 1996, p. 61-62.

Carru à paraître : CARRU (D.). La vaisselle consommée à Avignon à la fin du Moyen Age : mutations, influences et sources d'approvisionnement. In : Vle Colloque international sur la céramique médiévale méditerranéenne, Aix-en-Provence 1995. à paraître.

Cartron 1992 : CARTRON (I.), DORAY (I.). Les fouilles de la rue Bouquerie à Avignon (Vaucluse) : habitat médiéval et occupation protohistorique, Bulletin archéologique de Provence, 21, 1992, p. 31-57.

Cathma 1991 : CATHMA. Importations de céramiques communes méditerranéennes dans le midi de la Gaule (V-VIIe s.). In : A cerâmica medieval do mediterraneo ocidental, Lisbonne 1987, Mertola 1991, p. 27-47.

Cathma 1992 : DEMIANS D'ARCHIMBAUD (G.), BONIFAY (M.), PICON (M.), PITON (J.), VALLAURI (L.). Céramiques glaçurées de l'Antiquité tardive et du haut moyen âge en France méridionale. In : La ceramica invetriata tardo antica e altomedievale in Italia a cura di Lidia Paroli, Atti del seminario Certosa di Pontignano, Siena 1990, Firenze 1992, p. 65-74.

Cathma 1993 : LEENHARDT (M.), RAYNAUD (Cl.), SCHNEIDER (L.). Coord.. Céramiques languedociennes du haut Moyen Age (VII-Xle s.). Etudes micro-régionales et essai de synthèse, Archéologie du Midi Médiéval, 11, 1993, p. 111228.
Coulet 1991 : COULET (N.). L'équipement de la cuisine à Aixen-Provence au XVe siècle, Annales du Midi, tome 103, janvier-mars 1991, p. 1-17.

Couleurs de Tunisie 1994 : Couleurs de Tunisie, 25 siècles de céramique. Catalogue d'exposition, Institut du Monde Arabe, Paris - Musée des Augustins, Toulouse, 1994-1995, 1994, $319 \mathrm{p}$.

Démians d'Archimbaud 1981 : DEMIANS D'ARCHIMBAUD (G.). Les fouilles de Rougiers. Contribution à l'archéologie de l'habitat rural médiéval en pays méditerranéen. Paris, CNRS, 1981, $724 \mathrm{p}$.

Démians d'Archimbaud et al. 1980 : DEMIANS D'ARCHIMBAUD (G.), THIRIOT (J.), VALLAURI (L.). Céramiques d'Avignon. Les fouilles de l'hôtel de Brion et leur matériel. Avignon, Mémoires de l'Académie du Vaucluse, fasc. horssérie, éd. Aubanel, 7ème série, I, 1980, 195 p.

Démians d'Archimbaud, Gagnière 1995 : DEMIANS D'ARCHIMBAUD (G.), GAGNIERE (S.). Châteauneuf-du-Pape : des archétypes réfractaires. In : Petits carrés d'histoire : Pavements et revêtements muraux dans le midi méditerranéen du Moyen Age à l'époque moderne, catalogue d'exposition, Avignon, 1995, p. 36-39.

Démians d'Archimbaud, Lemoine 1980 : DEMIANS D'ARCHIMBAUD (G.), LEMOINE (C.). Les importations valenciennes et andalouses en France méditerranéenne : essai de classification en laboratoire. In : La céramique médiévale en Méditerranée occidentale, Xe-XVe siècles. Valbonne 1978, Paris, C.N.R.S., 1980, p. 359-372.

Démians d'Archimbaud, Picon 1980 : DEMIANS D'ARCHIMBAUD (G.), PICON (M.). La céramique médiévale en France méditerranéenne. Recherches archéologique et de laboratoire. In : La céramique médiévale en Méditerranée occidentale, Xe-XVe siècles. Valbonne 1978, Paris, C.N.R.S. 1980, p. 16-42.

Démians d'Archimbaud, Vallauri à paraître : DEMIANS D'ARCHIMBAUD (G.), VALLAURI (L.). Productions et importations de céramiques médiévales dans le Midi méditerranéen français. In :Curs de postgrau de cerámica medieval $i$ postmedieval, Université de Barcelone, à paraître.

Du nouveau sur l'Arles Antique 1987 : catalogue d'exposition. Revue d'Arles n 1 , Arles, 1987.

Faure-Boucharlat et al. 1996 : FAURE-BOUCHARLAT (E.), VICART (T.), MACCARI-POISSON (B.), SAVAY-GUERRAZ (S.). Pots et potiers en Rhône-Alpes, époques médiévales et modernes. DARA n ${ }^{\circ}$ 12, Lyon 1996, 315 p.

Fossati, Mannoni 1975 : FOSSATI (S.), MANNONI (T.). Lo scavo della vetreria medievale di Monte Lecco, Archeologia Medievale, II, 1975, p. 31-98.

Foy 1986 : FOY (D.). Verres du XIVe au XVIe siècles provenant de la place de la cathédrale à Montauban, Archéologie du Midi médiéval, 4, 1986, p. 83-92.

Foy 1988 : FOY (D.). Le verre médiéval et son artisanat en France méditerranéenne, Paris, 1988.

Gaday et al. 1995 : GADAY (R.), LEFEVRE-GONZALEZ (L.), MARKIEWICZ (C.). R.H.I. Philonarde, Avignon (Vaucluse), Fouille préventive, rapport d'intervention, Avignon, 1995. 
Gay 1887 : GAY (V.). Glossaire archéologique du Moyen-Age et de la Renaissance. 2 T., Paris, 1887, 1928.

Guyonnet 1993 : GUYONNET (F.). Les fouilles d'habitats semirupestres au Prieuré Saint-Sýmphorien, (Mémoire de maîtrise, Aix-Marseille I, 1993).

Hesnard et al. 1993 : HESNARD (A.), PASQUALINI (M.), VALLAURI (L.). Tant va la cruche à l'eau. In : AMOURIC (H.), ABEL (V.) dir. - Un goût d'Italie : céramiques et céramistes italiens en Provence du Moyen Age au XXe siècle. Catalogue de l'exposition, Aubagne, éd. Narration, 1993, p. 19-20.

Istria 1996 : ISTRIA (D.). Les céramiques importées en Corse : XIIIe-première moitié du XIVe siècle. Bulletin de la Société des sciences historiques et naturelles de la Corse, 674-675, 1996, p. 9-29.

Koechlin 1968 : KOECHLIN (R.). Les ivoires gothiques fraņais. 3 T., Paris, 1968.

Konaté 1980 : KONATE (D.). Une étude urbaine : le secteur sudouest de la fouille du Petit-Palais d'Avignon : approches méthodologiques et archéologiques. (Thèse de 3e cycle, AixMarseille 1), 1980, 2 vol., 421 p.

Lambert 1972 : LAMBERT (N.). La Seube : témoin de l'art du verre en France méridionale du Bas-Empire à la fin du Moyen Age, Journal of Glass Studies, 1972, p. 77-116 ;

Lambert 1982-1983 : LAMBERT (N.). La verrerie médiévale forestière de la Seube (Claret, Hérault). Archéologie en Languedoc $\mathrm{n}^{\circ}$ 5, 1982-1983, 177-244.

Lang 1991 : LANG (W.). Une verrerie forestière du XVe siècle dans la vallée de Nassach (Bade-Wurtemberg). In : Ateliers de verriers de l'Antiquité à la période pré-industrielle, (Actes des $4 \mathrm{e}$ rencontres de l'AFAV, Rouen 24-25 novembre 1989), Rouen, 1991, p. 83-88.

Le Vert et le Brun 1995 : Le Vert et le Brun, de Kairouan à Avignon, céramiques du Xe au XVe siècle, catalogue d'exposition, Marseille, La Vieille Charité, 1995, R.M.N., 246 p. : ill.

Leclaire 1992 : LECLAIRE (A.). La maison des chevaliers de Pont-Saint-Esprit, sondages archéologiques 1990-1992, 79 p.

Lecuyer 1995 : LECUYER (N.). Le Garissou (Béziers Hérault). Un atelier du Bitterois. In : LEENHARDT (M.) dir. Poteries d'Oc, céramiques languedociennes VIIe-XVIIe siècles, catalogue d'exposition, Nimes, Musée archéologique, 1995, éd. Narration p. 39-40.

Leenhardt 1995a : LEENHARDT (M.). Montpellier : une production éphémère en pâte rouge glaçurée. In : LEENHARDT (M.) dir.. Poteries d'Oc, céramiques languedociennes VlleXVIIe siècles, catalogue d'exposition, Nimes, Musée archéologique, 1995, éd. Narration, p. 43-44.

Leenhardt 1995b : LEENHARDT (M.). Vie quotidienne à Montpellier au XIIle s. In : LEENHARDT (M.) dir.. Poteries d'Oc, céramiques languedociennes VIle-XVIle siècles, catalogue d'exposition, Nimes, Musée archéologique, 1995, éd. Narration, p. $45-47$

Leenhardt 1995c : LEENHARDT (M.). Naissance et développement des glaçures de l'Uzège. In : LEENHARDT (M.) dir.. Poteries d'Oc, céramiques languedociennes VIle-XVIle siècles, catalogue d'exposition, Nimes, Musée archéologique, 1995, éd. Narration, p. 55-57
Leenhardt 1995d : LEENHARDT (M.). Le vaisselier des verriers de la Seube. In : LEENHARDT (M.) dir. Poteries d'Oc, ćéramiques languedociennes VIle-XVIle siècles, catalogue d'exposition, Nimes, Musée archéologique, 1995, éd. Narration, p. 103-104.

Leenhardt 1996 : LEENHARDT (M.) Céramiques du XIVe siècle. $\boldsymbol{l} n$ : FIXOT (M.), PELLETIER (J.-P.), BARRUOL (G.).dir. Ganagobie, Mille ans d'un monastère en Provence. Alpes de Lumière 1996, p. 235-236.

Leenhardt 1997 : LEENHARDT (M.). La céramique commune claire glaçurée. In : MARCHESI (H.), THIRIOT (J.), VALLAURI (L.) dir. Marseille, les ateliers de potiers du XIIIe siècle et le quartier Sainte-Barbe (Ve-XVIle siècles), Documents d'Archéologie Française, 1997.

Leenhardt et al. 1995 : LEENHARDT (M.), RAMONAT (R.), RAYNAUD (C.), SCHNEIDER (L.). Poteries rouges des garrigues montpelliéraines (Argelliers, Mas Viel). In : Poteries d'Oc, Céramiques languedociennes VIle-XVIle s., catalogue d'exposition, Nimes, Musée archéologique, éd. Narration, 1995, p. 34-35.

Leenhardt, Raynaud 1995 : LEENHARDT (M.), RAYNAUD (C.). Pots funéraires en bordure du Larzac. Cruches du Puits de Lunel-Viel. In : LEENHARDT (M.) dir. Poteries d'Oc, céramiques languedociennes VIIe-XVIIe siècles, catalogue d'exposition, Nimes, Musée archéologique, 1995, éd. Narration, p. 50-51

Leenhardt, Thiriot 1989 : LEENHARDT (M.), THIRIOT (J.). Poteries grises médiévales produites à Saint-Gilles-du-Gard, $A r$ chéologie du Midi Médiéval, 7, 1989, p. 73-104.

Leenhardt, Vallauri 1988 : LEENHARDT (M.), VALLAURI (L.). Le cimetière du cloître cathédral de Viviers : rites et mobilier funéraire. In : ESQUIEU (Y.). Viviers, cité épiscopale : études archéologiques. Documents d'Archéologie en RhôneAlpes, Lyon, 1988, p. 67-11.

Mannoni 1975 : MANNONI (T.). La ceramica medievale a Genova e nella Liguria. Genova: Instituto internazionale di studi liguri, 1975. 207 p. (Studi genuensi, VII, 1968/69).

Mendera 1989 : MENDERA (M.). La produzione di vetro nella Toscana bassomedievale. Lo scavo della vetreria di Germagnana in Valdesa (Quaderni del Dipartimento di Archeologia e Storia delle Arti - Sezione Archeologica - Università di Siena, 15), Firenze, 1989.

Mendera 1991 : MENDERA (M.). La production du verre médiéval en Toscana : les fouilles d'une verrerie à Germagnana (Gambassi-Florence). In : Ateliers de verriers de l'Antiquité à la période pré-industrielle. (Actes des $4 \mathrm{e}$ rencontres de l'AFAV, Rouen 24-25 novembre 1989), Rouen, 1991, p. 89102.

Michel 1989 : MICHEL (J. M.). Céramique et verre du palais épiscopal de Fréjus (XIVe s.). In : FIXOT (M.), VALLAURI (L.) dir. L'église et son environnement. Archéologie médiévale en Provence. catalogue d'exposition. Aix-en-Provence. 1989, p. 87-88.

Moliner 1990 : MOLINER (M.). Protomajolique et majolique archaïque du XIIIe s. à Marseille. In : Atti XXIII convegno internazionale della ceramica Albisola. 1990. p. 201-217. 
Moliner 1993 : MOLINER (M.). Un puits du Panier, In : AMOURIC (H.), ABEL (V.) dir. Un goût d'Italie : céramiques et céramistes italiens en Provence du Moyen Age au XXe siècle. Catalogue de l'exposition, Aubagne, éd. Narration, 1993, p. 15-17.

Montreal, Barrachina 1983 : MONTREAL (L.), BARRACHINA (J.). El castell de Llinars del Vallès. Un casal noble a la Catalunya del segle XV, Montserrat, 1983.

Ollivier 1995 : OLLIVIER (L.). Aniane : un dépotoir d'atelier. In : LEENHARDT (M.) dir. Poteries d'Oc, céramiques languedociennes VIIe-XVIle siècles, catalogue d'exposition, Nimes, Musée archéologique, 1995, éd. Narration, p. 108-109.

Parent 1991 : PARENT (F.). La céramique du bas Moyen Age au monastère de Saint-Pierre de l'Almanarre (Hyères) et à l'église Saint-Pierre d'Hyères (Var). (Mémoire de maîtrise dactylographié, Université de Provence Aix-Marseille I) 1991.

Pelletier 1997 : PELLETIER (J.-P.). Les céramiques communes régionales en pâte brune et grise. In : MARCHESI (H.), THIRIOT (J.), VALLAURI (L.) dir. Marseille, les ateliers de potiers du XIIle siècle et le quartier Sainte-Barbe (VeXVIle siècles), Documents d'Archéologie Française, 1997.

Pelletier, Bérard 1997 : PELLETIER (J.-P.), BERARD (G.). Fours de potiers et céramiques du XIe siècle à Cabasse (Var). Archéologie du Midi médiéval, 1997.

Pelletier, Vallauri 1992 : PELLETIER (J.-P.), VALLAURI (L.). Mimet : à la recherche d'un atelier perdu. Archéologie du Midi Médiéval, X, 1992, p. 229-239.

Picon, Démians d'Archimbaud 1980 : PICON (M.), DEMIANS D'ARCHIMBAUD (G.). Les importations de céramique italienne en Provence médiévale : état des questions. In : DEMIANS D'ARCHIMBAUD (G.), PICON (M.). La céramique médiévale en Méditerranée occidentale, Xe-XVe siècles. Valbonne, 1978, éd. du CNRS, Paris 1980, p. 125-135.

Piton 1993 : PITON (J.). Les "vetrina pesante" d'Arles (XeXIe s.). In : AMOURIC (H.), ABEL (V.) dir. Un goût d'ltalie : céramiques et céramistes italiens en Provence du Moyen Age au XXe siècle. Catalogue de l'exposition, Aubagne, éd. Narration, 1993, p. 14.

Piton et al. 1995 : PITON (J.), LEENHARDT (M.), VALLAURI (L.). Arles : un dépotoir exceptionnel. In : LEENHARDT (M.) dir. Poteries d'Oc, céramiques languedociennes VIIeXVIIe siècles, catalogue d'exposition, Nimes, Musée archéologique, 1995, éd. Narration, p. 53-54.

Poey d'Avant 1961 : POEY D'AVANT (F.). Monnaies féodales de France, Tome 1, éd. 1961.

Poteries d'Oc 1995 : LEENHARDT (M.) dir. Poteries d'Oc, céramiques languedociennes VIIe-XVIIe siècles, catalogue d'exposition, Nîmes, Musée archéologique, 1995, éd. Narration, 144 p. : ill.

Richarté 1991 : RICHARTE (C.). La céramique médiévale issue des fosses-dépotoirs du lycée Mignet à Aix-en-Provence (Mémoire de Maîtrise, Aix-Marseille I, 1991).

Riu de Martin 1995 : RIU DE MARTIN (M. del C.). Analisis tipológico de las cerámicas halladas en las iglesisias barcelonesas del siglo XIV : commentario del poster tipóligico. In : Ve Colloque international de la céramique médiévale en Méditerranée occidentale, Rabat, 1991, p. 427-428.
Schneider 1990 : SCHNEIDER (L.). Beaucaire le Château, fouilles de sauvetage programmé. Rapport de fouilles, Service Régional de l'Archéologie de Languedoc-Roussillon, Montpellier 1990, $96 \mathrm{p}$.

Schneider 1995 : SCHNEIDER (L.). Le château de Beaucaire (Gard) : nouvelles données chronologiques. In : LEENHARDT (M.) dir. Poteries d'Oc, céramiques languedociennes VIIe-XVIle siècles, catalogue d'exposition, Nimes, Musée archéologique, 1995, éd. Narration, p. 52.

Stouff 1970 : STOUFF (L.). Ravitaillement et alimentation en Provence aux XIVe et XVe siècles. Paris, La Haye 1970.

Thiriot 1986 : THIRIOT (J.). Les ateliers médiévaux de poterie grise en Uzège et dans le Bas-Rhône : Premières recherches de terrain. Paris, Ed. de la Maison des Sciences de l'Homme, 1986, 148 p., 40 pl. et 1 microfiche. (Documents d'Archéologie Française $n^{\circ} 7$ ).

Thiriot 1987 : THIRIOT (J.). Approche de la typologie de production potière de Bollène (Vaucluse) au XIIIe siècle : essai sur le four 187D de "Saint-Blaise-de-Bauzon". In : La céramique (Ve-XIXe siècle), Fabrication - commercialisation - utilisation, Paris 1985, Caen 1987, p. 121-132.

Thiriot 1989 : THIRIOT (J.). Le dépotoir du Petit-Palais, Avignon. In : L'église et son environnement, Archéologie médiévale en Provence, Aix-en-Provence, 1989, p. 12.

Vallauri 1995 : VALLAURI (L.). La circulation des céramiques méditerranéennes au Moyen-Age : exemples en Provence et Corse. In : Recherches récentes d'archéologie médiévale corse. Actes du séminaire d'archéologie, Patrimoine d'une île, Patrimoniu isulanu, 1, Ajaccio, DRAC-SRA, 1995, p. 69-77.

Vallauri 1997 : VALLAURI (L.). Les céramiques importées. In : MARCHESI (H.), THIRIOT (J.), VALLAURI (L.) dir. Murseille, les ateliers de potiers du XIIIe siècle et le quartier Sainte-Barbe (Ve-XVIle siècles), Documents d'Archéologie Française, 1997.

Vallauri, Leenhardt 1995 : VALLAURI (L.), LEENHARDT (M.). Le Languedoc et la Méditerranée : sources archéologiques. In : LEENHARDT (M.) dir. Poteries d'Oc, céramiques languedociennes VIIe-XVIIe siècles, catalogue d'exposition, Nimes, Musée archéologique, 1995, éd. Narration, p. 110-112.

Vallauri, Leenhardt 1997 : VALLAURI (L.), LEENHARDT (M.). Les productions céramiques. In : MARCHESI (H.), THIRIOT (J.), VALLAURI (L.) dir. Marseille, les ateliers de potiers $d u$ XIIle siècle et le quartier Sainte-Barbe (Ve-XVIIe siècles), Documents d'Archéologie Française, 1997.

Vallauri, Leenhardt à paraître : VALLAURI (L.), LEENHARDT (M.). Mutations et transferts : l'apparition des glaçures dans le Midi méditerranéen. In : VIe Colloque international sur la céramique médiévale méditerranéenne, Aix-enProvence 1995.

Varaldo à paraître : VARALDO (C.). La graffita arcaica tirrenica. In : Vle Colloque international sur la céramique médiévale méditerranéenne, Aix-en-Provence, 1995, à paraître.

Vayssettes 1995 : VAYSSETTES (J. L). Poteries communes languedociennes au travers des sources écrites aux XVIe et XVIIe siècles. In : LEENHARDT (M.) dir. Poteries d'Oc, céramiques languedociennes VIIe-XVIIe siècles, catalogue d'exposition, Nimes, Musée archéologique, 1995, éd. Narration, p. 126-128. 
Verdié 1971 : VERDIE (S.). Etude de la céramique médiévale décorée d'oxyde de cuivre et de manganèse retrouvée au château royal de Collioure. (Mémoire de maîtrise dactylographié. Université d'Aix-Marseille I), 1971.

Visser Travagli 1985 : VISSER TRAVAGLI (A.M.). Vetri. Palazzo Paradiso. Il materiale delle vasche sotteranee. In : Il Museo Civico in Ferrara. Donazioni e Restauri, Firenze, 1985, p. 216-217.

Visser Travagli 1996 : VISSER TRAVAGLI (A.M.). Testimonianze figurative della produzione vetraria a ferrara nella seconda meta' del XV secolo. In : Il Vetro dall'Antichità all' età contemporanea (Giornata nazionale di studio, Venezia, 2 dicembre 1995, I Quaderni del Giornale Economico, supplemento n 5 :96), Venezia, 1996, p. 65-67.

Whitehouse 1983 : WHITEHOUSE (D.). Medieval glass in Italy : some recent developments, Journal of Glass Studies, vol. 25,1983 , p. 115-120.

Whitehouse 1987 : WHITEHOUSE (D.). Medieval glass from Tarquinia, Annales du 10e congrès de l'Association Internationale pour l'Histoire du Verre (Madrid-Ségovie, 23-28 septembre 1985), Amsterdam 1987, p. 317-333. 